LA-8182-M

Manual

UC-32

Issued: January 1980

\title{
DYMAC Communications System
}

\author{
Kathleen A. Lindsey
}
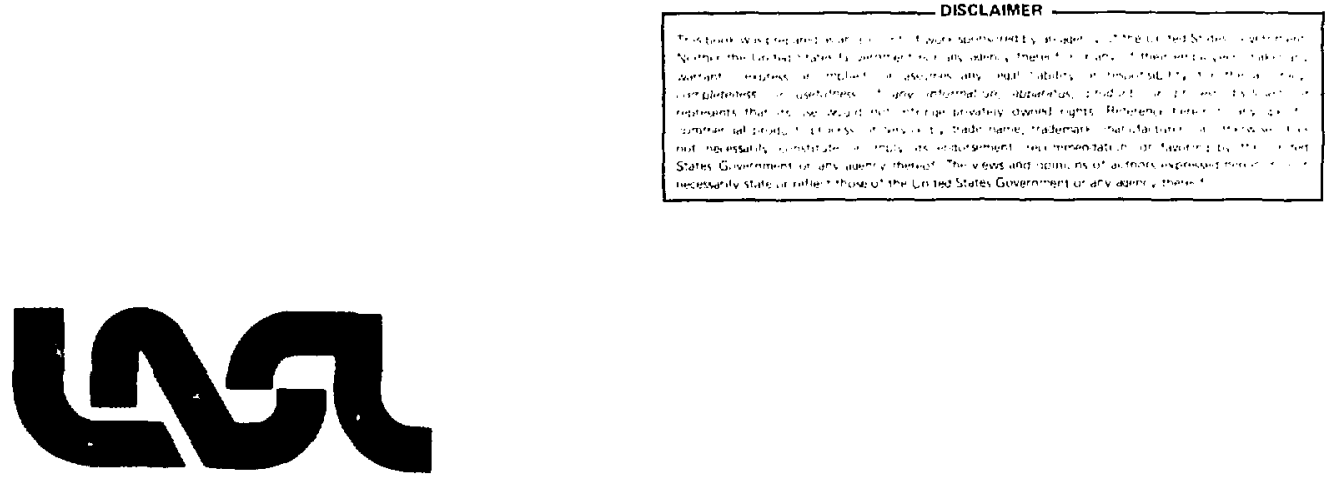


\title{
DYMAC COMMUNICATIONS SYSTEM
}

\author{
by
}

\author{
Kathleen A. Lindsey
}

\begin{abstract}
The DYMAC Communications System is part of a nuclear safeguards system called DYMAC--short for DYnamic Materials ACcountability--that gathers accountability information at the Los Alamos Scientific Laboratory (LASL) Plutonium Processing Facility. The communications system handles transmissions between data-entry terminals and nondestructive assay (NDA) instruments located in the facility, and a computer located in an adjacent building. System design emphasizes reliability rather than high speed to ensure the integrity of data transmissions.

This manual is directed toward the person responsible for maintaining the DYMAC Communications System. It describes the components that make up the communications network, explains how they operate, and gives detailed information about all of the connections. Many of the system components are commercially available; some have been modified at LASL for DYMAC purposes; others were designed and fabricated at LASL. This manual provides circuit diagrams for all of the LASL modifications and LASL-fabricated equipment. In addition, it provides a series of procedures for tracing cables, reconfiguring various parts of the system, testing data transmissions, and troubleshooting malfunctions.
\end{abstract}




\section{CONTENTS}

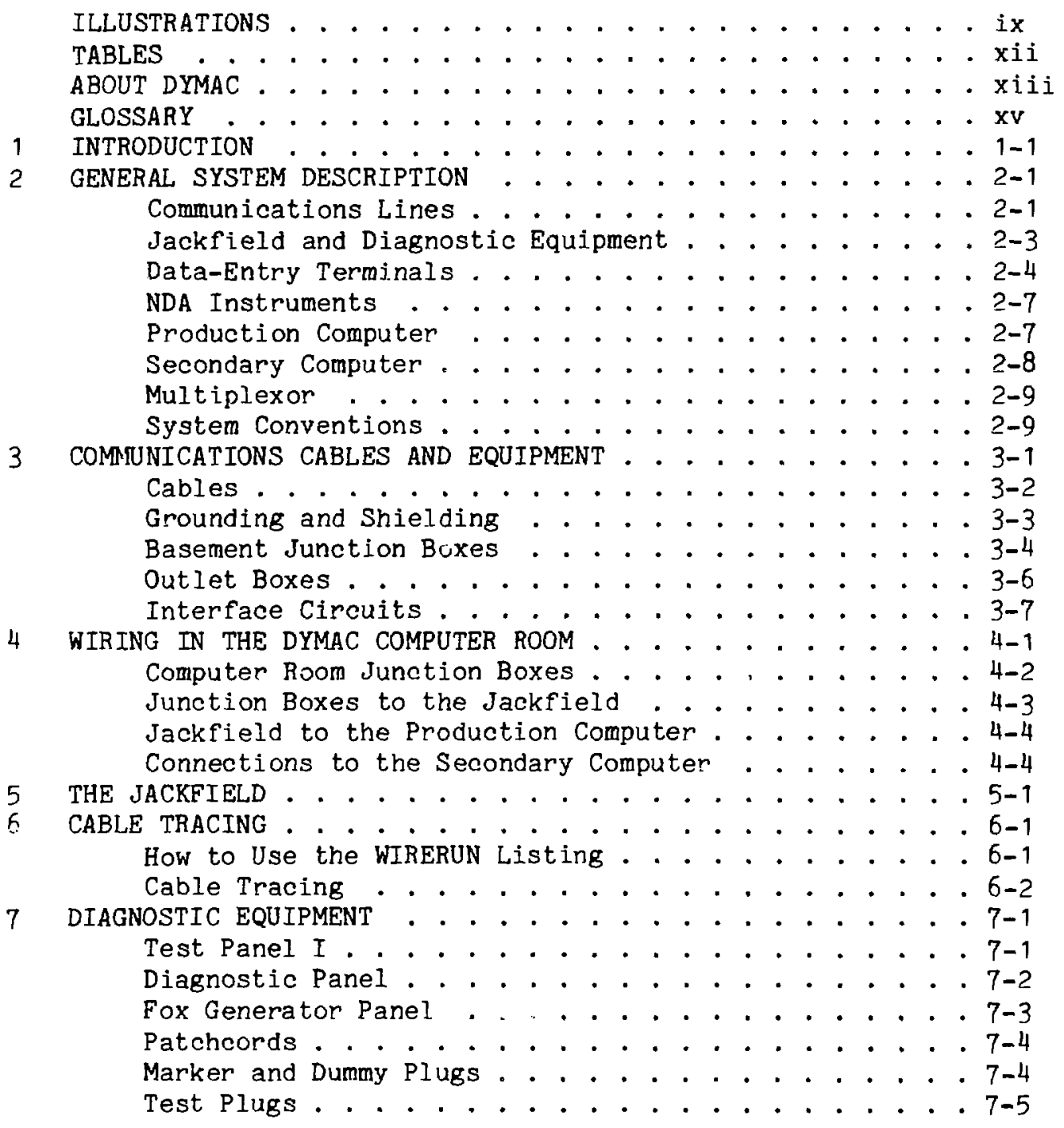


JACKFIELD USE .................... 8-1

Normal Use ............... . 8-1

Testing and Diagnostics . . . . . . . . . 8-1

Troubleshooting the Communications System . . . . . 8-2

Voltage Monitoring ................ . 8-2

Data Transmission Tests . . . . . . . . . 8-2

JACKFIELD PROCEDURES . . . . . . . . . . . . . . . 9-1

1. Patching a Remote Location to a Spare Port

on the Production Computer . . . . . . . . . . . . . . 9-2

2. Patching a Remote Location to a Secondary

Computer Port . . . . . . . . . . . . . . . 9-3

3. Continuity Check............. . 9-4

4. Polarity Check . . . . . . . . . . . . 9-5

5. Resistance Measurement . . . . . . . . . .9-6

6. Capacitance Measurement . . . . . . . . . . 9-8

7. Loop-Back Test, Using the Fox Generator . . . . .9-9

8. Loop-Back Test, Using the Diagnostic Panel . . . 9-10

9. Connecting the Diagnostic Terminal to a

MUX Port at the Jackfield . . . . . . . . . . . 9-11

10. Checking Transmission between a Remote

Terminal and the Diagnostic Terminal . . . . . . . 9-12

11. Monitoring Transmissions between the Computer

and a Remote Device, Using the Diagnostic Panel . . 9-13

12. Troubleshooting .............. 9-14

13. Data Receive ............... . 9-16

14. Data Transmit .............. 9-17

ACKNOWLEDGMENTS . . . . . . . . . . . . . . . 9-18

APPENDIX A PARTS LIST .................... . . . . .

APPENDIX B EQUIPMENT PURCHASES . . . . . . . . . . . . . . B-1

APPENDIX C VENDOR INDEX . . . . . . . . . . . . . C-1

APPENDIX D OUTLET BOX LOCATIONS . . . . . . . . . . . . D-1

APPENDIX E TO OBTAIN DRAWINGS AND WIRERUN LISTING . . . . . E-1

APFENDIX $\mathrm{F}$ CIRCUIT DIAGRAMS . . . . . . . . . . . . F-1

APPENDIX G COMPUTER ROOM CONNECTIONS TO MULTIPLEXOR . . . . G-1

APPENDIX H CABLE CONNECTIONS . . . . . . . . . . . . . H-1

APPENDIX J COMMUNICATION LINES ................ . . . .

APPENDIX $\mathrm{K}$ EQUIPMENT MAINTENANCE ............... . . $\mathrm{K}-1$ 


\section{ILLUSTRATIONS}

1-1 Trunk cables connect terminals and NDA instruments in the Plutonium Processing Facility to the production computer located in the adjacent Cold

Support Building. . . . . . . . . . . . . . . . 1-2

2-1 Sequence of connections from a remote device to the production computer. . . . . . . . . . . . . . 2-1

2-2 DYMAC Communications System. . . . . . . . . . . . . 2-2

2-3 The jackfield offers patching capability in addition to permanently wired connections. . . . . . . . . 2-3

2-4 Teleray 3741 terminal with CRT screen. . . . . . . . . . 2-4

2-5 The switches on a Teleray terminal should be set as shown. . . . . . . . . . . . . . . . . . 2-5

2-6 Low-speed TI 733 hard-copy terminal. . . . . . . . . 2-6

2-7 Label-printing TI 810 terminal. . . . . . . . . . . . 2-6

3-1 Diagram of the wiring from the MUX board on the production computer to an outlet box in the plutonium

facility. . . . . . . . . . . . . . . . 3-1

3-2 Junction box locations in the basement of the plutonium facility. . . . . . . . . . . . . . . 3-2

3-3 Basement junction boxes are connected in series to ensure that the maximum number of cable pins are available at each box. . . . . . . . . . . 3-5

3-4 Outlet box. . . . . . . . . . . . . . . . 3-6

4-1 Wiring in the DYMAC computer room. ........... 4-1

4-2 Computer room junction box (J02). .......... . 4-2

4-3 Location of terminal strips in computer room junction boxes J01 and J02. ............... 4-3

4-4 Sample terminal strip in computer room junction boxes. 4-4

4-5 Multiplexor port locations at rear of production computer. . . . . . . . . . . . . . . . . 4-5

4-6 Wiring of secondary computer ports to jackfield locations. .................... 4-5

5-1 Jackstrip front panel, with enlarged view of two jack circuits that together consistute one communications line. 
5-2 Jackstrip rear panel, with enlarged view of two of the four 50-pin AMP connectors. . . . . . . . . . 5-2

6-1 Sample Extended Card Listing for tracing one of the four signals of a communications line from the outlet box to the computer room junction box. . . . .6-2

6-2 Sample Extended Card Listing for tracing all four signals of a communications line from the outlet box to the computer room junction box. . . . . . . . 6-4

6-3 Basement junction box connected to outlet box. . . . . 6-5

7-1 Three diagnostic panels are mounted at the top of the jackfield rack. . . . . . . . . . . . . . . . 7-2

7-2 Twin-plug gray patchcord with curved side. . . . . . . 7-5

7-3 Twin-plug black, rectangular patchcord with notched side. . . . . . . . . . . . . . . 7-5

7-4 Single-plug gray patchcord. . . . . . . . . . . . 7-5

8-1 Flow diagram of terminal diagnostics procedure. . . . 8-2

8-2 Flow diagram of device diagnostics procedure. . . . . . 8-3

9-1 Horizontal insertion of a twin plug into jackstrip. . . 9-1

9-2 Vertical insertion of a twin plug into jackstrip. . . . . 9-1

9-3 Jackfield configuration for patching a remote location to a spare port on the production computer. . . . 9-2

9-4 Jackfield configuration for patching a remote location to a secondary computer port. . . . . . . . . 9-3

9-5 Continuity test jackfield configuration for patching a remote location to Test Panel I . . . . . . . . . 9-4

9-6 Jackfield configuration for meisuring the resistance of a line, using Test Panel I. . . . . . . . . . . . 9-7

9-7 Jackfield configuration for measuring the capacitance of a line, using Test Panel I. . . . . . . . . . . 9-8

9-8 Jackfield configuration for performing a ioop-back test, using the Fox Generator. . . . . . . . . . . . 9-9

9-9 Jackfield configuration for performing a loop-back test, using the Diagnostic Panel. . . . . . . . . . 9-10

9-10 Jackfieid configuration for connecting the Diagnostic Terminal to a MUX port at the jackfield. . . . . . 9-11

9-11 Jackfield configuration for connecting a remote terminal to the Diagnostic Terminal. . . . . . . . . 9-12

9-12 Jackfield configuration for monitoring transmissions between the computer and a remote device, using the Diagnostic Panel. . . . . . . . . . . . . 9-13

9-13 Multiplexor port fuse location at front of production computer. . . . . . . . . . . . . . . 9-15

D-1 Outlet box locations in the 100 Wing. . . . . . . . . . . D-2

D-2 Outlet box locations in the 200 Wing. . . . . . . . . . D-3

D-3 Outlet box locations in the 300 Wing. . . . . . . . . . D-4

D-4 Outlet box locations in the 400 Wing. . . . . . . . . . . D-5

F-1 Cable type A connects an outlet box to a Teleray terminal. . . . . . . . . . . . . . . . . . F-1

F-2 Cable type $\mathrm{B}$ connects an outlet box to a TI 733 hard-copy terminal. . . . . . . . . . . . . F-2 
F-3 Cable type $C$ connects an outlet box to a TI 810 label

F-4 Cable type D connects a Teleray terminal directly to one port of the MUX chassis. . . . . . . . . . . . . F-3

F-5 Cable type $\mathrm{E}$ connects a Teleray terminal to a jackstrip or to the Diagnostic Panel. . . . . . . . . . F-3

F-6 Cable type $F$ connects a Teleray terminal to a jackstrip when the Fox Generator is in use. . . . . . . . F-4

F-7 Modified interface circuit for the Teleray 3741 CRT terminal. . . . . . . . . . . . . . . . F-5

F-8 Interface circuit for the TI 733 hard-copy terminal. . . F-6

F-9 Interface circuit for the TI 810 label printer. . . . . . F-7

F-10 Serial-to-parallel interface printed-circuit board

for the digital electronic balance. . . . . . . . . F-8

F-11 Modified 20-mA interface for the Eclipse computer. . . . F-9

F-12 Front-to-rear wiring of a jackstrip. . . . . . . . . . . F-9

F-13 The circuitry on the right side of Test Panel $I$ is

for polarity and continuity tests. . . . . . . . F-10

F-14 The circuitry on the left side of Test Panel I is for

capacitance and resistance measurements. . . . . . . F-10

F-15 Circuit diagram of the Diagnostic Panel. . . . . . . . . F-11

F-16 Circuit diagram of the Fox Generator. . . . . . . . . . F-12

F-17 Test I plug circuit diagram. . . . . . . . . . . . . F-13

F-18 Loop-Back plug circuit diagram. . . . . . . . . . . . F-13

F-19 Short plug circuit diagram. . . . . . . . . . . . F-13 


\section{TABLES}

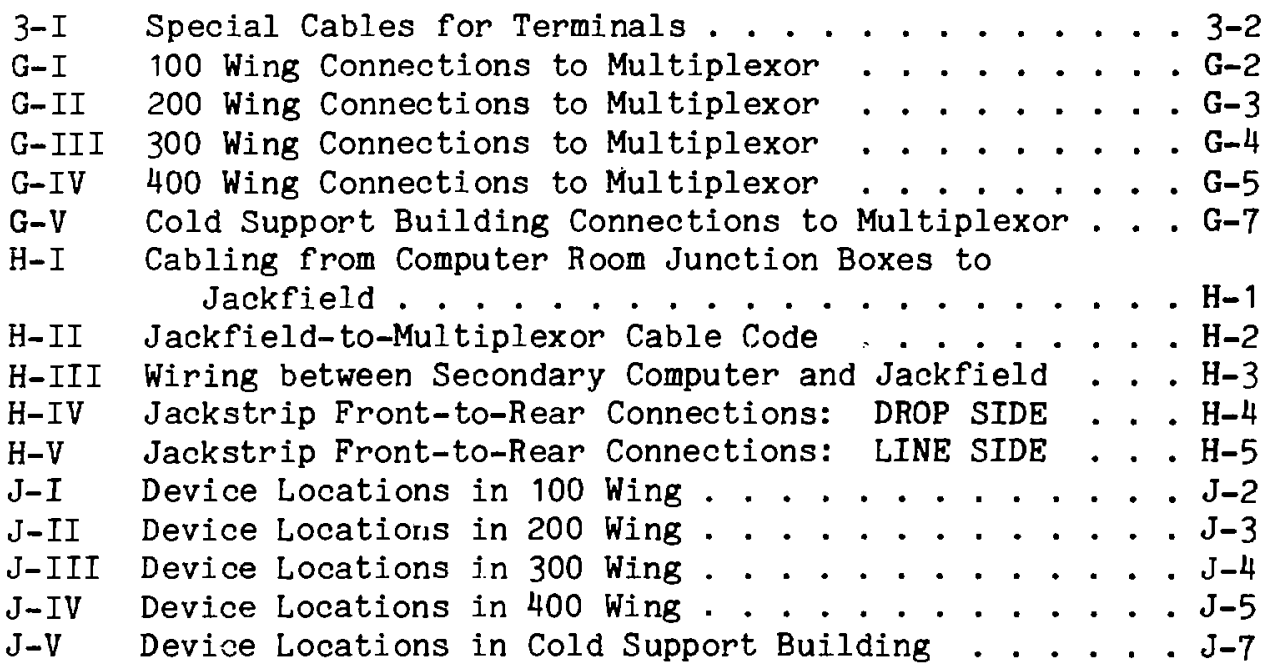




\section{ABOUT DYMAC...}

The DYMAC System collects accountability information at the LASL Plutonium Processing Facility for the purpose of safeguarding the nuclear material inside the facility. The system maintains a computer inventory file for every item of nuclear material in the facility, which includes the type of material, its amount, and the location. This file is kept current by facility personnel who notify the DYMAC System whenever they change the location or composition of an item during processing.

Such a timely accountability system is made possible by the use of NDA instruments that measure nuclear material during the course of processing. Two types of DYMAC NDA instruments, the thermalneutron coincidence counter (TNC) and fast-neutron coincidence counter (FNC), base their measurements on a count of neutron emissions. Two other types, the segmented gamma scanner (SGS) and solution assay instrument (SAI), count gamma rays. The most widely used DYMAC instrument in the facility is the digital electronic balance, which weighs items of known composition to determine the amount of nuclear material present.

Accountability rules dictate when the computer inventory must be updated. These rules are incorporated in the accountability procedures for each process. When an item changes location in the facility, and at certain stages during processing, personnel make transactions at data-entry teminals to update the computer inventory file. Frequently a transaction is coupled with a measurement. In the process of making a transaction with an associated measurement, a technician informs the computer which instrument he used. The instrument retains the measured amount until. the transaction is completed and the technician resets it to zero.

The primary purpose of collecting timely inventory information in a computer is for accountability. Because of the nature of plutonium, uranium, and other strategic nuclear materials, it is 
crucial to know exactly what material is in the facility at all times and where it is located.

DYMAC is a nuclear safeguards program designed to detect missing material. Most "missing" material is really not lost; it is simply "material in process," or MIP. It can be stuck to glovebox walls or left in the bottom of containers. MIP can also result from measurement errors. The DYMAC System calculates the MIP for each accountability area to determine whether a diversion has taken place. Then it is the responsibility of the Nuclear Materials Officer, who has custodianship of all the nuclear material in the facility, to investigate.

Collecting timely inventory information for safeguards purposes has three additional benefits: production control, quality control, and ease of inventory-taking. Timely status reports enable a supervisor to alter the work schedule as processing requires. At each stage of processing, the reports inform the supervisor whether the product will meet quality-control inspection. From a printout of the computer inventory for a particular locatior, a supervisor can readily verify the physical inventory. Annual inientory is greatly simplified because mistakes are quickly detected and resolved as they occur. 


\section{GLOSSARY}

\begin{tabular}{|c|c|}
\hline ALM & asynchronous line multiplexor \\
\hline AMP & AMP company, electronic component manufacturer \\
\hline ASCII & American Standard Code for Information Interchange \\
\hline bps & bits per second \\
\hline CAL & calorimeter \\
\hline CRT & cathode-ray tube \\
\hline CSB & Cold Support Building \\
\hline DCE & data communications equipment \\
\hline $\mathrm{DR}$ & data ring (current return, -) \\
\hline $\begin{array}{l}\text { DT } \\
\text { DTE }\end{array}$ & $\begin{array}{l}\text { data tip (current source, +) } \\
\text { data terminal equipment }\end{array}$ \\
\hline DYMAC & DYnamic Materials ACcountability \\
\hline EIA & Electronic Industries Association \\
\hline FNC & fast-neutron coincidence counter \\
\hline$I / 0$ & input/output \\
\hline LASL & Los Alamos Scientific Laboratory \\
\hline LED & light-emitting diode \\
\hline MUX & multiplexor \\
\hline NDA & nondestructive assay \\
\hline NEMA & National Electrical Manufacturers Association \\
\hline PR & TI 810 label-printing terminal \\
\hline $\mathrm{RX}$ & receive \\
\hline SAI & solution assay instrument \\
\hline SGS & segmented gamma scanner \\
\hline $\mathrm{T}$ & Teleray 3741 CRT terminal \\
\hline $\mathrm{T}_{1}$ & $\begin{array}{l}\text { Supervisory station: Teleray } 3741 \text { CRT terminal } \\
\text { paired with TI } 733 \text { hard-copy terminal }\end{array}$ \\
\hline TI & Texas Instruments \\
\hline TNC & thermal-neutron coincidence counter \\
\hline TNC-B & TNC for barrels \\
\hline TTL & transistor-transistor logic \\
\hline $\mathrm{TX}$ & transmit \\
\hline UART & universal asynchronous receiver/transmitter \\
\hline VOM & (n) \\
\hline$W_{1}$ & electronic balance, $0-5.5 \mathrm{~kg}, 0.1-\mathrm{g}$ precision \\
\hline $\begin{array}{l}W_{1 A} \\
W_{2}\end{array}$ & $\begin{array}{l}\text { electronic balance, } 0-5.5 \mathrm{~kg}, 0.01-\mathrm{g} \text { precision } \\
\text { electronic balance, } 0-15 \mathrm{~kg}, 0.1-\mathrm{g} \text { precision }\end{array}$ \\
\hline
\end{tabular}




\section{INTRODUCTION}

The DYMAC Communications System transmits accountability information from remote terminals and NDA instruments in the four wings of the LASL Plutonium Processing Facility to the production computer. Resident in the computer is an inventory of every item in the facility that contains nuclear material. Information about an item's change in status is transmitted from a terminal to the computer where it updates the inventory. Information about the alwayscurrent computer inventory is transmitted to the requesting terminal.

The communications system car be considered in continuous operation. There is no need to turn off terminals or instrument interfaces when they are not in use. However, none of these devices can be used to transmit information unless the production computer is in operation. As soon as the computer system is brought up at the beginning of a processing day, the START UP menu appears on the CRT (cathode-ray tube) screens of all the terminals. The appearance of this menu notifies facility personnel that they can begin sending infor.ation to the computer and requesting information from it.

The DYMAC Communications System consists of data-entry terminals, communications lines, interface circuits, junction boxes, outlet boxes, a jackfield, and diagnostic equipment. Communications lines connect the remote terminals and NDA instruments in the Plutonium Processing Facility to the production computer, a Data General Eclipse $\mathrm{C330}$, in the adjoining Cold Support Building (Fig. 1-1). A few terminals are also located in the Cold Support Building. Terminals and instruments are connected to the production computel via a jackfield, which permits flexibility in reconfiguring the system. A second Eclipse computer, located in the same room as the production computer, handles off-line tasks such as software development, report generation, accountability procedures, and training. Diagnostic equipment, located in the jackfield rack, is used for troubleshooting all parts of the communications system. 


\section{PLUTONIUM PROCESSING FACILITY}

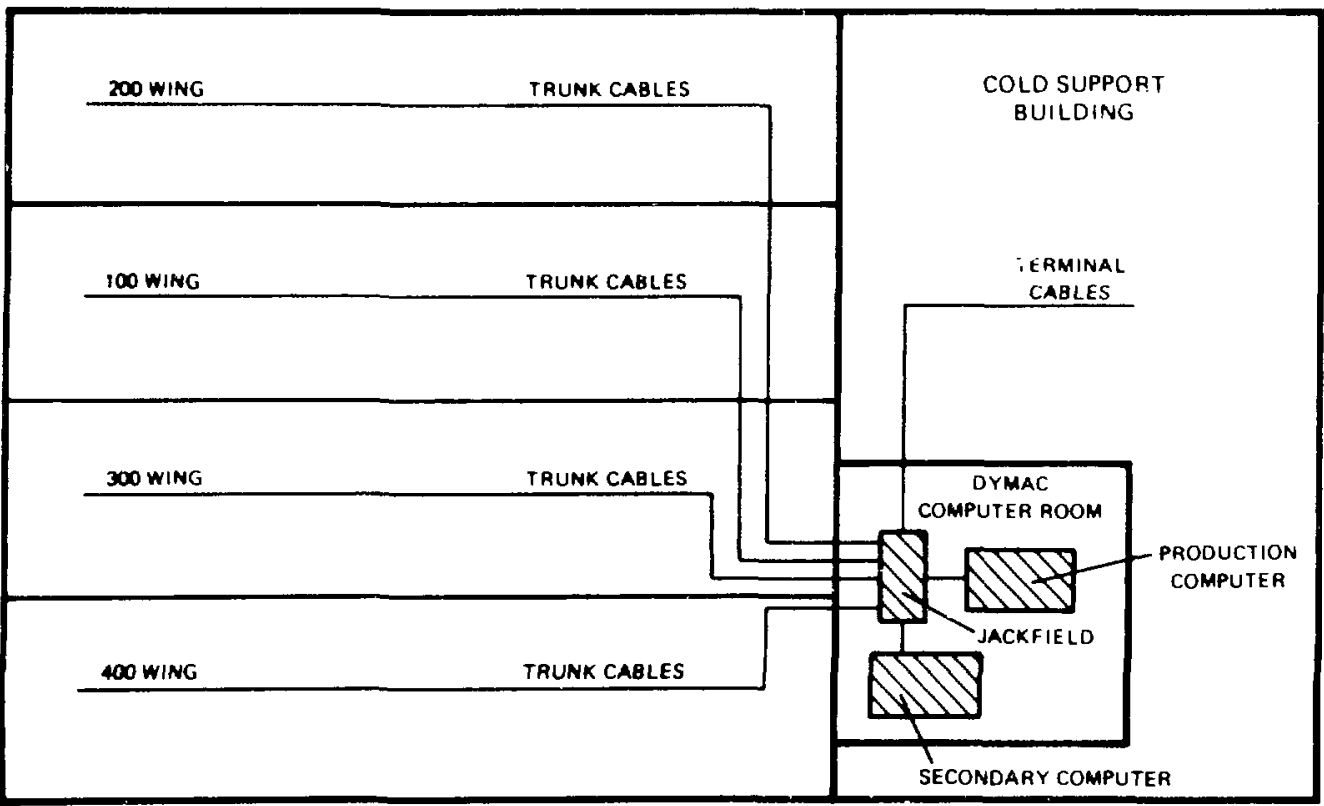

$\because i e^{2} \cdot i-1$.

Trunk cables connect terminals and NDA instrumerts in the

plutonium Processing Facilitu to the proluction computer

located in the adiacent Cold Supnort Buildino.

DYMAC data-entry terminals and some NDA instruments* are connected on-line to the production computer. This means that they transmit information directly to the computer ria communications lines. The information consists of transactions, inquiries, and measirements. Facility personnel are required to make transactions whenever items change location or undergo chemical or physical change. They can make inquiries whenever they need information about the inventory. The volume of data transmitted from the terminals $\mathrm{fa}_{2}$ exceeds that transmitted from the instruments. The computer transmits information to the terminals upon request, in the form of prompts and messages. It issues commands to the NDA instruments that cause them to transmit measurement data.

* Instruments connected on-line to the computer change too frequently to list in this manual. Consult the Line Definition (LINEDEF) table computer listing, available in the DYMAC computer room, for an accurate account. 
The DYMAC System uses on-line NDA measurements to ensure reliable, timely entry of measurement cata into the computer. A transaction must be made at the same time the measurement is made because the two are coupled. For exampie, when an item is weighed on an electronic balance, its weight is locked in the balance readout unit for transmission to the computer. The technician makes a transaction concerning the item and identifies the electronic balanct. The computer then reads the weight stored in the balance readout unit without going through the terminal. The computer can perform diagnostics on all measurement data that is directly transmitted from the instruments, to ensure that the transmission has been erpor-free. 


\section{GENERAL SYSTEM DESCRIPTION}

The DYMAC Communications System is made up of commercially available equipment and equipment fabricated at LASL. LASL personnel designed and fabricated the diagnostic equipment, the cables that connect the ierminals to the communications system, and circuits for the digital electronic balances. All the other equipment--data-entry terminals, jackstrips, cables, connectors, junction boxes, patchcords, and so forth--is commercially available. Appendix A itemizes the commercial equipment and the LASLfabricated equipment. Appendix $B$ documents specific purchases by order number, date, and vendor. Appendix C lists the vendors' addresses and telephone sumbers.

\section{COMMUNICATIONS LINES}

The DYMAC Communications System extends through the four wings of the Plutonium Processing Facility and the Cold Support Building. It connects remote terminals

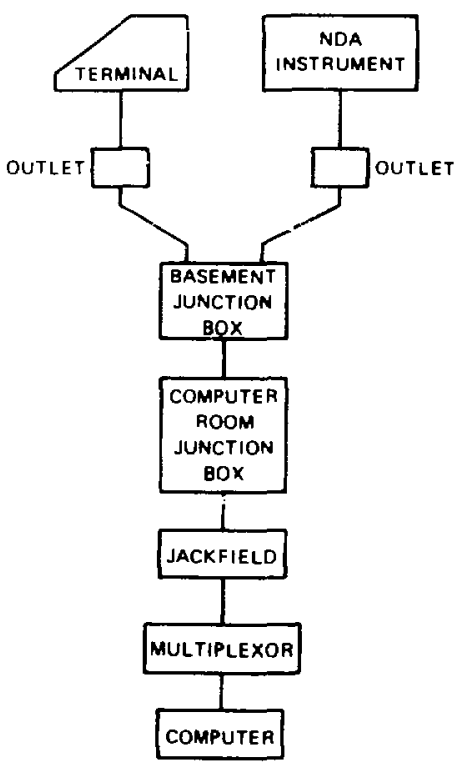
and NDA instruments to the production computer through a series of connections, as shown in Fig. 2-1.

Fig. 2-1.

Sequence of connections from a remote device to the production computer. 
Comprehensive laycuts of the facility's four wings in Appendix D show the location of every outlet box through which a terminal or NDA instrument can be connected to the production computer.

Five to seven trunk cables run in the basement beneath each wing, as shown in Fig. 2-2. A trunk cable consists of 24 pairs of wires and is constant for the entire length of a wing. For example, the seven trunk cables in the 400 Wing have a total of 168 wire pairs that extend throughout the wing, including the areas between the junction boxes. All 168 wire pairs in the trunk cable are avajlable in the three basement junction boxes for connection to an nut?et box.

A short cable $(2$ to $3 \mathrm{~m}$ long) with a four-prong phone plug connects an NDA instrument or terminal to the production computer at an outlet box that contains a mating phone jack. The plugs and jacks ire the type used by telephone companies for extension phones in residential and commercial installations. Cables consisting of two pairs of wires connect individual outlet boxes to the trunk cables at the basement junction boxes.

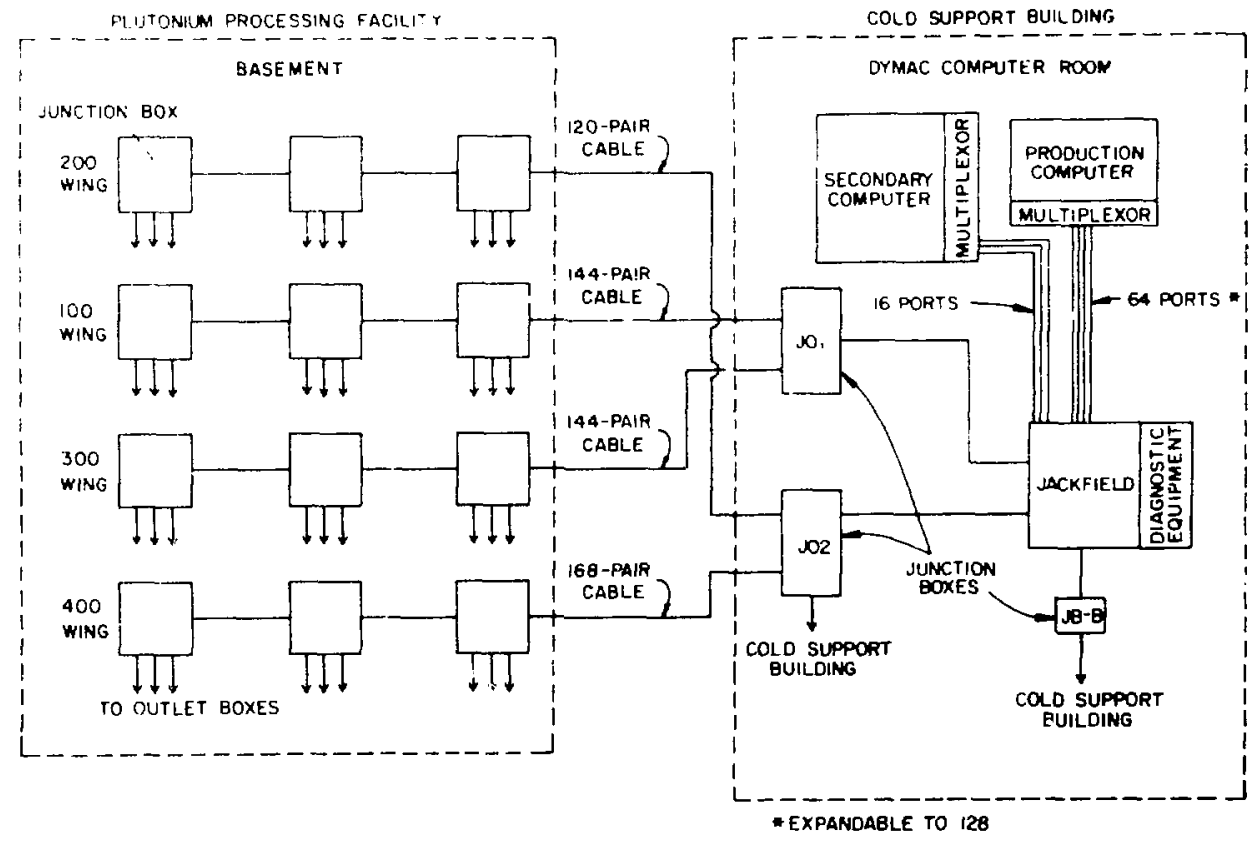

Fig. 2-2.

DYMAC Communications System. 
Trunk cab?es run from the iunction boxes ?crated in the hasement to two iunction boxes in the DYMAr computer moom. Other aables connect these boxes to the jackfjeld. About thinty $24-p a i r$ cables onnnent the iackfield to the computer mu? tiplexor (MIX).

Connections that lirk a? ${ }^{2}$ of the communication out? ats in the Plutonium Processing Facility and Cold Suppryt Bullding to the junntion boxes in the DYMAC computer room are spenified in the WIRERUN Listing, a separate document. (Refer to Sec. f for information on how to use the WIRERUN listing, and Appendix $E$ nn how to obtin a ropy.) Changes to the communications system require changes to the WIRERUN Listing. More complete information on rommunications lina: and conrections appears in Sers. 3,4 , and 6 .

\section{JACKFIELD AND DIAGNOSTIC EQUIPMENT}

me iackfield and its associated diagnostic equipment (shown in Fig. 2-3) are installed in a $0.5-m-w i d e$ rack located near the production computer. The iackrield serves a trreefold purpose: it houses the hard-wired connections betweon the remote devices and the computer, it is a manual patching point where lines can be reconnected to obtain the system configuration neeiled, and it provides a maintenance point where diagnostics can be performed. For example, MUX ports can be easily checked at the jackfield to determine whether the computer is malfunctioning. More complete information on the jackfield and diagnostic equipment appears in Secs. $5,7,8$, and 9 .

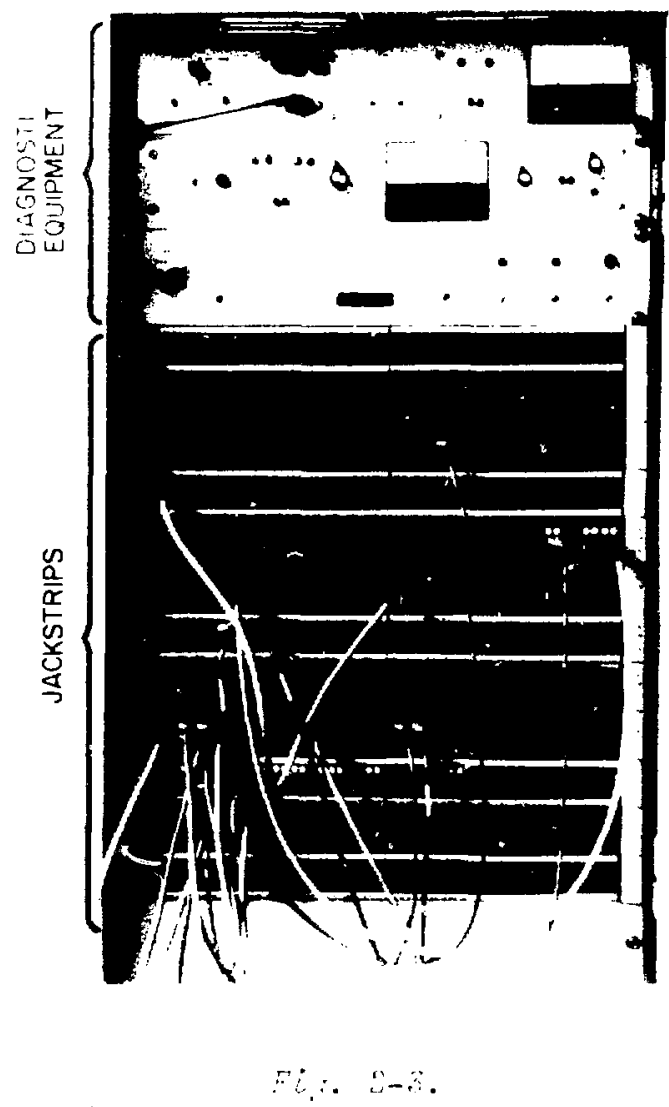

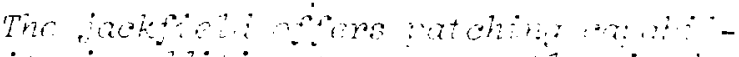

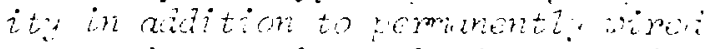

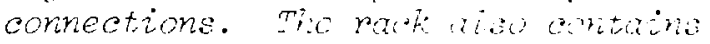
diagnoutic eqiirment. 


\section{DATA-ENTRY TERMINALS}

The DYMAC System incorporates three types of remote terminals for data entry and retrieval. The three are commercial products available from Teleray* or Texas Inst.ruments.*

The most common type of terminal used in the plutonium racility is a Teleray 3741 termina? with CRT screen, * shown in Fig. 2-4. It operates at high speed (4800 bps) over the communication lines. To operate the terminal properly, the switch settings should be in the positions shown in Fig. 2-5.

* See Appendix C ror complete addresses.

* Teleray 3700 C1 Series, CRT Data Terminal, Instruction Manual.

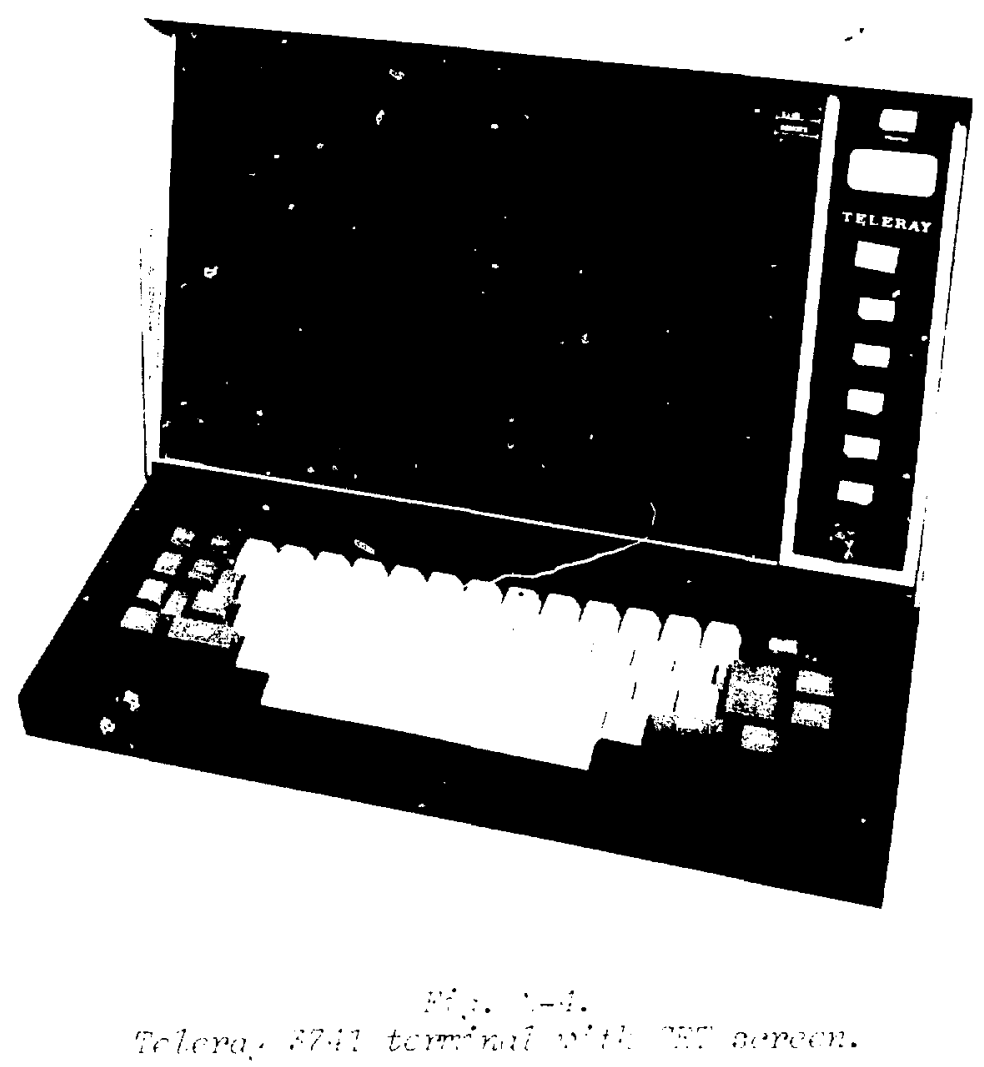


Some minor modifications have been made to the Teleray terminals to adapt them to the DYMAC System. The CAPS LOCK key on the keyboand has been permanently locked; this prevents transmission of lower-case characters, which the computer does not recognize. The 20-mA current loop circuits were modified by insertion of a $62 \mathrm{k}$-onm resistor between the base of the terminal's recejve sptoisolaton and grourd. A $22 \mathrm{k}$-ohm resistor was inserted between the base of the terminal's transmit optoisolator and $j t s$ emitter. These resistors improve the receive- and transmit-current waveforms of the terminals and eliminate communications prob?ems on some longer lines.

Another type of terminal, a TI 733 , show in Fig. 2-6, produces hard copy.* It is milch slower than the Teleray, transmitting 300 bps. A hard-copy terminal can be used only in conjunction with the Teleray it is associated with, enabling the user to display report information on the Teleray screen or print it on the hard-copy terminal. Together, a Teleray and a TI 733 hard-copy terminal form a supervisory station. The hard-copy terminal is connected separately to the computer.

The third type of terminal is the TI 810 label printer, ** shown in Fig. 2-7. Considerably faster than the hard-copy terminal, it prints information on continuous forms at the rate of 1200 bps. A label printer cannot be used independently of the Teleray terminal with which it is associated. Just like the hard-copy terminal, it enables the user to choose a display or printed form for report or label information. Its main function is to produce iabels for items as they enter and leave the vault. The label printer is connected separately to the computer.

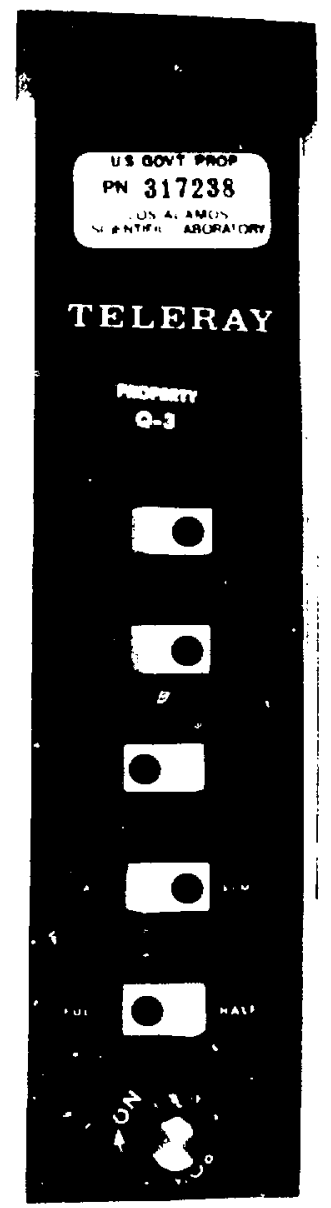

Fig. 2-5. The switches on a Teleray terminal should be set as shown. The dot indicates the prorer position.

* Texas Instruments Model 733 terminal, Service Manual 960129-9701.

* Texas Instruments Model 810 Printer Maintenance Manual 994386-9701. 


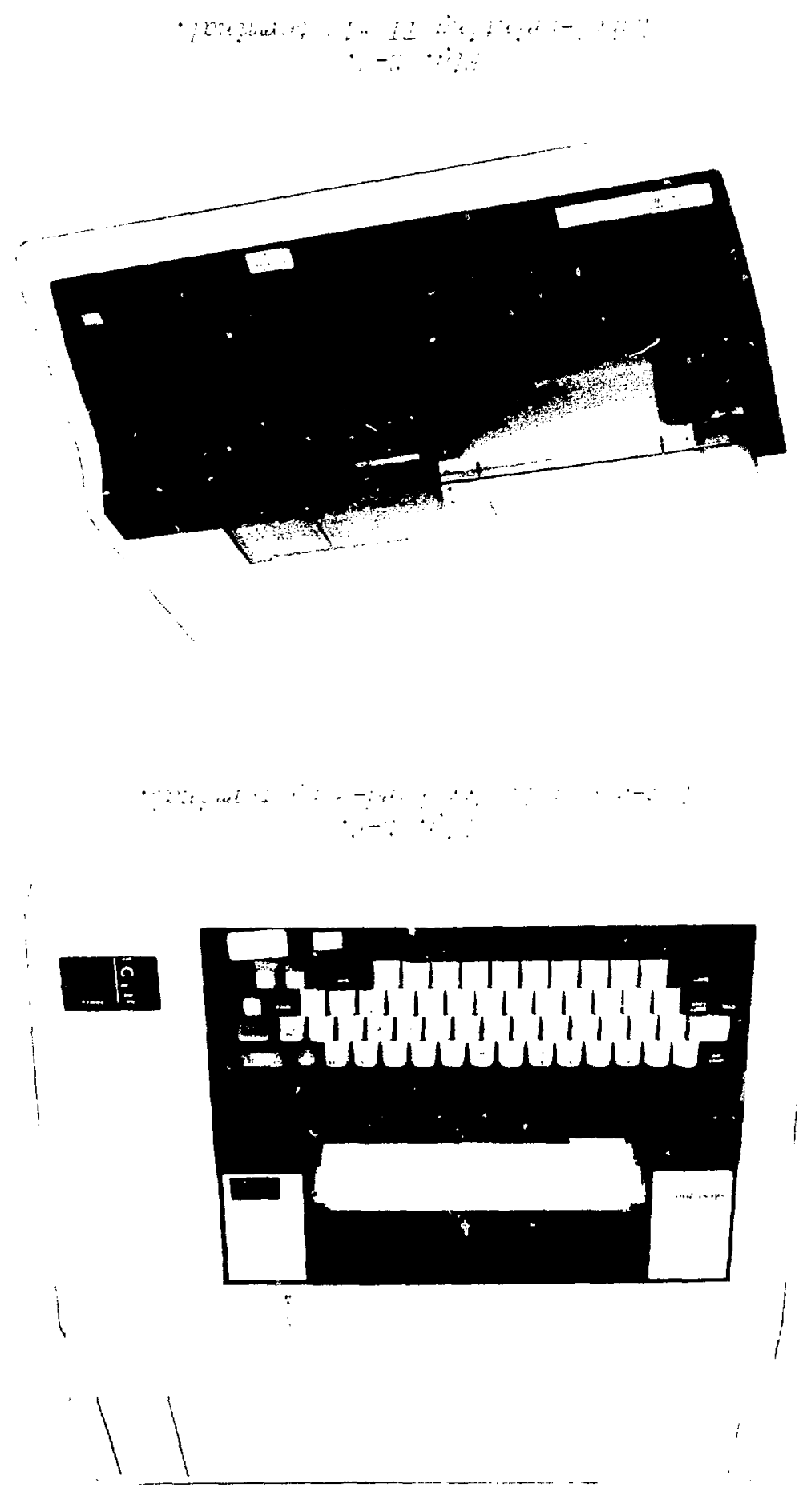

WGLSAS SNOILUJINCWWOD JULIAG! 


\section{NDA INSTRUMENTS}

NDA instruments are a major part of the DYMAC system and are treated in separate manuals.* These instruments determine the nuclear content of items quickly, in the course of processing. They make a near-real-time accountability system possible.

One type of NDA instrument is the digital electronic balance. It can be used to determine the nuclear content of an item when the proportion of the item's nuclear material to the rest of its makeup is already known. The weight of the item can then be multiplied by a predetermined factor to establish the nuclear content. About onehalf of all the DYMAC NDA instruments in use in the plutonium facility are electronic balances.

The other NDA instruments assay items to determine their nuclear composition. Two types of instruments count gamma-ray emissions and two others count neutron emissions. The segmented gamma scanner (SGS) counts gamma rays in low-concentration material to determine the amount of plutonium. The solution assay instrument (SAI) also counts gamma-ray emissions from solutions to determine their concentrations of plutonium. The thermal-neutron coincidence counter (TNC) and fast-neutron coincidence counter (FNC) count neutron emissions to determine the amount of plutonium in a particular item.

Another instrument, the calorimeter, determines the amount of plutonium in an item from the amount of heat generated. The calorimeter is not a DYMAC instrument but is used for accountability purposes.

\section{PRODUCTION COMPUTER}

The DYMAC production computer handles all of the transactions and inquiries made during the processing day. It maintains an up-to-date inventory of every item in the piutonium facility and produces sorted inventory information in different report formats. The computer remains in operation during working hours so that personnel can update the inventory as the status of processing changes.

The production computer is a Data General Eclipse C330 with 256k 16 -bit words of core memory. Data processing peripherals include

In draft form at the time the Communications Manual is being published. 
two system consoles, two disk storage systems, a 600-line-per-minute printer, and two magnetic tape units. The system consoles permit simultaneous operation in foreground and background modes. A Diablo $\because$.sk stores 20 megabytes of data and a Zebra disk stores 96 megabytes. The tape units are used for dumping the inventory files and for logging all transactions at the end of each processing day.

The computer multiplexor allows data transmission from the jackfield to the computer over 128 communications lines; 54 are implemented. The lines connect the production computer with terminals and NDA instruments in the plutonium facility. Detailed information about connecting the production computer to the jackfield is given in Sec. 4.

\section{SECONDARY COMPUTER}

The second Eclipse C330 in the DYMAC computer room handles off-line tasks and can replace the production computer in case of a major failure. It is similar to the production computer except that it has fewer ports. The secondary computer system consists of 64 communications lines between the multiplexor and the alackield; however, only 16 ports are available at the multiplexor. The ports are located on the bottom three jackstrips in the jackfield rack. Terminals or instruments may be patched or connected to these ports at the jackfield.

Normally, the secondary computer is used for software development, training, report generation, and accountability procedures. Before routines are added or changed on the production computer, they are tested on the secondary computer to detect errors and remedy them. Facility personnel are trained in making transactions and inquiries on the secondary computer before using the production system. Development of accountability procedires, such as tracing an item from the time it enters the plutonium facility until the time it leaves, also takes place on the secondary computer.

In its backup function, the secondary computer replaces the prom duction computer. The switch is made at the jackfield by patching a maximum of 16 secondary computer ports to specific device locations. Detailed information about connecting the secondary computer to the jackfield is given in Sec. 4. 


\section{MULTIPLEXOR}

The asynchronous line multiplexor of a Data General Eclipse computer is the input and output interface between the computer and remote devices. The computer transmits data to and receives data from remote devices via the multiplexor, which enables the computer to communicate with several devices simultaneously.

The computer scans each MUX line (port) to determine if a device is ready to transmit data. The receive lines that go to the computer are given the highest priority by the multiplexor; if no receive lines are active, then the computer scans the transmit lines from the computer and proceeds to transmit the data that is ready. The lower numbered MUX ports for both the receive and transmit lines are serviced first by the computer.

Each MUX interface board contains 16 ports. The production computer has eight MUX boards, for a total of 128 ports. The secondary computer has one MUX board, for a total of 16 ports. Extra cables are available at the rear of the secondary computer to increase the number of ports to a maximum of 64 .

Each MUX board plugs into the back panel of the computer chassis. Cable ends having several 6-pin AMP connectors connect to wirewrap pins on the back panel. The other end terminates in 50-pin AMP connectors at the jackfield.

Data General personnel maintain both the production and secondary computers, including all MUX interface boards. Additional information on the Eclipse multiplexor is published elsewhere.*

\section{SYSTEM CONVENTIONS}

The DYMAC Communications System conforms to jesign criteria that were specified during the initial design of the computer system. All comnunications lines are half- or full-duplex, asynchronous, with an upper speed limit of 9500 bps and with programmable line characteristics. All terminals have a minimum of 72 characters per line. CRT display screens have a minimum of 24 lines per page. Upper-case ASCII (American Standard Code for Information Interchange) is the character set. Transmission is on a character basis with echo from the computer. Terminals have an audible device that

Technical Reference, Data General Communications System 014-000070. 
issues a beep in response to the ASCII bell code. The terminals have standard ESCAPE and RETURN keys. All of the NDA instruments connected to the computer send data in the same mode as the terminals, that is, using upper-case ASCII, on a character basis, terminated by a RETURN. The computer echoes all characters.

A $20-m A$ current loop is the signaling standard between the computer and the individual instruments and terminals. This loop has great immunity to noise and requires little additional equipment, such as modems. * The communication links to the NDA instruments were chosen for reliability rather than high speed to ensure transmission of correct data. Bit-serial transmission, which is reliable and cost-effective, is sent cver twisted pair cables. Individually shielded wire pairs reduce crosstalk and errors due to extraneous noise sources.

The "intelligence" of the DYMAC computer system is centralized in the computer, instead of in each remote terminal. This allows the computer to make diagnostic checks during the course of a transaction. Real-time inventory searches, made possible by the centralized intelligence of the computer system, detect many dataentry errors as soon as they occur.**

\footnotetext{
*We rejected the EIA (Electronic Industries Association) RS-232C interface method because high transmission rates (up to $4800 \mathrm{bps}$ ) and the long distances (up to 120 or $150 \mathrm{~m}$ ) between the computer and instruments or terminals could result in marginal transmission.

**A different approach, which we rejected, was to distribute the intelligence of the computer system by using relatively expensive terminals that include some processor capability and memory, or to use remote minicomputer concentrators to drive the interactive terminals. Typically, in systems where the intelligence is so distributed, elementary diagnostics such as syntactical checks are performed at the remote processor, then the complete set of transaction data is transmitted to the central computer to update the inventory files. The shortzoming of this approach is that an entire transaction is rejected if the item involved in the transaction is not found in the inventory.
} 


\section{COMMUNICATIONS CABLES AND EQUIPMENT}

The trunk cables that run beneath the four facility wings contain a constant number of wire pairs for the length of an entire wing. This makes it possible to connect any wire pair in the cable to a terminal or NDA instrument wherever it is located in the wing. Figure 3-1 traces the wiring from an outlet box in the facility, through a basement junction box, to the computer multiplexor.

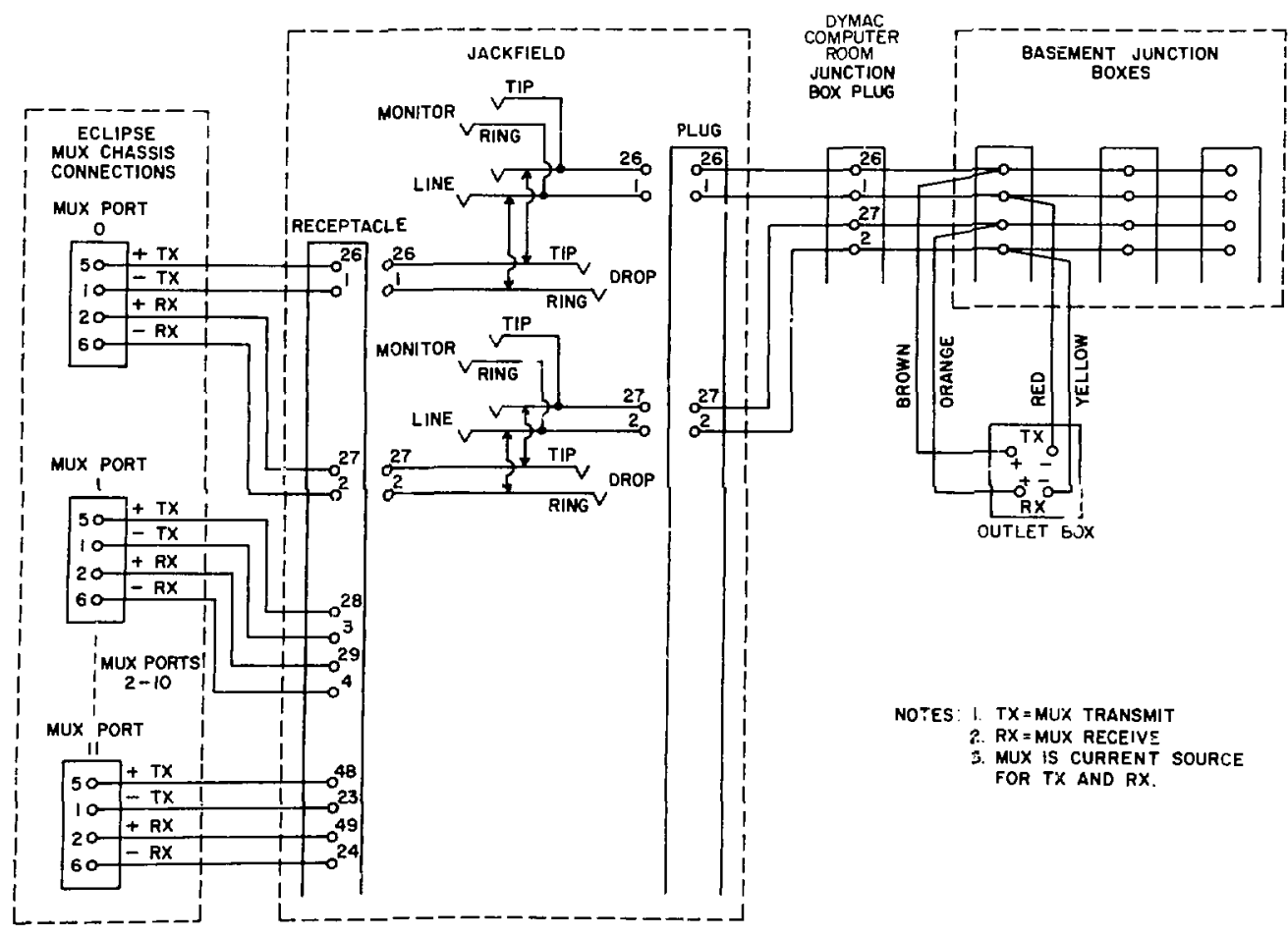

Fig. 3-i.

Diagrom of the wiring from the MUX board on the production computer to an outlet bov in the plutonium facilitu. 


\section{CABLES}

A1I cables used in the DYMAC Communications System are commercially available except for LASL-fabricated cables that connect to the data-entry terminals. The commercial cables are itemized in A ppendix A.

Six cable types were fabricated at LASL according to DYMAC design specifications. Each cable has a different function, depending on the terminal it is associated with and its intended destination. Table 3-I specifies the function of each cable type. Wiring for each cable is shown in Appendix F, Figs. F-1 through F-6.

To reduce manual wiring, 50-pin connectors are used on jackstrips, terminal strips in computer room junction boxes, and cable ends that go to the jackfield. Cable ends that go to the multiplexor have twelve 6-pin connectors, although only four of the six pins are used: $1,2,5$, and 6 .

TABLE 3-I

SPECIAL CABLES FOR TERMINALS

\begin{tabular}{cll}
$\begin{array}{c}\text { Type of } \\
\text { Cable }\end{array}$ & \multicolumn{1}{c}{$\begin{array}{c}\text { Type of } \\
\text { Terminal }\end{array}$} &
\end{tabular}




\section{GROUNDING AND SHIELDING}

The 20-mA current loop chosen as the signaling standard between the computer and NDA instruments or terminals provides a high degree of noise immunity. In addition, each pair of wires in the communications system is covered with a mylar shield to avoid signal pickup between wire pairs and to minimize noise pickup from extraneous sources in the plutonium facility. The mylar shield can be terminated by using the uninsulated drain wire (which is in physical contact with the conductive coating on the shield) for grounding any noise picked up by the shield. The shield for a pair of wires from an outlet box to a basement junction box is connected to the shield for the corresponding pair of wires that runs from that basement junction box to a computer room junction box. Thus, the shield is continuous from the outlet box to the computer room junction box.

Shields are tied to ground at only one location to ensure minimum ground-loop pickup. The shields are cut and taped at each outlet box; they are not connected electrically. All communications shields are tied together in the two computer room junction boxes. A green wire connects the shields in these boxes to the chassis of the computer rack; the chassis is connected to the green wire (ground) of the AC distribution system.

For example, if noise on the lines in the 200 Wing becomes a problem, the cable shields in the 200 Wing basement junction boxes can be jumpered together in the last junction box (214) and then tied to the ground wire in any or all of the three junction boxes for that wing. In this manner, one can determine whether grounding a shield at several points will alleviate the noise problem.

A current probe can be used to measure the current in the ground wire of junction box 214 and in the individual or collective drain wires of several cables in the 200 Wing. This probe measures the ground-loop currents flowing in the drain wires and the amount of common mode noise that is picked up. These measurements can be made in the time domain, but measurements made in the frequency domain may be more useful. 


\section{BASEMENT JUNCTION BOXES}

Basement junction boxes are connected in series to provide the maximum number of wires available at each junction box. The location of the junction boxes in the facility basement is shown in Fig. 3-2. To designate the location of each junction box, one can use the DYMAC numbering system or the nearest coordinates of the junction box location as specified on LASL Engineering Department drawings. For example, DYMAC junction box number 114 is the same as the engineering drawing for junction box $\mathrm{K}-14$. The WIRERUN Listing designates it as $\mathrm{K}-14-114$ (see Sec. 6), acknowledging both numbering sy stems.

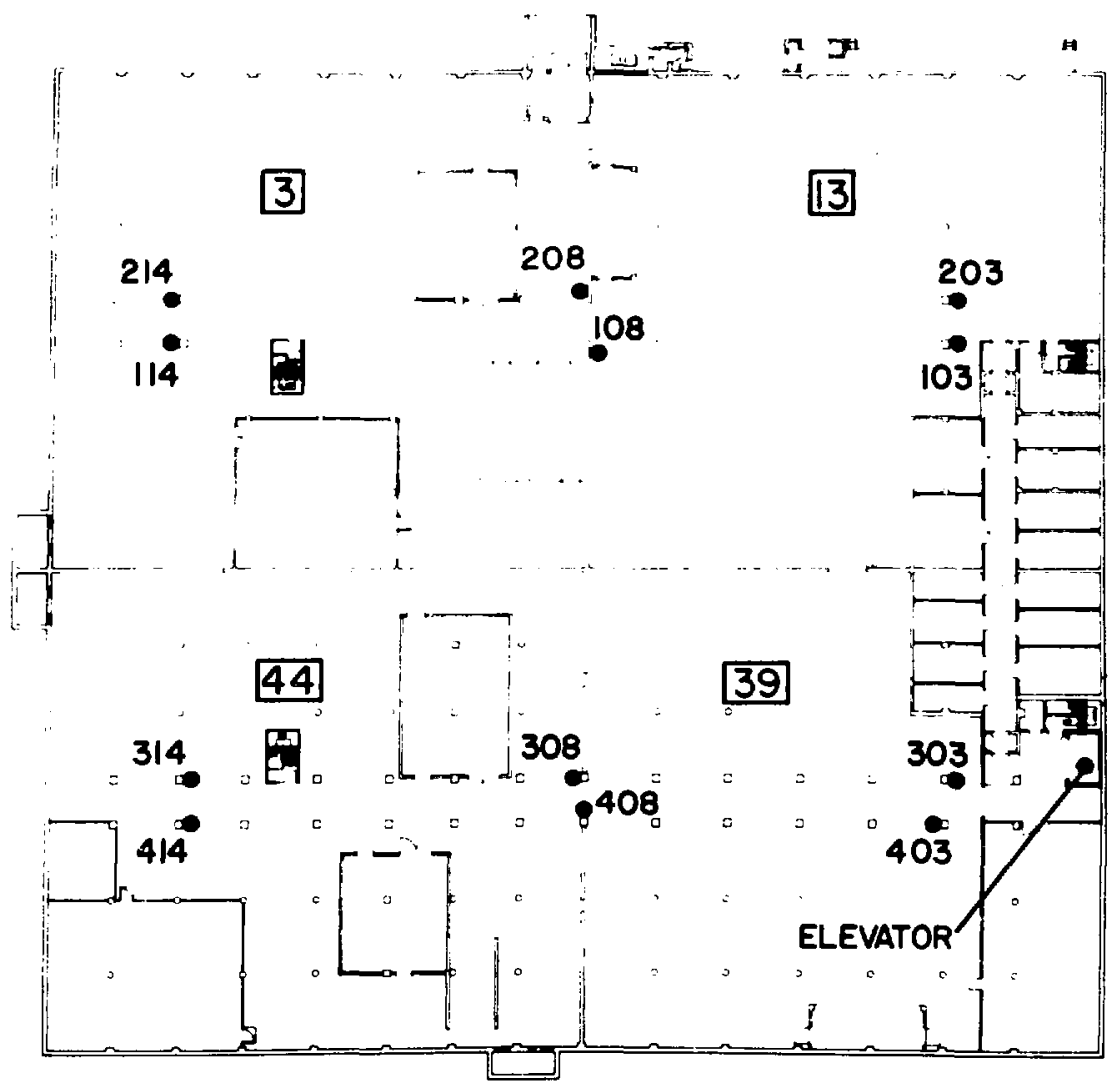

$\because \therefore \quad \therefore-5$.

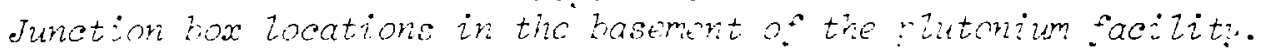


Each basement junction box has three adjacent, rectangular terminal strips, which are mounted lengthwise, as shown in Fig. 3-3. Terminal strips are identified by a $T$ number (for example, TO1) to identify the strip itself and a termination point number (for example, 018); together, they constitute a unique identifier ( T01-018).

Sec. 4.

Junction boxes in the DYMAC computer room are discussed in

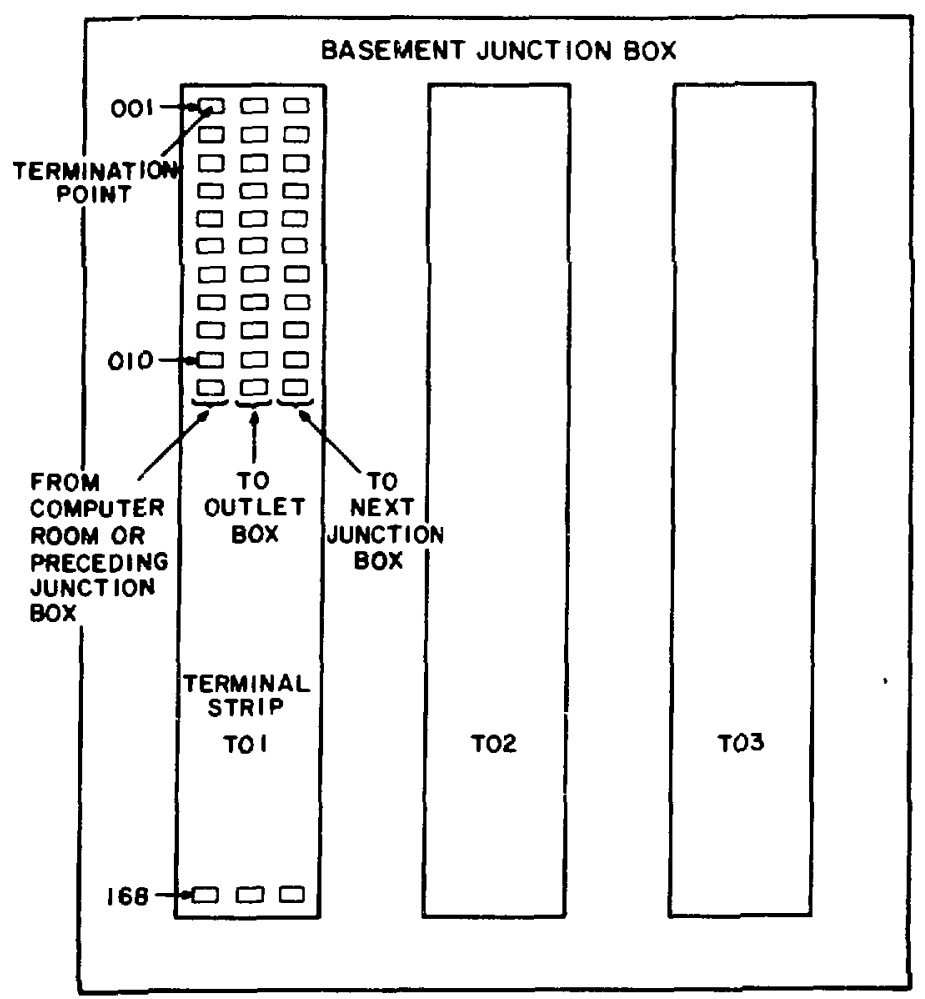

Fig. 3-3.

Basement junction boxes are connected in series to ensure that the maximum number of cable pins are available at each box. 


\section{OUTLET BOXES}

Figure 3-4 shows the wiring of a typical wall-mounted outlet box for connecting terminals or NDA instruments in the facility to the production computer. Each outlet box has four sockets. A brownand-red wire pair connects the upper two sockets of the box to the computer transmit circuit; an orange-and-yellow wire pair connects the lower two sockets to the computer receive circuit. The left socket of each pair (as viewed from the front of the box) is the source, or plus, signal socket (brown-and-orange wires), and the right socket is the return, or minus, signal socket (red-and-yellow wires).

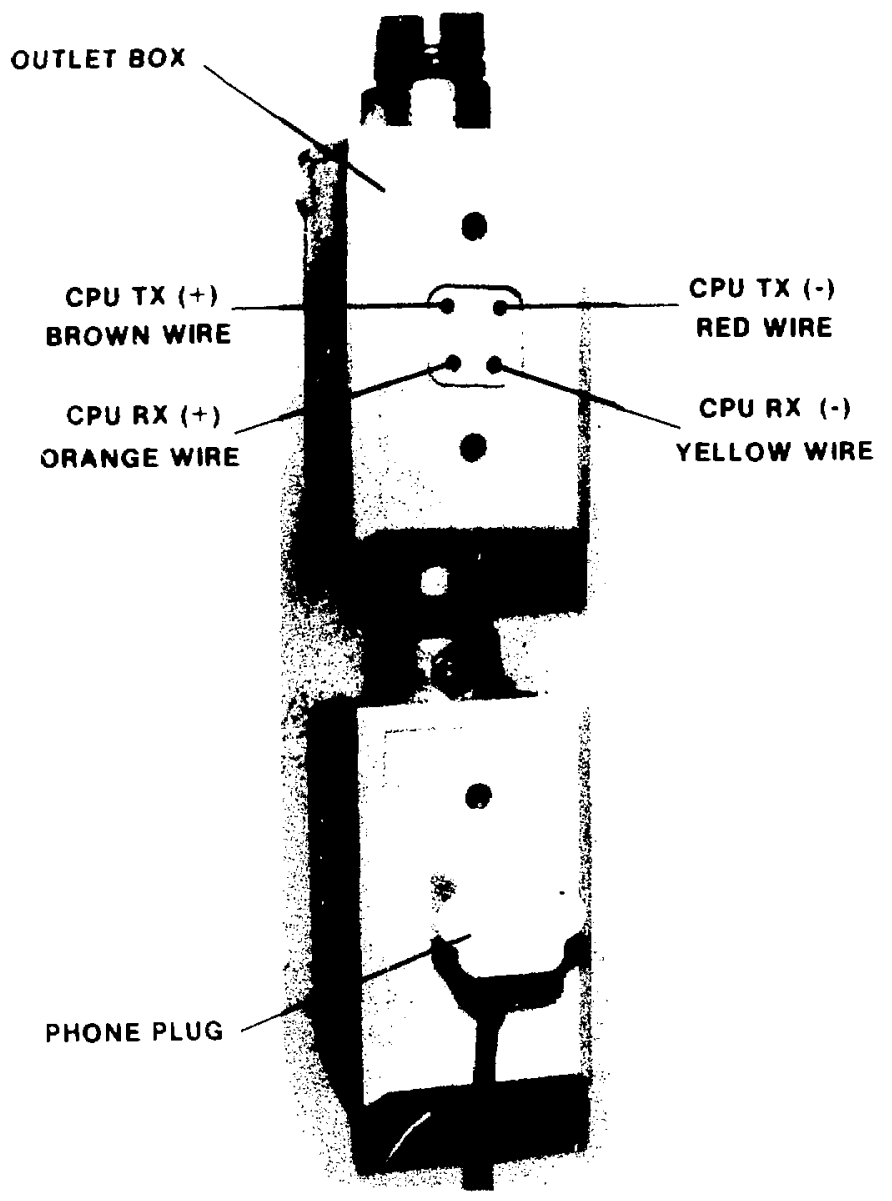

Fig. $3-4$.

outlet box. 
To avoid excessive ground loops (see Grounding and Shielding), the drain wire and shield for each wire pair are cut and taped at the point where they enter the outlet box. Outlet boxes are mounted with the wider spaced sockets at the top.

\section{INTERFACE CIRCUITS}

All remote terminals and NDA instruments used in the DYMAC System must contain a passive current-loop interface circuit that is optically isolated to communicate with the computer. The three types of terminals used in the DYMAC System, the Teleray 3741 CRT, TI 733 hard-copy, and TI 810 label-printing terminals already have optoisolator interface circuits. The modified interface circuit (See Sec. 2, Data-Entry Terminals) for the Teleray 3741 CRT terminal is shown in Appendix F, Fig. F-7. The 20-mA current-loop interface circuits for the TI 733 hard-copy terminal (Fig. F-8) and for the TI 810 label-printing terminal (Fig. F-9) are the type of interfaces that are standard for these terminals.

A printed-circuit interface board (Fig. F-10) was designed at LASL to optically isolate the NDA instruments from the computer. At present, the interface board is only being used with the electronic balances. The interface board contains a UART (universal asynchronous receiver/transmitter), which converts serial data to parallel data and vice versa, and operates with $a+5 v$ power supply.

In the receive circuit of the interface board (Fig. F-10), a voltage comparator ( $L M-311$ ) has a $3-V$ threshold for switching; it will not transfer noise spikes under $3 \mathrm{~V}$ to the UART. In this way, the comparator screens out noise which the UART would otherwise read as data. In addition, the $0.001-\mu F$ capacitor provides a small amount of frequency rolloff for fast noise transients.

In the transmit circuit of the interface board (Fig. F-10), a constant current diode limits the collector current of the optoisolator (MCT-2) to provide a low saturation voltage; this ensures that the next transistor $(Q-1)$ is turned on. The last transistor (Q-2) in the circuit should have enough base drive to provide a lowresistance path for the current from the computer. The inputs and outputs of the receive and transmit circuits are compatible wicin other TTL (transistor-transistor logic) circuits.

The current-loop interface circuit in the computer is shown in Fig. F-11. In the transmit circuit, the original 620-ohm resistor was replaced with a 510-ohm resistor. In the receive circuit, the orjginal 1200-ohm resistor was replaced with an 800-ohm resistor. The use of these lower-ohm-value resistors increases the current enough to meet the $20-\mathrm{mA}$ current-loop requirements. 
In addition to the resistor replacements, a $0.25-\mathrm{A}$ Littelfuse was added at the computer input of the receive/return circujt for each MUX port. Originally, one fuse protected the $-12 \mathrm{~V}$ supply on each MUX board. When a short occurred from the power supply to ground, all 15 MUX ports on the affected board were disabled. With the Littelfuse in each circuit, only the fuse connected to the shorted line blows when a short occurs; the other 15 ports on the board continue to function properly. 


\section{WIRING IN THE DYMAC COMPUTER ROOM}

An overview of the wiring in the DYMAC computer room (Room 131 in the Cold Support Building) is shown in Fig. 4-1. Trunk cables from remote locations enter the computer room through two junction boxes, J01 and J02. Individual cables from terminals in the Cold Support Building enter the computer room through a third junction box, JB-B. Other cables connect the junction boxes to the jackfield and the jackfield to the MUX ports on the computer. Appendix $G$ provides a comprehensive account of all the cable connections.

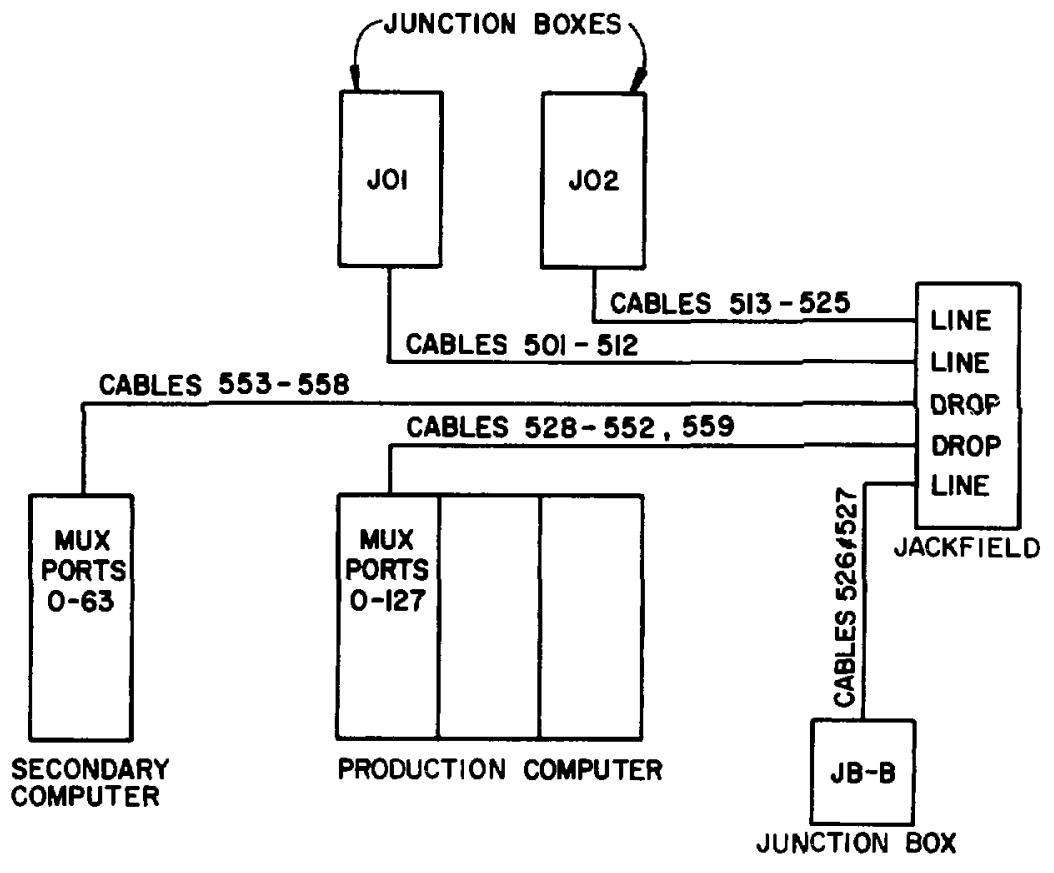

Fig. 4-1.

Wiring in the DYMAC computer room. 


\section{COMPUTER ROOM JUNCTION BOXES}

Each 24-pair trunk cable from the plutonium facility basement terminates in the DYMAC computer room in junction boxes J01 or J02, as shown in Fig. 4-2. Junction box J01 contains twelve 50-pin terminal strips (T01 - T12); junction box J02 contains 13 strips (TO1 T13), as shown in Fig. 4-3. Figure 4-4 shows a sample terminal strip.

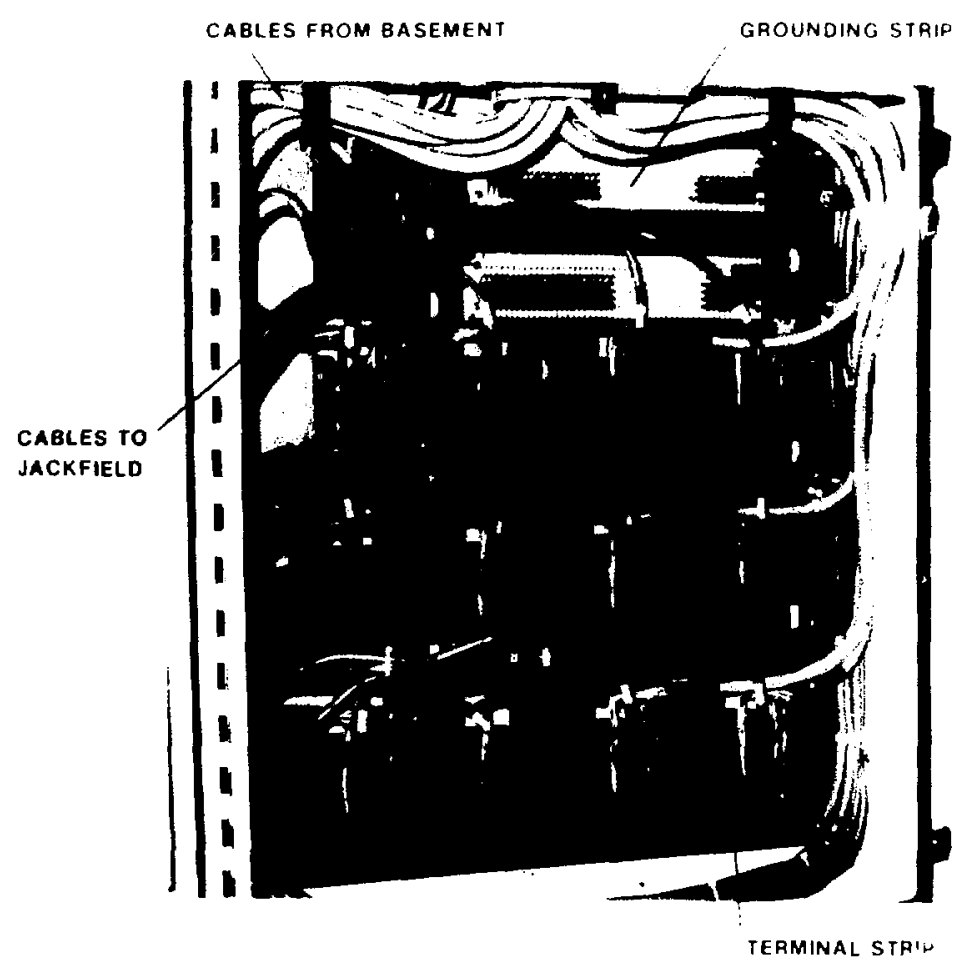

Fig. 4-2.

Computer room junction box (J02). 


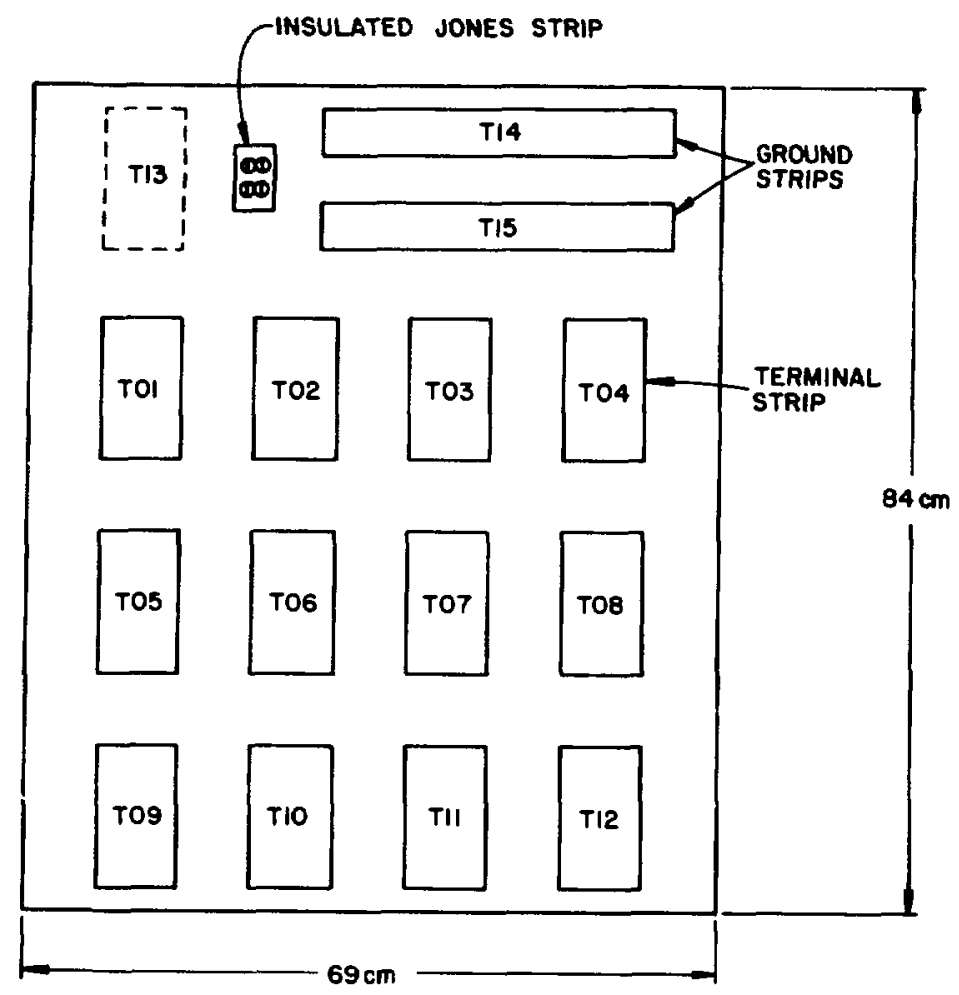

$$
\text { Fig. 4-3. }
$$

Location of terminal strips in computer room junction boxes JOI and J02. Texminal strip $T 13$ is used only in junction box J02; $T 13$ is connected to some of the terminals in the cold Support Buizding.

\section{JUNCTION BOXES TO THE JACKFIELD}

Cables with 50-pin AMP connectors on each end connect the three computer room junction boxes to the jackfield. The cables mate with female AMP connectors mounted on terminal strips in the junction buxes (Fig. 4-4) and with female AMP connectors on the jackstrips. Each cable connects a terminal strip to the LINE SIDE (side connected to remote locations) of the jackfield on a one-to-one basis. Table H-I in Appendj.x H specifies the cable connections from the computer room junction boxes to the jackstrips on the jackfield.

Manufacturer's name. 


\section{JACKFIELD TO THE PRODUCTION COMPUTER}

Cables with 50-pin AMP connectors on one end mate with the connectors on the jackstrip; on the opposite end, 6-pin AMP connectors connect to the computer multiplexor. Table H-II provides connection details. These cables connect the DROP SIDE of the jackfield to the computer multiplexor. Figure 4-5 shows the MUX port locations at the rear of the production computer. There are four MUX boards per chassis; they are labeled ALM for asynchronous line multiplexor; ALM is synonymous with MUX. MUX port assignments are given in Appendixes $G$ and $\mathrm{J}$.

\section{CONNECTIONS TO THE SECONDARY COMPUTER}

The secondary computer system consists of sjx 25-pair cables running directly from the bottom three jackstrips on the jackfield to the multiplexor at the rear of the secondary computer. Each cable terminates at the jackfield in a 50-pin AMP connector and at the secondary computer in several 6-pin AMP connectors. On the DROP SIDE of the jackstrips, 16 ports (0-15) are available. There are enough cables installed to expand the number of secondary computer ports to 64 . No connections are made to the LINE SIDE of the jackstrips, leaving the secondary computer available for off-line tasks or for use as a backup computer.

The assignment of secondary computer ports to jackfield locations is shown in Fig. 4-6 and listed in Table H-III. The wiring code follows the same conventions as the code for the production computer and is listed in Table H-II. No specific locations in the plutonium facility have been given priority for patching to the secondary computer ports if the production computer should fail. When the need arises, any of the 16 locations can be connected to the secondary computer by patching the LINE SIDE of a device location to the DROP SIDE of a secondary computer port at the jackfield. 


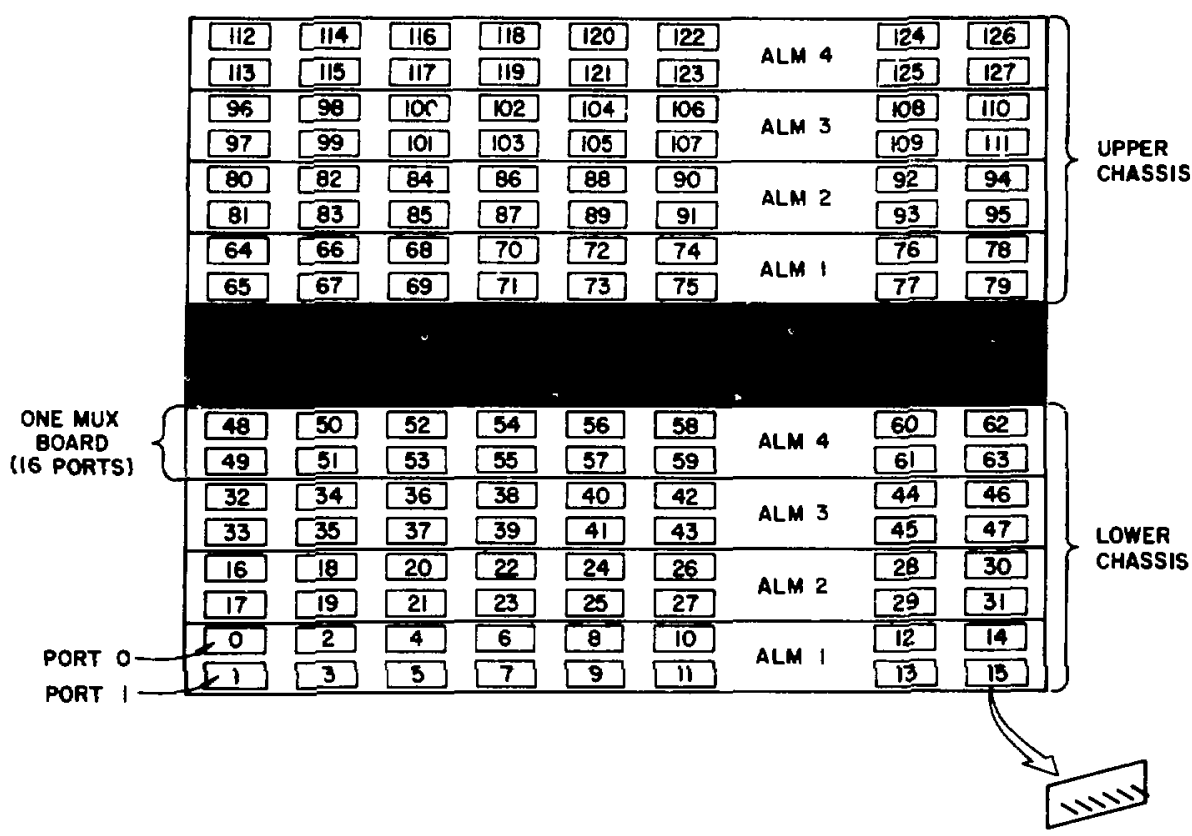

Fig. 4-5.

Multiplexor port locations at rear of production computer. (ALM is synonymous with MUY.)

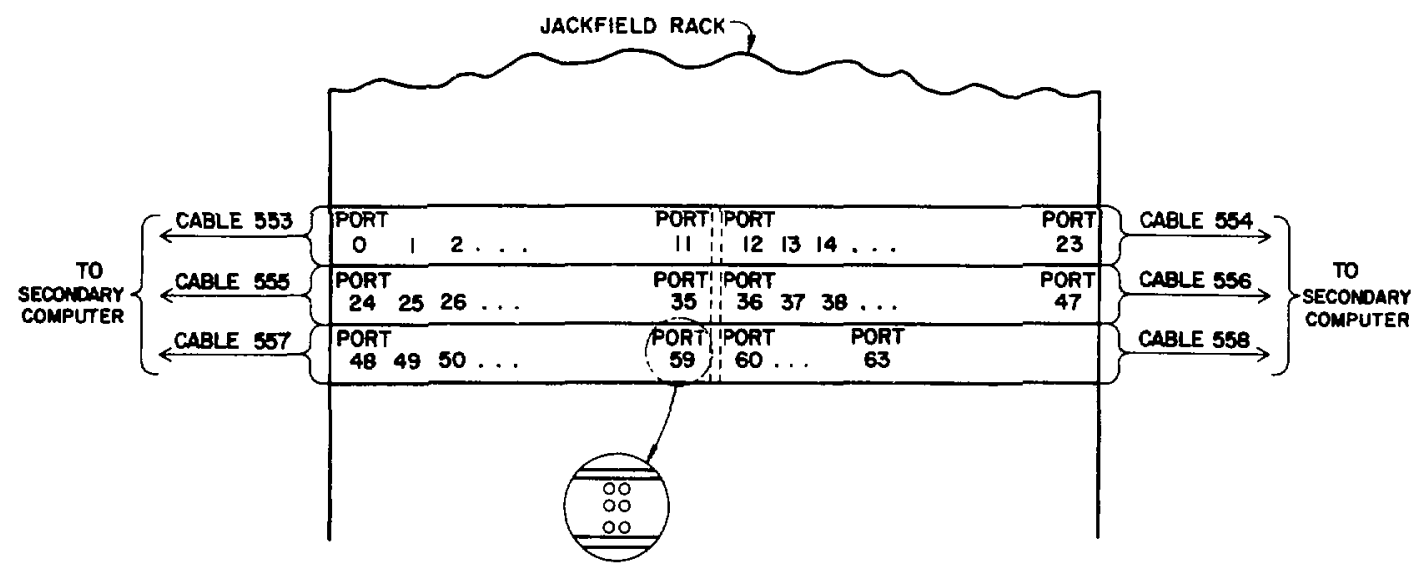

Eig. 4-6.

Wiring of secondary computer ports to jackfield locations. 


\section{THE JACKFIELD}

The jackfield provides flexibilty for maintenance and for making additional hook-ups. For example, a failed MUX port can be replaced with a spare port by patching at the jackfield. The jackfield is also used for checking out new lines, for troubleshooting the communications system, and for hooking up the secondary computer when needed.

The jackfield is located in the DYMAC computer room near the production computer. It is composed of twelve jackstrips mounted on top of one another in a 1.8-m-high rack (Fig. 2-3). A jackstrip is a chassis with three rows of 48 jacks mounted on the front panel. The jacks are specialized connectors on the front of the jackstrip, which are wired to four 50-pin AMP connectors on the rear panel. Figure 5-1 shows the front panel of an individual jackstrip, with an enlarged view of two jack circuits. Figure 5-' shows a detailed view of the corresponding rear panel.

Every NDA instrument and terminal in the facility has a separate communications line that connects it to the jackfield. A communications line runs from an outlet box in the Plutonium Processing Facility or the Cold Support Building to a pair of side-by-side jacks on the jackfield. Conventions dictate that data be transmitted frcm the production computer through the left jack of the pair to the outlet box. The computer receives data from the outlet box through the right jack. Each jack consists of two wires called data tip (DT) and data ring (DR). DT is the current source (+) and DR is its return (-).

A set of three vertically oriented jacks, one from each row on a jackstrip, constitutes a jack circuit, which is used either for transmission or reception. In one circuit, the LINE jack on top connects to a remote location in the facility; the DROP jack in the middle connects to a computer MUX port; and the MONITOR jack on the 


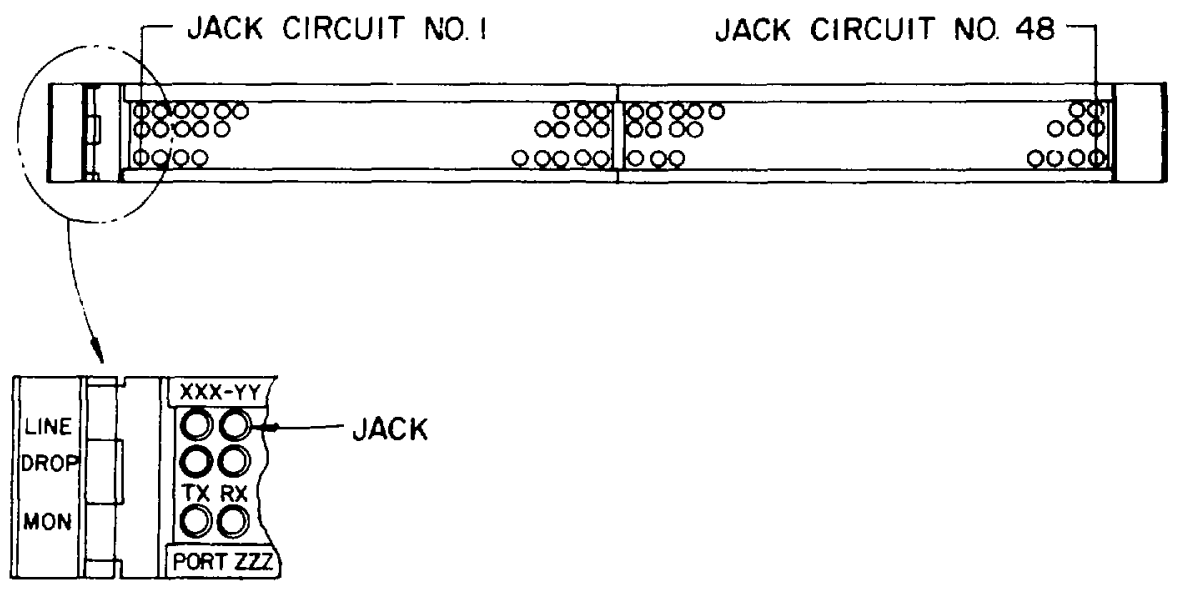

Fir. 5-1.

Jacistrin iont panel, with enlarged view of two jack circuits that torether constitute onf communications $2 i n e$. XXX specifies the wing and room number of a remote zocation, YY specifies the out let box number, and POST $2 Z 2$ specifies the number of the port connected to the outlet.

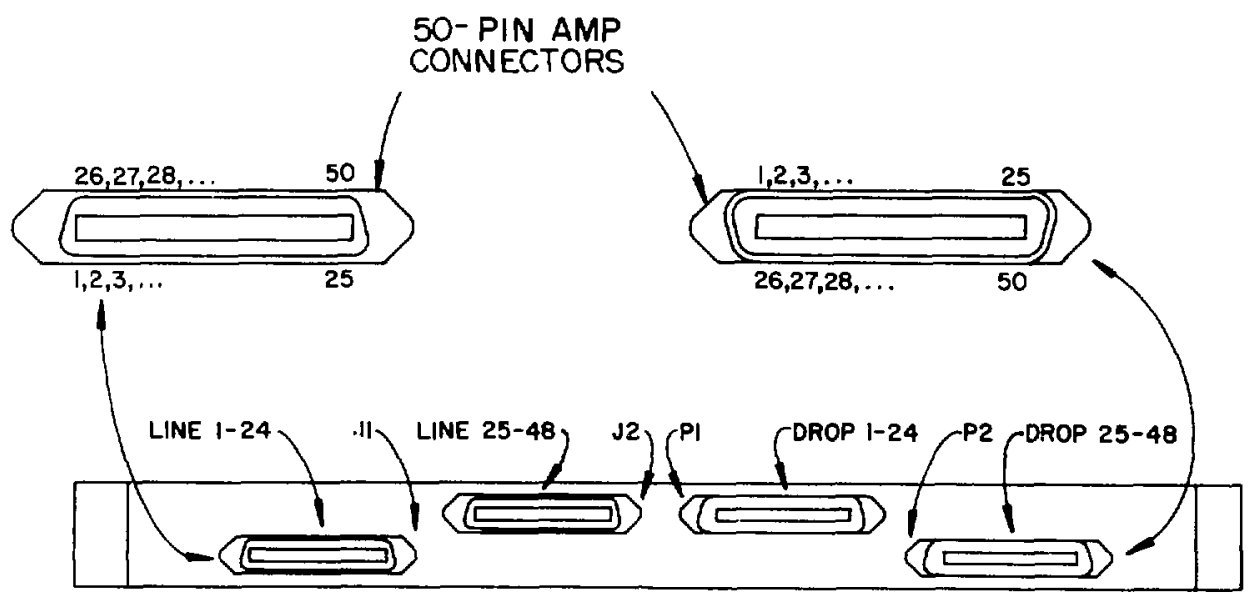

Fig. 5-2.

Jackstrip rear panel, with enlarged view of two of the four 50-pin AMP connectors. 
bottom is connected in parallel with its corresponding LINE fack. A.s its name suggests, the MONITOR jack monitors signals on the comm in cations line.

LINE jacks are not used on the three secondary computer jackstrips (see Seo. 4). The DROP jacks on the secondary computer jackstrips are used only when needed to connect a secondary computer port to a location in the plutonium facility.

Signals pass through the jacks from DROP to LINE or LINE to DROP on connections (indicated by small arrows in Fig. F-12) that are activated by switches. When the switch is closed, as in Fig. F-12, signals pass from tip to tip and ring to ring. If a plug (patchcord) is inserted into the DROP or LINE jack, the connection is broken. For example, a patchcord plugged into a LINE jack breaks the connection between an instrument or terminal and the computer; signals pass from the tip and ring of the LINE jack to the tip and $r$ ing of the patchcord. Refer to tables H-IV and $\mathrm{H}-\mathrm{V}$ for specific front-to-rear connections in a jackstrip. 


\section{CABLE TRACING}

All the intermediate connections in the DYMAC Communications System are specified in a separate document, called the WIRERUN Listing, which enables one to locate a wire or trace a signal at any point in the system. This section gives examples of using the WIRERUN Listing to trace cables.

\section{HOW TO USE THE WIRERUN LISTING}

The WIRERUN Listing is essential for making additions to the communications system; it is also helpful in maintaining the system. The iisting is too extensive to be included in this manual. A copy is available in the DYMAC computer room. To obtain a personal copy, refer to Appendix E.

The WIRERUN Listing contains many sections. The three Notes sections describe cable specifications, special hardware, and general information. The Wiring and Termination Schedule lists the wire destinations from a basement junction box according to the box number, terminal strip number, and pin number on the strip. The Cable Installation Scriedule describes the termination locations of every cable in the system and assigns a number to each cable. The terminations of the wires in a cable at each junction box are given in the Wire Installation Schedule. The Device Installation Schedule lists the instruments and terminals in each room of the plutonium facility. The most useful section is the Extended Card Listing, which lists all of the connections between an outlet box and the termination point associated with it in one of the three junction boxes in the DYMAC computer room.

Tracing one signal through Fig. 6-1 defines all of the parameters used in the Extended Card Listing. The columns headed CODE, PATH, and RTE are used only by the computer processing program; they are not involved in tracing signals. 


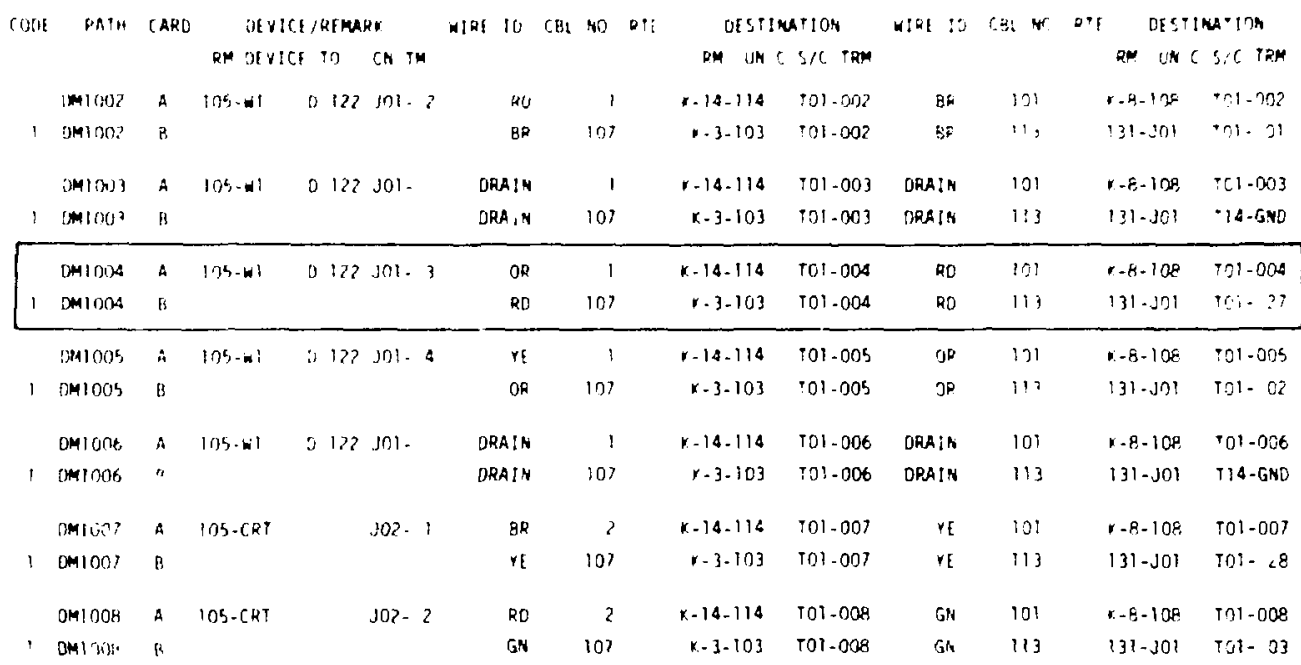

$$
\text { Pig. 6- } 2 \text {. }
$$

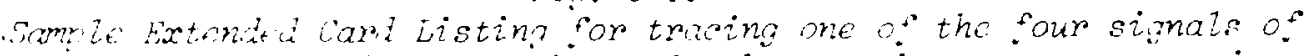
$x$ :ommutications line from the outlet bor to the computer ron sunction box.

The fifth and sixth lines, which are highlighted in Fig. 6-1, are for a weighing device (W1) located in Room 105 in the 100 Wing. The device is located in dropbox 122 (D122) and connects to the first of two outlets in Room 105 (J01). The third pin on the first communication outlet (J01-03) is in cable 1 and is connected to an orange wire. Cable 1 goes to a junction box (114) in the basement located at coordinates $\mathrm{K}$ and 14 , as taken from the LASL Engineering Department drawings. The orange wire terminates on terminal strip 1 (TO1), at termination $4(004)$ in the junction box. The signal enters the trunk line at this point and goes through trunk cables 101 and 107 where it is available on the same terminal strip and terminates in the other two basement boxes for the $100 \mathrm{Wing}(\mathrm{K}-8-108$ and $K-3-103)$. The signal then goes through trunk cable 113 to the DYMAC computer room where it terminates in junction box $\mathrm{J01}$ on pin 27 of T01.

\section{CABLE TRACING}

To trace a signal or a pair of wires, first identify the Iocation of either the MUX port on the computer or the outlet box to which an instrument or terminal is connected. These two points can

*DYMAC numbering system. 
be correlated by mefarring to Appendixes $G$ or $J$, which list the outlet box that is connected to each MUX port. Locations and MUX ports are clearly labeled on the jackfield.

Each MUX port and outlet box is listed in Appendix G, which also gives the numbers of the cable and line that connect to the multiplexor. Each connector at the multiplexor is labeled with the number of the MUX port to which it is connected. Individual pairs in the 25-pair cables are color-coded. The color codes used are given in Table H-II.

The DROP SIDE cable numbers in Appendix $G$ identify the cable connecting a MUX port and a particular jackstrip; the jackstrip is labeled with the remote location number given in Appendix $G$. The LINE SIDE cable numbers refer to the cable between the jackstrip and its termination on a terminal strip in one of the three junction boxes ( $\mathrm{J01}$, J02, or JB-B) in the DYMAC computer room. The numbers of the junction box and of the individual terminal strip connected to a LINE SIDE cable are also listed. The termination-point number for each wire on a terminal strip is given in the WIRERUN Listing; this number is also the pin number on the connector for that wire at the jackfield.

Here are directions for signal tracing from outlet box 409-05, where an electronic balance $\left(W_{1 A}\right)$ is connected to the fifth outlet in Room 409. First, find the 400 Wing locations in Appendix G. Location 409-05 is connected to MUX port 98 with line 11 of cable 546. Table H-II identifies the wires for line 11 as a violet-blue/ blue-violet pair and a violet-orange/orange-violet pair. The first pair is the computer transmit pair and the second is the computer receive pair. The first pair is also the tip and ring (Sec. 5) on the DROP SIDE of the left jack for this location; the other pair is the tip and ring of the right jack (alsC DROP SIDE). As shown in Appendix G, cable 518 is connected to the LINE jacks in this case and terminal strip T06 in J02.

The Extended Card Listing of the WIRERUN Listing is the most useful listing for following signals from the computer room junction boxes J01, J02, or JB-B to each outlet box. The wiring list for outlet 409-05 is found in the 400 Wing section of the Extended Card Listing (Fig. 6-2). The J05 under the DEVICE/REMARK heading identifies the fifth outiet in froom 409. The device is listed as a $W_{1 A}(5.5-\mathrm{kg}$ balance with $0.1-8$ precision) in dropbox 414 .

The wires from the basement junction box to this outlet box are in a two-pair cable (58), which consists of a brown-and-red pair and an orange-and-yellow pair. These wires terminate on outlet box sockets 1 (brown), 2 (red), 3 (orange), and 4 (yellow), as shown in Fjg. 3-4. Socket 1 is the computer transmit (TX) source and socket 2 is its return; socket 3 is the computer receive (RX) source and 


\begin{tabular}{|c|c|c|c|c|c|c|c|c|c|c|c|c|c|c|c|}
\hline \multirow[t]{3}{*}{$\cos$} & \multirow[t]{2}{*}{ bath } & \multirow[t]{2}{*}{ CARD } & \multicolumn{4}{|c|}{ OCVICE/REMARK } & \multirow[t]{2}{*}{ HIRE IO } & \multirow[t]{2}{*}{ cal } & \multirow[t]{2}{*}{ NO } & \multicolumn{2}{|c|}{ DESTIMTION } & \multirow[t]{2}{*}{ HIRE JD } & \multirow[t]{2}{*}{ CBL MO } & \multicolumn{2}{|c|}{ DESTIMTIOH } \\
\hline & & & PM DCVIC & t To & CN TI & $\mathrm{TM}$ & & & & RH UN $C$ & $S / C$ TRM & & & RH UN C & $S / C \mathrm{TH}$ \\
\hline & DMAOE 1 & $A$ & - & & $\cdot$ & 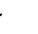 & & & & 0.14 .414 & 101.061 & HHORYE & 401 & $0-8-400$ & TO1 - 061 \\
\hline \multirow[t]{3}{*}{1} & $(\mathbf{M} 4061$ & $B$ & & & & & WHORYS & & 409 & $0.3-403$ & $101-061$ & WORYE & 415 & $131-302$ & TO6- 46 \\
\hline & iJ44061 & 0 & $409-b^{i} 1 A$ & 5414 & J05- & -1 & BR & & $5 B$ & $D-8-408$ & T01-061 & & & - & - \\
\hline & i*44062 & A & - & & - & - & & & & $0-14-414$ & [0]-062 & WHORGH & 401 & D-8-408 & $101-062$ \\
\hline \multirow[t]{3}{*}{1} & DN4062 & $B$ & & & & & WHORGN & & 408 & $0-3-403$ & T01-062 & WHORGA & 415 & $131-302$ & $106-21$ \\
\hline & OMAOf? & 0 & $409-W 1 A$ & 0414 & J05- & -2 & $\mathrm{RD}$ & & 58 & $0-8-408$ & $101-062$ & & & - & - \\
\hline & $2+406^{2}$ & A & - & & - & - & & & & $D-14-414$ & T01-063 & DRAIN & 401 & $0-8-408$ & T01-063 \\
\hline \multirow[t]{3}{*}{1} & $\{M 4063$ & $B$ & & & & & DRAIN & & 408 & $D-3-403$ & $T 01-063$ & DRA!N & 415 & $131-\mathrm{J} 02$ & TIS-GNO \\
\hline & $1 \times 4063$ & 0 & $409-W ! A$ & 0414 & J05- & & DRAIN & & $5 \varepsilon$ & D-8-408 & T01-063 & & & - & - \\
\hline & DM4064 & A & - & & - & - & & & & $D-14-414$ & T01-064 & WHORBU & 401 & $0-8-408$ & T01-064 \\
\hline \multirow[t]{3}{*}{1} & JM4064 & f & & & & & WHOREU & & 408 & $D-3-403$ & TO1-064 & WHORBU & 415 & $131-j 02$ & T06- 47 \\
\hline & DM4ก64 & $b$ & $409-H 1 A$ & 0414 & J05. & 3 & $O R$ & & 58 & $0-8-408$ & TDI -064 & & & $\sim$ & - \\
\hline & $0 M 4065$ & $A$ & • & & - & & & & & $0-14-414$ & TO1-065 & HHORVI & 401 & $D-8-408$ & T01-065 \\
\hline \multirow[t]{3}{*}{1} & DM4065 & R & & & & & WHORVI & & 408 & $0-3-403$ & T01-065 & WHORVI & 415 & $131-\mathrm{J} 02$ & $106-22$ \\
\hline & 0144065 & [1, & $4 \cap 9-W 1 A$ & 0414 & J05- & 4 & $Y:$ & & 58 & $D-8-408$ & TO1.065 & & & - & - \\
\hline & DM4066 & A & - & & - & & & & & $D-14-414$ & TO1-066 & DRAIN & 401 & $0-8-408$ & T01-066 \\
\hline \multirow[t]{2}{*}{ l } & $0 M 4066$ & 8 & & & & & DRAIN & & $40 \%$ & $0.3-403$ & T01-066 & DRAIN & 415 & $131-302$ & T15-GND \\
\hline & DMAOE.6 & ח & $409-w 1 t$ & 0414 & 305 - & & DRAIN & & $5 ?$ & $0-8-409$ & $T 01-066$ & & & - & - \\
\hline
\end{tabular}

\section{Fig. $6-2$.}

Somple Extended Cari Listing for tracing all four signals of a comminirtions line srom the outlet box to the computer room junction box.

socket 4 is its return. The wires terminate on terminal strip 1 (TO1) in junction box 408 in the basement, at locations 61, 62, 64, and 65. A drain wire runs with each pair of wires; the drain wires terminate at locations 63 and 66 .

Basement junction box 408 is the middle one of the three junction boxes that serve the $400 \mathrm{Wing}$, as show in Fig. 6-3. The wires in junction box 408 connect in series to junction boxes 414 and 403 at the same terminals as in junction box 408. Hence, junction box 403 is also connected in series with the outlet box. From junction box 403, the four lines for outlet box 409-05 terminate in junction box J02 in the DYMAC computer room on terminal strip 6 (TO6), at locations $46,21,47$, and 22 . The signals on this strip are paired across the 50-pin connector in J02. Thus, locations 46 and 21 are one pair; 47 and 22 are another pair.

The foregoing example traces the signal lines from the computer multiplex or to an outlet box. Using this procedure, one can trace any pair of wires. Maintenance should seldom require signal tracing between the computer multiplexor through the jackfield to one of the three computer room junction boxes. 


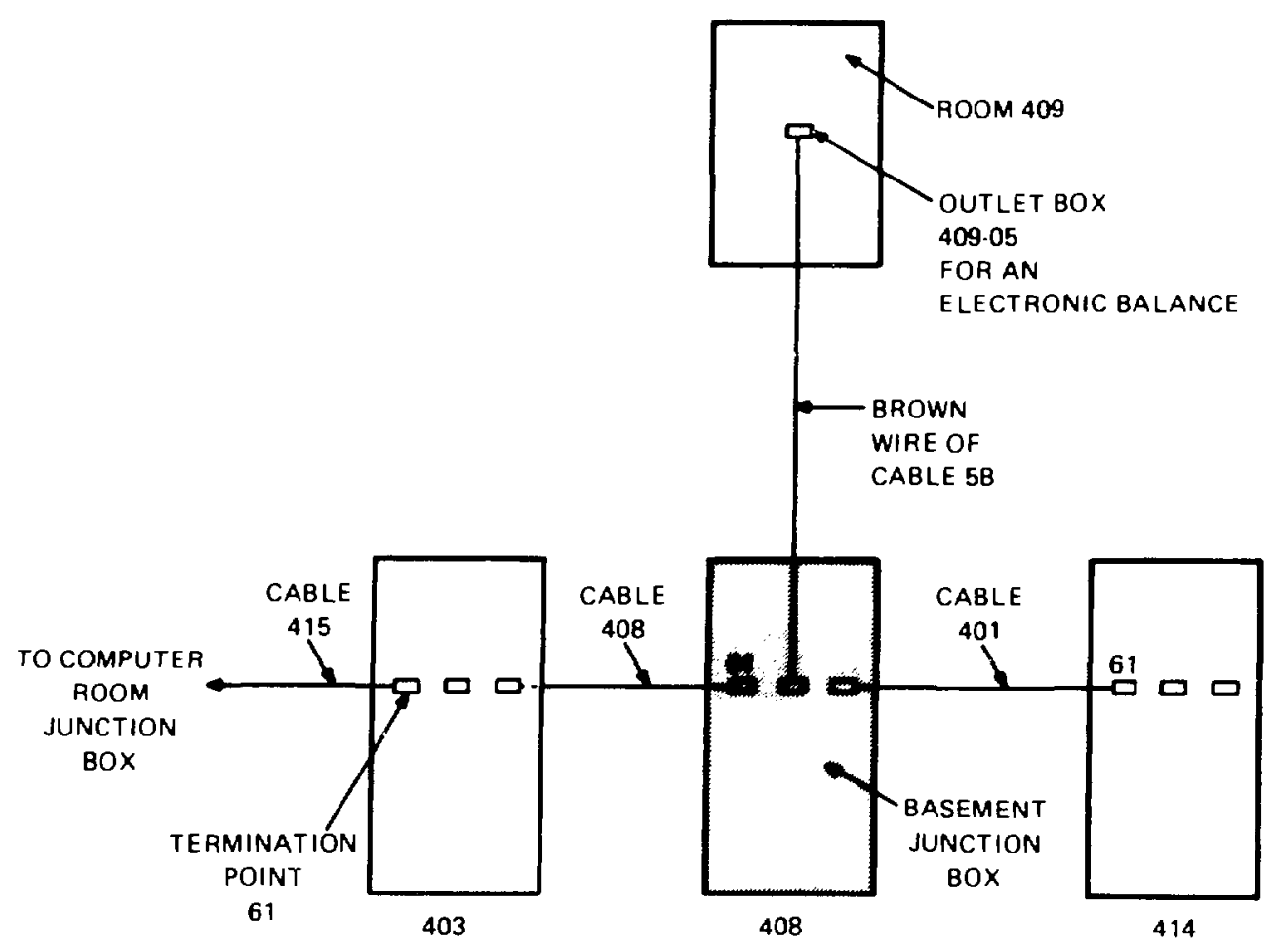

Fia. 6-3.

Basement junction box connected to outlet box. The brown wire from outlet box 408-05 terminates at location 61 in basement junction box 408 . Boxes 403 and 414 are also connected in series with outlet box 409-05. 


\section{DIAGNOSTIC EQUIPMENT}

LASL personnel designed and fabricated the three diagnostic panels mounted in the jackfield rack shown in Fig. 7-1. The panels are used for preliminary line check-out and for maintenance of the communications system. Test Panel I, the top panel in the rack, is used to check continuity and polarity as well as to measure the capacitance and resistance of a line. The second panel, the Diagnostic Panel, permits one to check an entire communications line from the computer multiplexor to a remote device, to determine which portion of the system is malfunctioning. The third test panel, the Fox Generator, is used to check a line from the jackfield to an outlet box and vice-versa.

\section{TEST PANEL I}

The right side of Test Panel I (see Fig. F-13) is used to test polarity and continuity; the left side (Fig. F-14) is used to measure the capacitance and resistance of a line. A power supply can be patched into a jackfield location by connecting a patchcord between either of the two jacks on the right side of Test Panel $I$ and any location on the jackfield. The right jack of the pair is connected in series with a 0-20 mA current meter. Test Panel I provides a voltage that is current-limited by two paralleled current-limiting diodes that allow approximately $10 \mathrm{~mA}$ to flow. The tip of each jack is the source, or positive side of the power supply, and the ring is the return, or negative side.

The switch on the far left of the panel (Fig. 7-1) is springloaded and returns to the middle position (DT-DR) when not held in another position. Measurements between the tip and ring of a jack are performed when the switch is in the DT-DR position. Similarly, the DT-GND position allows measurements to be made between the tip of a jack and ground; measurements between the ring and ground are made in the DR-GND position. 


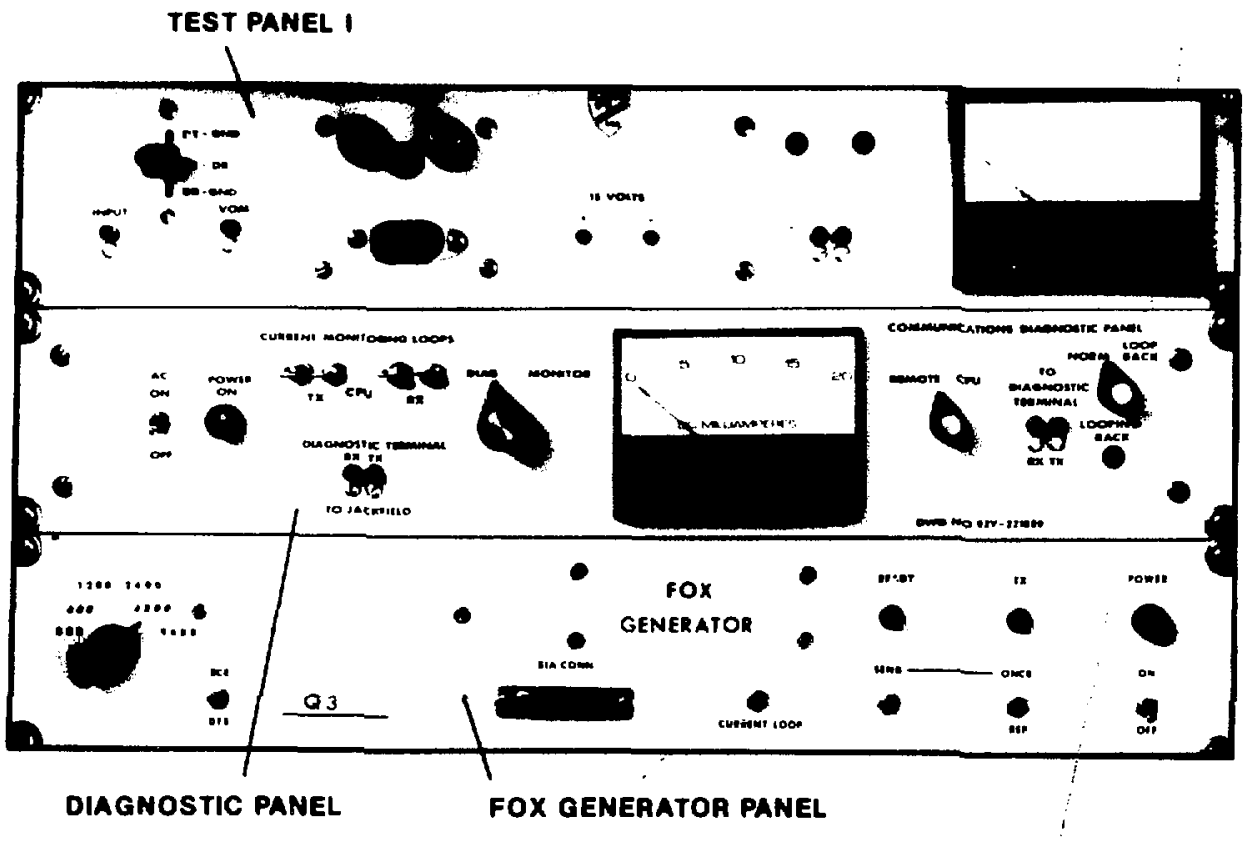

Fig. 7-1.

Three diagnostic panels are mounted at the top of the jackfield rack.

The VOM jack on the panel is connected to a volt-ohm meter for resistance measurements or to capacitance meter for capacitance measurements.

\section{DIAGNOSTIC PANEL}

The Diagnostic Panel allows one to perform six tests on a communications line:

1. Check MUX port at the jackfield.

2. Cheok transmission to the jackfield from a remote device.

3. Check transmission from the jackfield to a remote device.

4. Check the lines to and from a location by looping back the lines at the device.

5. Monitor transmission from the computer to a remote device.

6. Monitor transmission to the computer from a remote device.

All these diagnostic tests, require the use of la Teleray terminal located in the DYMAC computer room, which is referped to as the Diagnostic Terminal. The Diagnostic Terminal is cpnnected to the right pair of jacks on the Diagnostic Panel. The current-loop 
interface circuits in the Diagnostic Terminal are passive circuits, as are all of the interface circuits in the remote devices. Thus, the Diagnostic Panel contains circuits that make a passive receive input circuit simulate an active transmit circuit, which allows two passive devices to communicate with each other. These circuits, shown in Fig. F-15, are used when the Diagnostic Terminal is connected to a remote device. They are by-passed when the Diagnostic Terminal is connected to the multiplexor.

Another feature built into the Diagnostic Panel allows data transmitted to or from the computer to be monitored on the Diagnostic Terminal. The Diagnostic Terminal responds to characters in the same way any remote terminal responds; there is no provision for display of nonprinting characters. The MONITOR function uses the $0-20 \mathrm{~mA}$ current meter on the Diagnostic Panel to measure the quiescent current flowing in the circuit being tested. The current waveforms transmitted both to and from the computer can be observed by using oscilloscope current probes on the wire loops on the front of the Diagnostic Panel.

The loop-back function is one of the most useful features of the Diagnostic Panel. A Loop-Back plug is used at the remote location to loop the signal transmitted from the Diagnostic Terminal to the remote location and then back to the terminal, for checking lines between the jackfield and the remote location. The loop-back procedure is given in sec. 9 .

\section{FOX GENERATOR PANEL}

The Fox Generator Panel is used in loop-back tests to check the continuity and polarity of a line from the jackfield to a remote location and vice-versa. Using the Fox Generator, one can test all three types of terminals used in the DYMAC System. The Fox Generator transmits several consecutive lines of data in a block. The data consists of the message THE QUICK BROWN FOX JUMPED OVER THE LAZY DOG'S BACK 0123456789, which exercises every alphanumeric character on the keyboard. A switch on the panel allows this message to be sent in a single block or in a continuous transmission of blocks. There is also a switch on the Fox Generator for selecting the transmission rate.

In normal operation, the Fox Generator's 20-mA current loop output is used for transmission. However, the output from the Fox Generator is also available in EIA RS-232 levels via the 25-pin connector on the panel. By selecting the position of the DTE-DCE (data terminal equipment - data communications equipment) switch on the panel, the RS-232 output is transmitted to either a terminal or a communications modem. When the switch is in the DTE position, the 
RS-232 output is accessible at pin 3; with the switch in the DCE position, the output is at pin 2 (see Fig. F-16).

If the Fox Generator Panel is not operating properly, there is a spare Fox Generator chassis in the computer room. It is functionally identical to the one in the jackfield rack and is connected in the same manner.

\section{PATCHCORDS}

Three types of patchcords are commonly used for connections at the jackfield. One type is gray with twin plugs; one side of the plug is straight and the other is curved (Fig. 7-2). Another type is black, with twin plugs; the plug is rectangular with a notched side (Fig. 7-3). Twin plugs have a curved or notched side to help avoid crossing the transmit and receive lines. Notched and curved patchcords can be used interchangeably. A third type of patchcord frequently used has gray single plugs** (Fig. 7-4).

The standard twin-plug patchcords are modified by LASL so that the sleeve of the transmit plug is not connected to the sleeve of the receive plug. This modification reduces the possibility that the patchcord wjll short the computer's $-12 \mathrm{~V}$ supply to ground.

Special twin-plug patchcords are also available for use at the jackfield. These patchcords have six separate conductors: two for the tip connections, two for the ring connections, and two for the sleeve connections (the transmit and recejve sleeves are not connected).

\section{MARKER AND DUMMY PLUGS}

Marker and dummy plugs are made of plastic. Marker plugs can be red, white, yellow, or green. They have a short prong that breaks no connections when inserted into the jackfield. Marker plugs simply mark problem locations, spare ports, and secondary computer ports. Dummy plugs can be red, white, or black. They have a long prong that opens the connection between the computer and the remote device during spare port patching or diagnostic procedures.

* A twin-plug patchcord has a two-prong plug at each end.

**A single-plug patcheord has a one-prong plug at each end. 


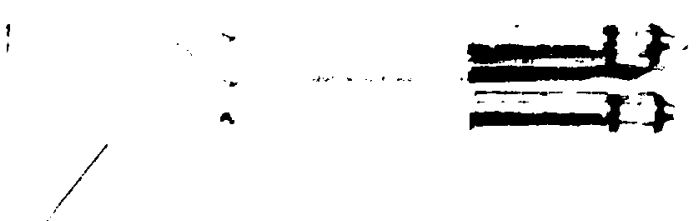

\section{CURVED SIDE}

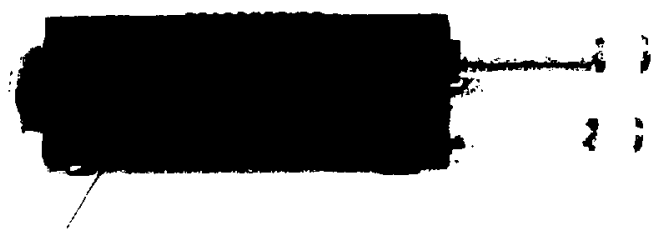

y , ri: :ifit
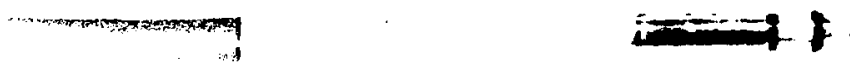

TEST PLUGS

Three types of test plugs are used for diagnostic procedures: a Test I plug (Fig. F-17), a Loop-Back plug (Fig. F-18), and a Short plug (Fig. F-19). The type is clearly labeled on each plug. A Test I plug is used in checking the continuity and polarity of a Iine. A Loop-eack plug is used in testing a line's ability to conduct a transmission without altering it. A short plug is used in measuring the resistance of a 1 ine. 


\section{JACKFIELD USE}

This section explains the different functions of the jackfield, such as patching remote locations and spare ports and troubleshooting malfunctioning parts of the communications system. Section 9 gives detailed procedures for using the jackfield.

NORMAL USE

The jackfield is normally used to patch a remote location to a spare port or a secondary computer port (Procedures 1 and 2 in sec. 9).

\section{TESTING AND DIAGNOSTICS}

Several methods of testing communications lines are available. The diagnostic equipment is flexible enough to allow the best methods to be used in each situation. The continuity check (Procedure 3), polarity check (Procedure 4), resistance measurement (Procedure 5), capacitance measurement (Procedure 6), and a loop-back test (Procedure 7 or 8 ) must be performed in checking out a new line. These checks are also useful for troubleshooting problems with a line.

The loop-back test verifies a line's ability to conduct a transmission without alteration. There are two loop-back tests available in the communications system: the Fox Generator test (Procedure 7) and the Diagnostic Panel test (Procedure 8). Both tests serve the same purpose; however, the Fox Generator test is much easjer to perform. Only use the Diagnostic Panel loop-back test if the Fox Generator is not functioning properly. (When the Fox Generator was fabricated, it made the loop-back test obsolete on the Diagnostic Panel.) 
Other testing and diagnostic procedures check data transmissions. Procedure 9 provides instructions on connecting the Diagnostic Terminal to a MUX port at the jackfield. Procedure 10 is for checking transmission hetween a remote device and the Diagnostic Terminal. Procedure 17 is for using the Diagnostic Terminal to monitor transmissions between the compiter and a remote terminal.

TROUBLESHOOTING THE COMMUNICATIONS SYSTEM

To troub?eshoot any line in the communications system, perform the steps in Procedure 12 sequentially or as directed in each step until the cause of the problem is found. The troubleshooting process is summarized in two flow diagrams, one for troubleshooting terminals (Fig. $8-11$, the other for troubleshooting NDA instruments and other system hardware (Fig. $8-2)$. Refer to Appendi: $\mathrm{K}$ to contact the proper maintenance service for malfunctioning components.

\section{VOLTAGE MONITORING}

The jackfield MONITOR jacks are permanently wired in parallel with the LINE jacks. Therefore, the voltage waveforms can be monitored on the jackfield MONITOR jacks as long as nothing is plugged into either the LINE or DROP jacks of the location being monitored. A standard oscilloscope will give faulty readings because the ring of a jack is not at ground. Thus, a differential preamp must be used to monitor voltage with an oscilloscope. Because data is transmitted in 20-mA current loop mode, voltage waveforms may or may not be useful in maintaining the communications system.

\section{DATA TRANSMISSION TESTS}

Data transinission can be tested only if the production computer is not in routine operation. Data can be received from a teminal (Procedure 13) and transmitted to it (Procedure 14) by typing the appropriate form of the XFER/A command on the computer console. 
DEVICE DIAGNOSTICS

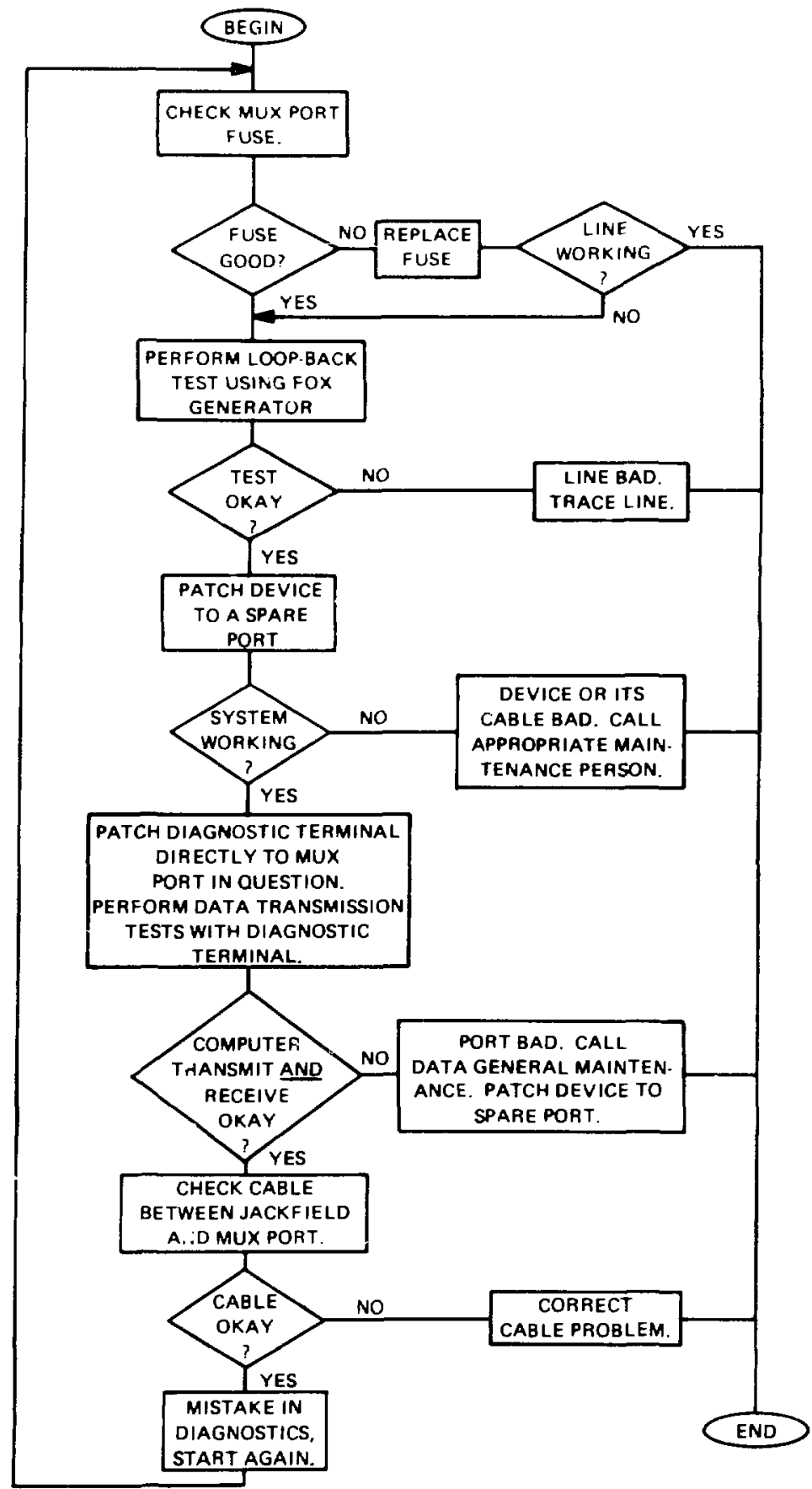

Fig. 8-2.

Flow diagram of device diamostics mroedure. 


\section{JACKFIELD PROCEDURES}

The procedures in this section are for normal jackfield use, for testing and diagnostic purposes, for troubleshooting the communications system, and for data transmission tests.

Insertion of a twin-plug patchcord into the jackfield or diagnosti pane?s requires proper orientation so that the transmit and receive lines are not crossed. Figure 9-1 shows the proper orientation for horizontal insention of a twin plug and Fig. 9-2 shows the proper orientation for vertical insertion.
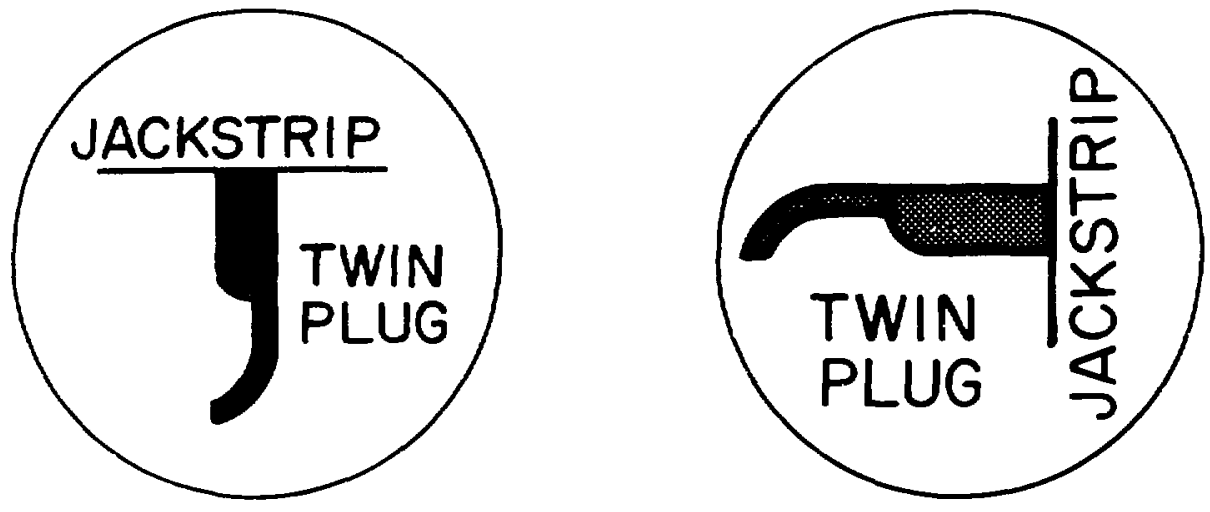

$$
\because \because 9-1 \text {. }
$$

Loriontat inemption of a twin lize into iackstrip.

Curved or noteheri side must ace to the left.

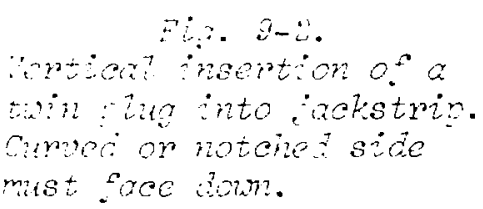




\section{PROCEDURE 1, PATCHING A REMOTE LOCATION TO A SPARE PORT} ON THE PRODUCTION COMPUTER

1. Disconnect the multiplexor from the remote location to be tested by inserting two dummy plugs into the DROP jacks for that location on the jackfield.

2. Insert a twin-plug patchcord into the LINE jacks for the remote location to be patched (see Fig. 9-3).

3. Plig the other end of the patchcord into the DROP jacks of the spare port. The curved or notched sides of the plugs must face in the same direction (both to either the left or right).

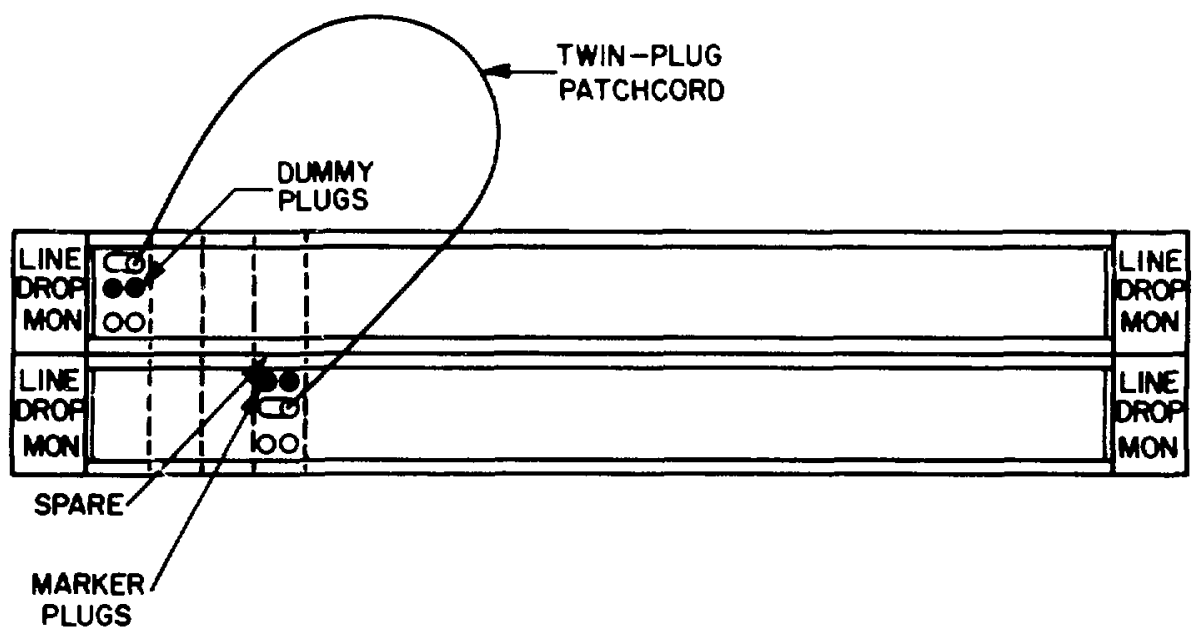

Fig. $9-3$.

Jackfiela configuration for patching a remote location to a spare port on the production computer. Both plugs must face in the same direction. 
PROCEDURE 2. PATCHING A REMOTE LOCATION TO A SECONDARY COMPUTER PORT

1. Secondary computer ports are connected to the DROP jacks of three bottom jackstrips on the jackfield rack. Disconnect the multiplexor from the remote location to be tested by inserting two dummy plugs into the DROP jacks for that location (see Fig. 9-4).

2. Insert a twin-plug patchcord into the LINE jacks for the remote location. Plug the other end of the patchcord into the DROP jacks for the secondary computer port to be used. The curved or notched sides of the plugs must face in the same direction.

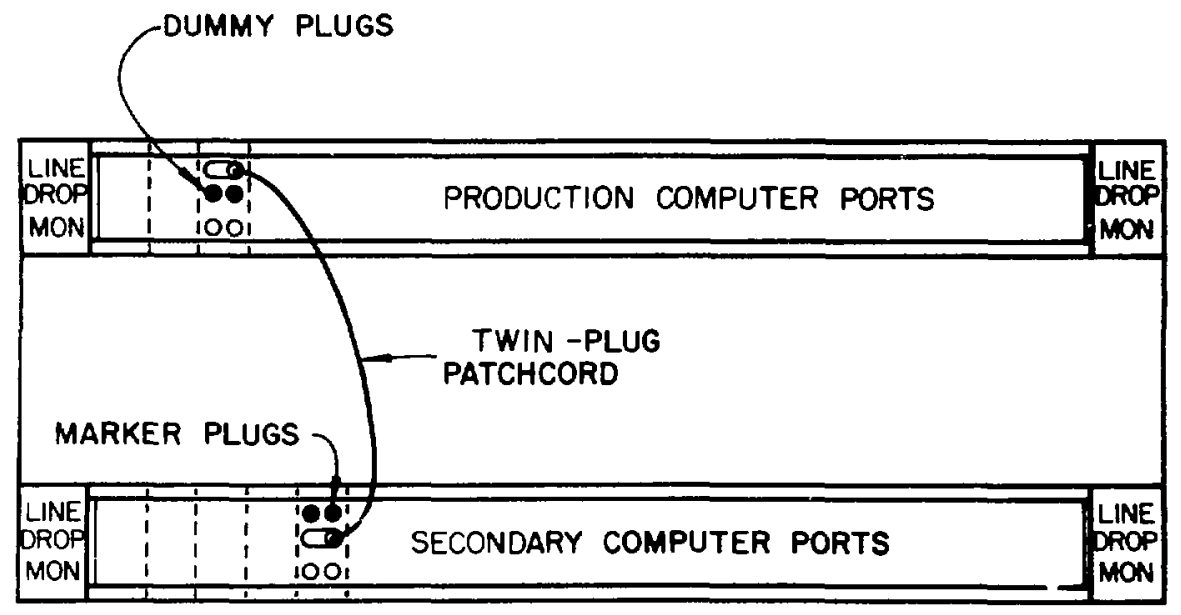




\section{PROCEDURE 3. CONTINUITY CHECK}

1. To check the continuity of a line, insert a Test I plug into the remote location outlet. The plug has two LEDs (light-emitting diodes) that indicate continuity and crossed wires (see Fig. F-17).

2. Insert two dummy plugs into the DROP jacks for the remote location on the jackfield.

3. Using a single-plug patchcord, patch from the right jack (the jack next to the meter) on Test Panel I to the left LINE jack for the remote location on the jackfield (see Fig. 9-5). If the line has continuity, the top LED on the Test I plug will light at the remote location. (See Procedure 4, polarity check, for proper LED color.) If the bottom LED on the plug lights, the receive and transmit pairs of wires are switched somewhere along the line. If the line is correctly wired, the LED on Test Panel I will also light and the current meter on the pane? will read approximately $9.5 \mathrm{~mA}$.

3. Repeat the entire procedure for the right LINE jack for the remote location. If the line is good, the bottom LED on the plug will light, the LED on the test panel will light, and the meter on the panel will read about $9.5 \mathrm{~mA}$.

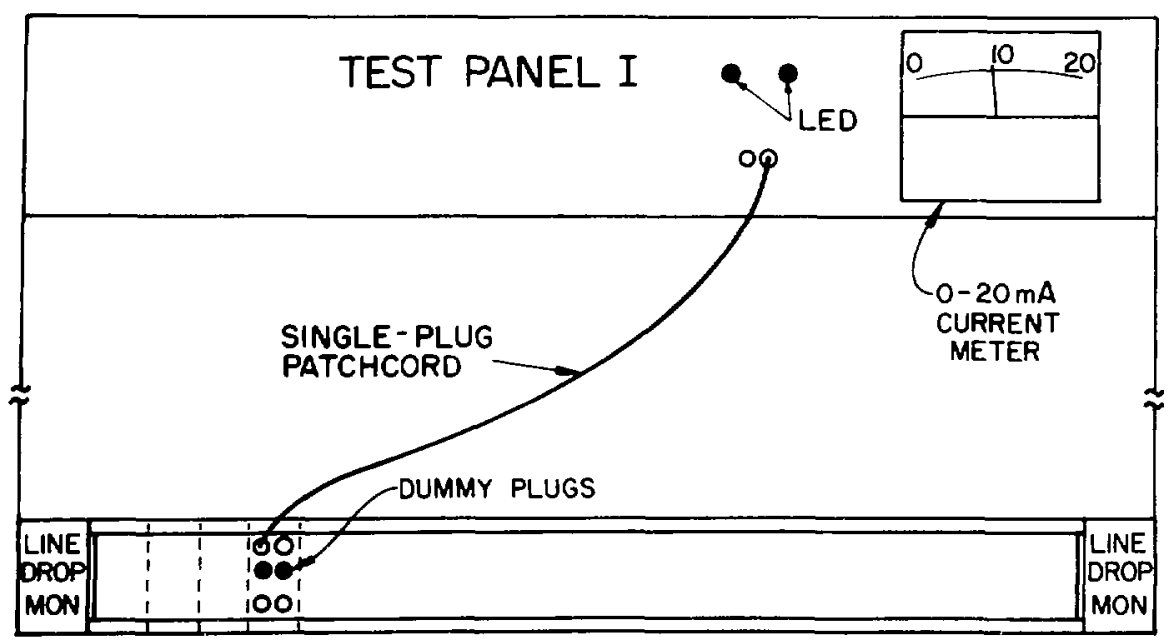

$$
\text { Fi } 9-6 \text {. }
$$

Continuity test jackfiezs configuration for witoing a remote Zocation to Test Panez I. 


\section{PROCEDURE 4. POLARITY CHECK}

The polarity of the line is correct if the LEDs on the test plug it the remote location in the continuity check (Procedure 3) light green. If an LED lights red, then the pair of wires associated with that LED is reversed somewhere between the jackfield and the remote location. 


\section{PROCEDURE 5. RESISTANCE MEASUREMENT}

1. Unplug the NDA instrument or terminal from the outlet box at the remote location. Measure the loop resistance of the line and the resistance to ground by following steps $2-8$.

2. Insert two dummy plugs into the DROP jacks for the remote location on the jackfield.

3. With a single-plug patchcord, patch from the INPUT jack on Test Panel I to the left LINE jack for the remote location on the jackfield (see Fig. 9-6). Patch from the jack labeled VOM on Test Panel I to the VOM and COM inputs on a volt-ohm meter.

4. Put the switch on the volt-ohm meter in the $\mathrm{R} \times 100 \mathrm{k}$ position. With nothing plugged into the outlet at the remote location and with the switch on Test Panel I in the DT-DR position, read the resistance measurement of the line. If the line has the proper resistance, the reading should be very high (infinite).

5. Now read the resistance with the Test Panel I switch in the DR-GND position and again with the switch in the DT-GND position. For proper resistance, these readings should be very high (infinite) and should show the meter charging the line capacitance for a few seconds.

6. Plug in the Short test plug (schematic shown in Fig. F-19) at the remote location. This test plug shorts the tip and ring of both the transmit (left) jack and the right (receive) jack.

7. With the switch on the volt-ohm meter in the $\mathrm{R} \times \mathrm{l}$ position, read the resistance measurement of the line. The reading should be very low (approximately 5-15 ohms). The correct resistance values for the line being tested appear in Appendix $\mathrm{J}$.

8. Repeat the entire procedure, using the right LINE jack for the remote location on the jackfield, patching it to the INPUT jack on Test Panel I. 


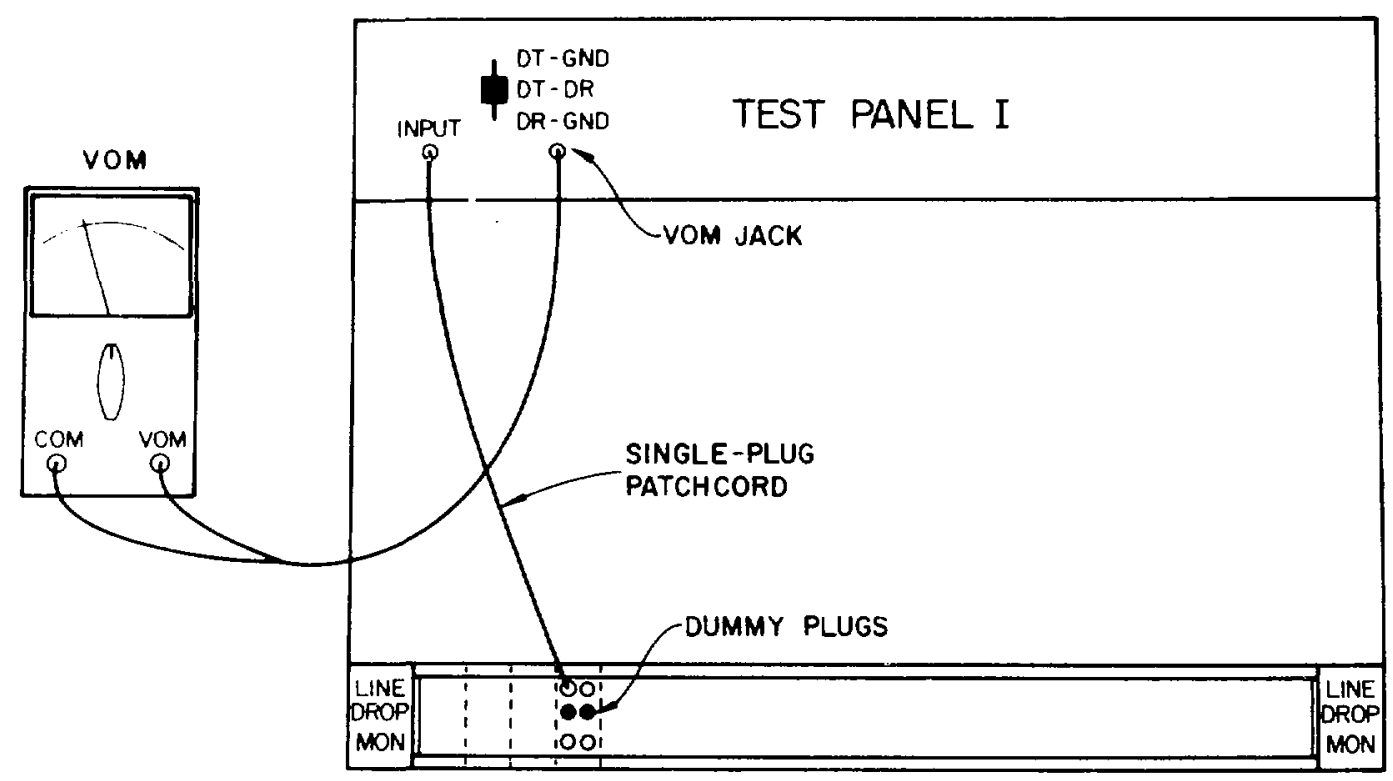

\section{$\because \therefore \therefore-9$}

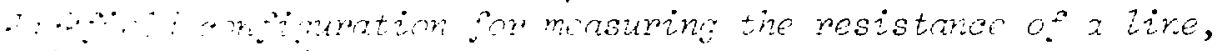
$\because \because \because \cdots \quad \cdots$ 


\section{PROCEDURE 6. CAPACITANCE MEASUREMENT}

1. Unplug the instrument or terminal from the outlet box at the remote location. Insert two dummy plugs into the DROP jacks for that location on the jackfield.

2. Using a single-plug patchcord, patch from the INPUT jack on Test Panel I to the left LINE jack for the remote location on the jackfield (see Fig. 9-7). Then patch from the VOM jack on Test Panel I to the inputs of the capacitance meter.

3. Read the capacitance of the line from the meter; if the capacitance is acceptable, the reading will be less than $50 \mathrm{nF}$. The correct capacitance values for the line being tested appear in Appendix J.

4. Repeat the entire procedure with the right LINE jask for the remote location patched to the INPUT jack on Test Panel I.

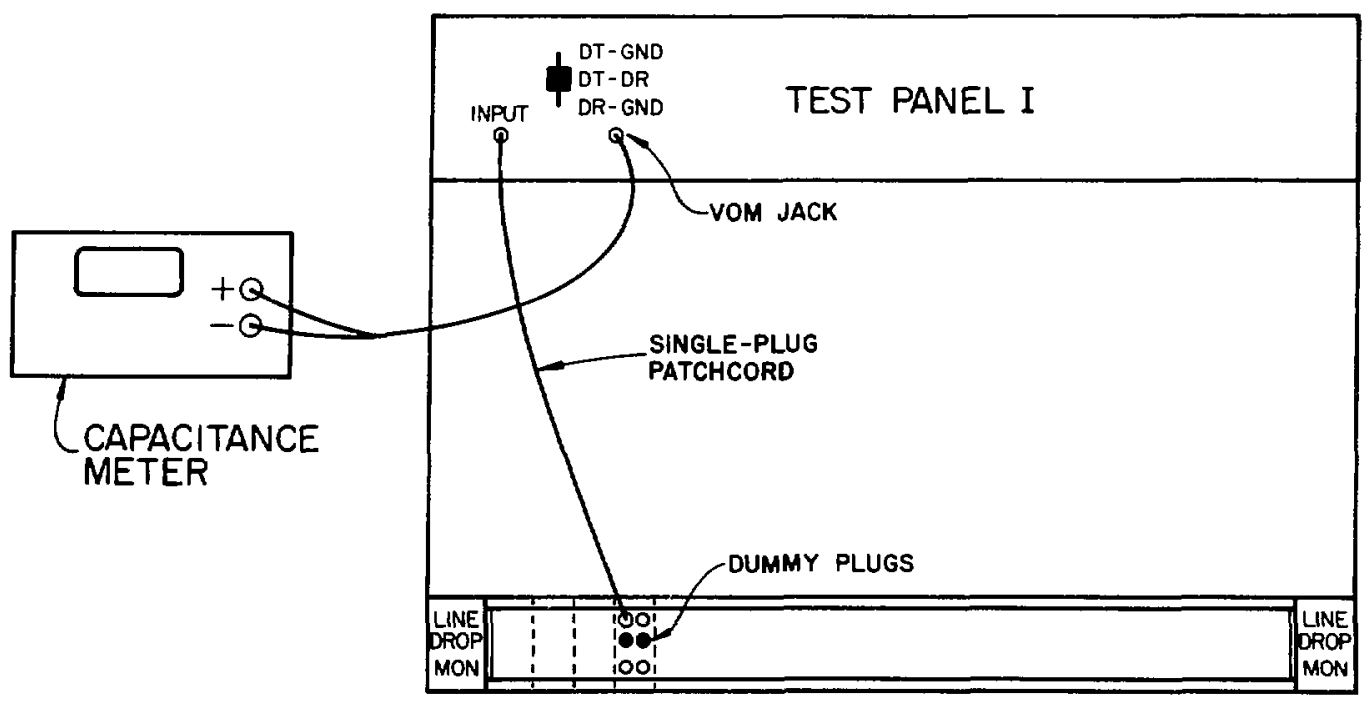

Fig. 9-7.

Jackfield configuration for measuring the capacitance of a line, using Test Panel I. 
1. Disconnect the multiplexor from the remote location to be tested by inserting two dummy plugs into the DROP jacks for that location on the jackfield (see Fig. 9-8).

2. Unplug the cable from the outlet box at the remote location and insert a Loop-Back plug (schematic shown in Fig. F-18).

3. Use a single-plug patchcord to connect the Fox Generator current output to the transmit (left) LINE jack for the location to be tested. Set the Fox Generator to the same speed at which the terminal is to be operated (usually 4800 bps). Put the switch on the Fox Generator in the REPEAT position for continuous data output; for one block of data, put the switch in the ONCE position.

4. Connect the Diagnostic Terminal to the jackfield with a type $F$ cable (Fig. F-6) that has a single plug on one end and a 25-pin Cannon connector on the other end. Insert the single plug into the receive (right) LINE jack for the location to be tested. Connect the other end of the cable to the SERIAL I/O connector at the rear of the Diagnostic Terminal.

5. The Fox Generator transmits data to the remote location; the data is then looped back to the Diagnostic Terminal. The Fox Generator message appears on the terminal screen where errors can be detected easily. If there are no errors, the comminications channels are good.

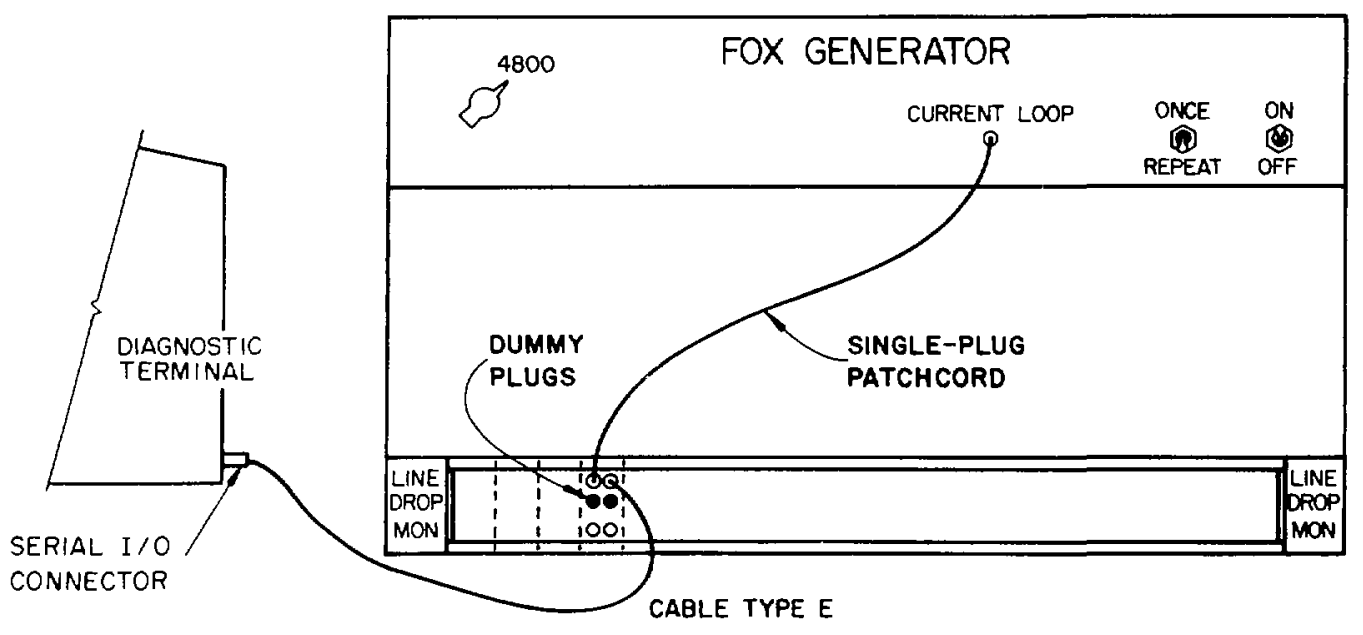

Fig. 9-8.

Jackfield configuration for performing a loop-back test, using the Fox renerator. 


\section{PROCEDURE 8. LOOP-BACK TEST, USING THE DIAGNOSTIC PANEL}

\section{Use this test only if the Fox Generator is not in service.}

1. Insert two dummy plugs into the DROP jacks for the location on the jackfield. Unplug the cable from the outlet box at the remote location and insert a Loop-Back plug (schematic shown in Fig. F-18).

2. Using a type $E$ cable (Fig. F-5), patch from the SERIAL I/O (input/output) connector at the rear of the Diagnostic Terminal to the jacks labeled TO DIAGNOSTIC TERMINAL on the right side of the Diagnostic Panel, with the curved or notched side of the twin plug facing to the left (see Fig. 9-9).

3. With a twin-plug patchcoro, patch from the jacks labeled DIAGNOSTIC TERMINAL TO JACKFIELD on the left side of the Diagnostic Panel to the LINE side for the location on the jackfield. The curved or notched side of the plugs should face to the left.

4. Put the switches on the Diagnostic Panel, from left to right, in the DIAG, REMOTE, and LOOP-BACK positions. Turn on the AC switch located on the panel.

5. Put the REMOTE-LOCAL switch on the Diagnostic Terminal in the REMOTE position. Data typed on the Diagnostic Terminal will now appear on the display screen.

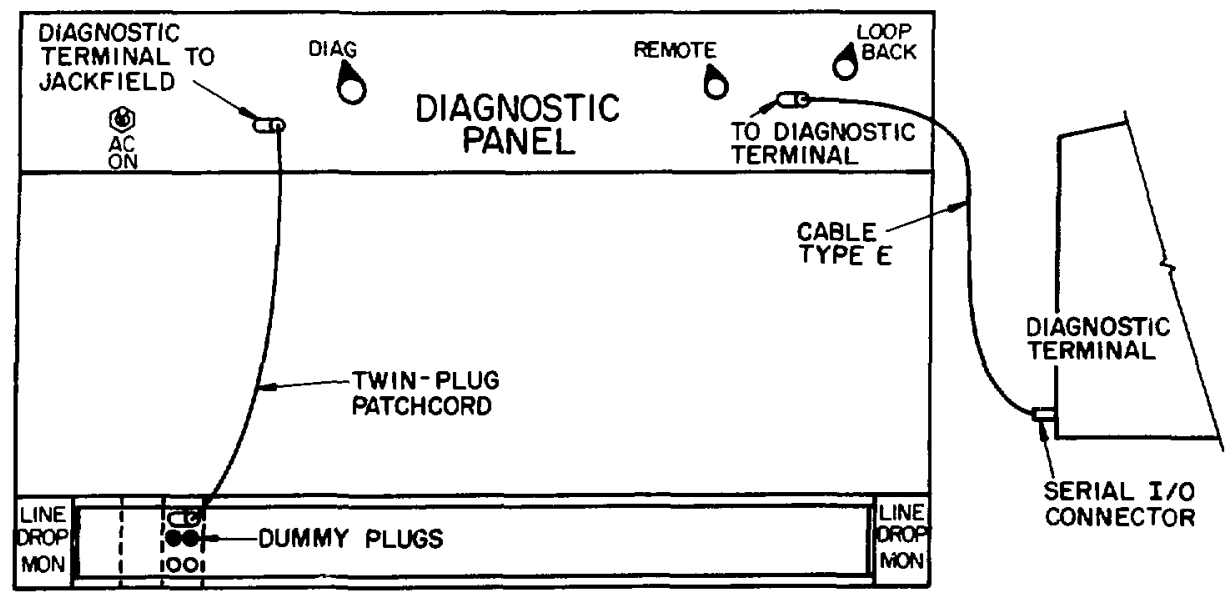

Fig. 9-9.

Jackfield configuration for performing a loop-back test, using the Diagnostic Panel. All three twin plugs must have curved or notched side facing to the left, as shown in Fig. 9-1. 
PROCEDURE 9, CONNECTING THE DIAGNOSTIC TERMINAL TO A MUX PORT AT THE JACKFIELD

1. Make sure that the Diagnostic Terminal switch settings are in position ancording to Fig. 2-5.

2. Using a type E cable (Fig. F-5), plug the end with the 25-pin Cannon connector into the SERIAL I/O connector at the rear of the Diagnostic Terminal.

3. Insert the twin plug of the cable into the DROP jacks for the port to be used. The curved or notched side of the plug is the computer transmit side and must face to the left. The straight side is the compilter receive side (see Fig. 9-10).

4. The Diagnostic Terminal is now connected to the computer port through the jackfield.

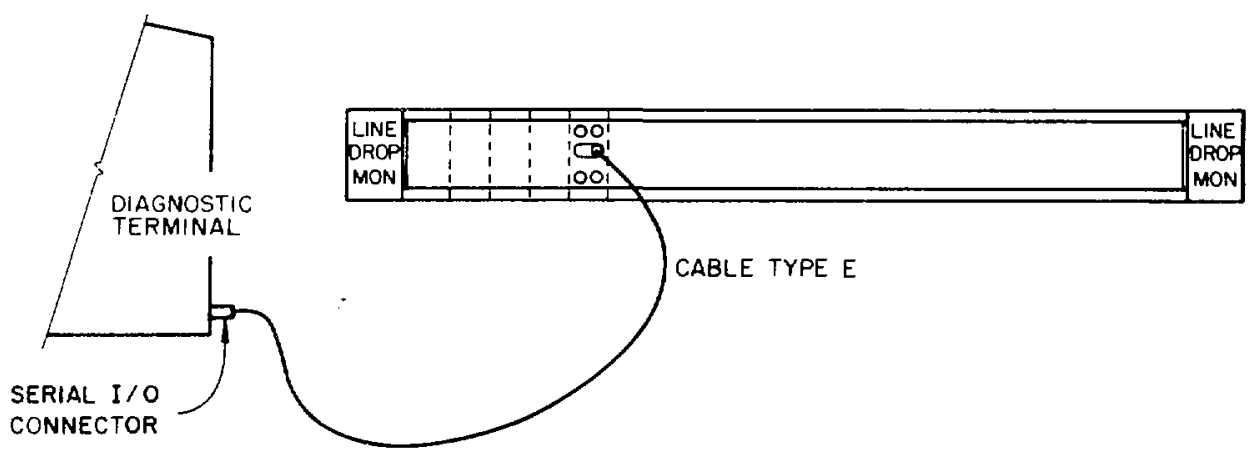

Fia. a-10.

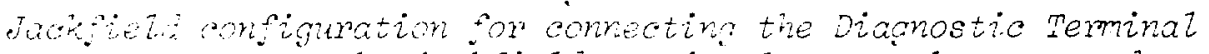

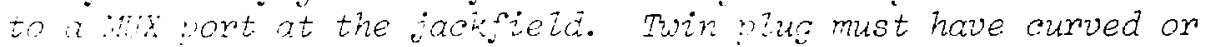
notcher aite facing to the left, as shown in ric. $9-1$. 


\section{PROCEDURE 10. CHECKING TRANSMISSION BETWEEN A REMCTE} TERMINAL AND THE DIAGNOSTIC TERMINAL

1. Disconrect the computer from the remote location by inserting two dummy plugs into the DROP jacks for the remote location on the jackfield (see Fig. 9-11).

2. With a type E cable (Fig. F-5), patch from the jacks labeled TO DIAGNOSTIC TERMINAL on the Diagnostic Panel to the SERIAL I/O connector at the rear of the Diagnostic Terminal, with the curved or notched side of the plug facing to the left.

3. Using a twin-plug patchcord, patch from the jacks labeled DIAGNOSTIC TERMINAL TO JACKFIELD on the Diagnostic Panel to the LINE side for the location on the jackfield, with the curved side of the plugs facing to the left.

4. Put the switches on the Diagnostic Panel, from left to right, in the DIAG, REMOTE, and NORM positions. Plug a Teleray terminal into the outlet box at the location and turn on the $A C$ switch on the panel.

5. Make sure that the Diagnostic Terminal is turned on. Type one line of characters and hit the RETURN key to transmit the message from the remote terminal to the Diagnostic Terminal; reverse the procedure. The terminals do not echo what they transmit; they oniy display received data.

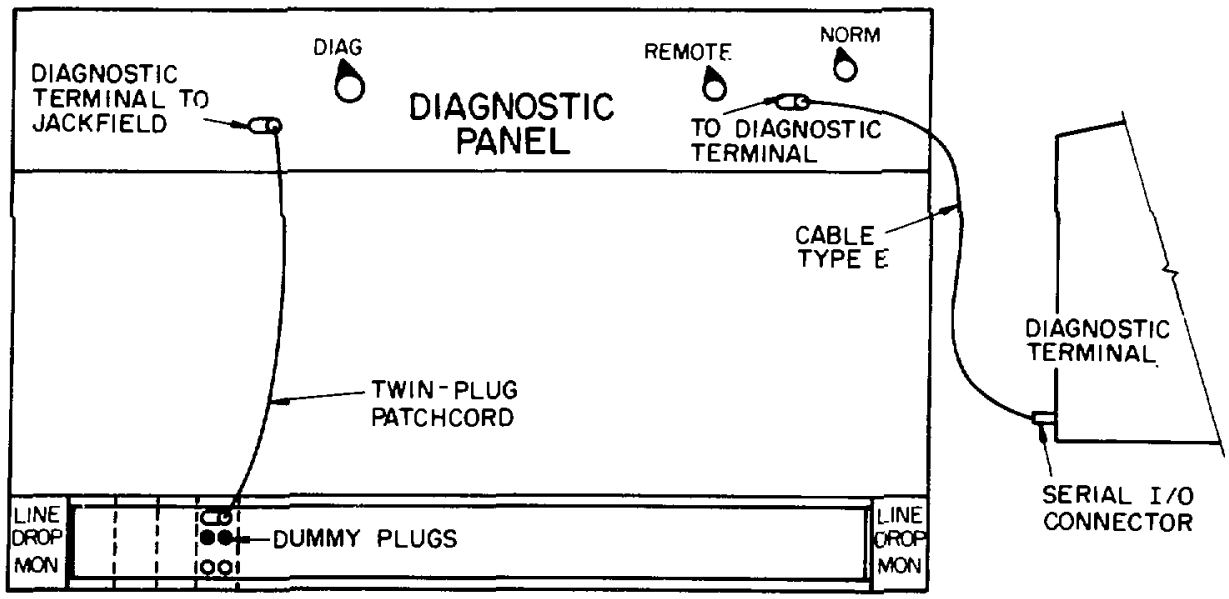

Fig. $9-11$.

Jackfield configuration for connecting a remote teminal to the Diagnostic Terminal. Ail three twin piugs must have notched or curved side facing to the left, as shown in Fia. $8-1$. 
PROCEDURE 11. MONITORING TRANSMISSIONS BETWEEN THE COMPUTER AND A REMOTE DEVICE, USING THE DIAGNOSTIC PANEL

1. Using a type $E$ cable (Fig. F-5), patch (with the curved or notched side of the twin plug facing to the left) from the jacks labeled TO DIAGNOSTIC TERMINAL on the Diagnostic Panel to the SERIAL I/O connector at the rear of the Diagnostic Terminal (see Fig. 9-12).

2. Using a twin-plug patchcord, patch from the jacks labeled DIAGNOSTIC TERMINAL TO JACKFIELD on the Diagnostic Panel to the left LINE and DROP jacks for the location on the jackfield. The curved or notched side of the piug should face to the left on the panel; on the jackfield, the curved or notched side of the piug should face down (this plug will be in a vertical position).

3. Put the switches on the Diagnostic Panel, from left to right, in the MONITOR, REMOTE, and NORM positions. You can now monitor transmissions from the computer to the remote device on the Diagnostic Terminal. The amount of current in this circuit can be read directly from the meter on the right side of the Diagnostic Panel. The current waveforms can be monitored on an oscilloscope using a current probe to connect the oscilloscope to one of the two wire loops on the Diagnostic Panel.

4. To monitor transmission from the remote device to the computer, move the patchcord on the jackfield from the left to the right DROP and LINE jacks with the curved or notched side of the plug facing down. The current can be read from the meter or monitored on an oscilloscope.

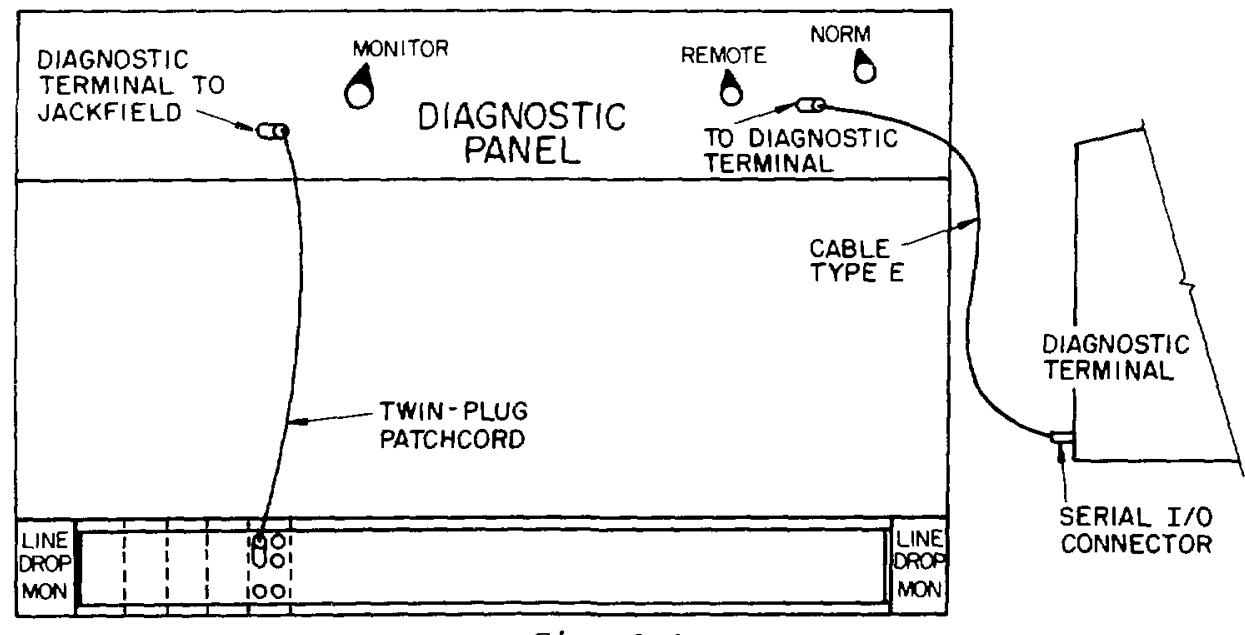

Pia. $.3-1 \cdots$

Jackieid configuration for monitoming tromemissions hetreen the comuter and a remote device, using the pincnostic panel. The twin pluas inserted into the Diamnstis panet mast have curved or notched side facing to the lest (Fia. 9-1). Fiarre $9-2$ shows moper vertical orientation of twin piar inserted into jarkstrin. 
If the device at the malfunctioning location is an NDA instrument and not a terminal, skip step 1 .

1. Put the LOCAL/REMOTE switch on the remote terminal in the LOCAL position and type a few characters. If the correct characters do not appear on the terminal screen, the terminal is malfunctioning. Call a terminal maintenance technician (Appendix $\mathrm{K}$ ). Otherwise, proceed to step 2.

2. With a volt-ohm meter, check the fuse at the front of the computer for the MUX port that is connected to the malfunctioning location (see Fig. 9-13). If the fuse is bad, replace it. If the fuse is good, go to step 3 .

3. If the Fox Generator is operable, perform a loop-back test with it. If not, perform a loop-back test using the Diagnostic Panel. If the loop-back test works properly, go to step 6 . Otherwise, proceed to step 4.

4. Perform a resistance measurement on the problem line. If the resistance measured is acceptable, go to step 5. If not, trace the wiring of the line from the jackfield to the outlet box using the WIRERUN Listing to determine what is wrong with the line.

5. Perform continuity and polarity checks on the line. If the results of these checks are correct, proceed to step 6 . Otherwise, trace the wiring of the line from the jackfield to the outlet box, using the WIRERUN Listing, to determine what is wrong with the line.

6. Check the MUX port by patching the Diagnostic Terminal to the port at the jackfield. If data cannot be sent from the computer to the terminal or vice versa, use a type D cable (Fig. F-4) to plug the Diagnostic Terminal directly into the MUX port at the rear of the computer. (See Fig. 4-5 for the MUX connections.) If you still cannot transmit data from the computer to the terminal or vice versa, the MUX port is malfunctioning; patch the remote location to a spare port. However, if the port is operating properly, make sure that the cable from the jackfield is correctly plugged into the pcrt at the rear of the computer and go to step 7 .

7. Replace the cable between the remote device and the outlet box. If data still cannot be transmitted from the computer or remote device, replace the device. 


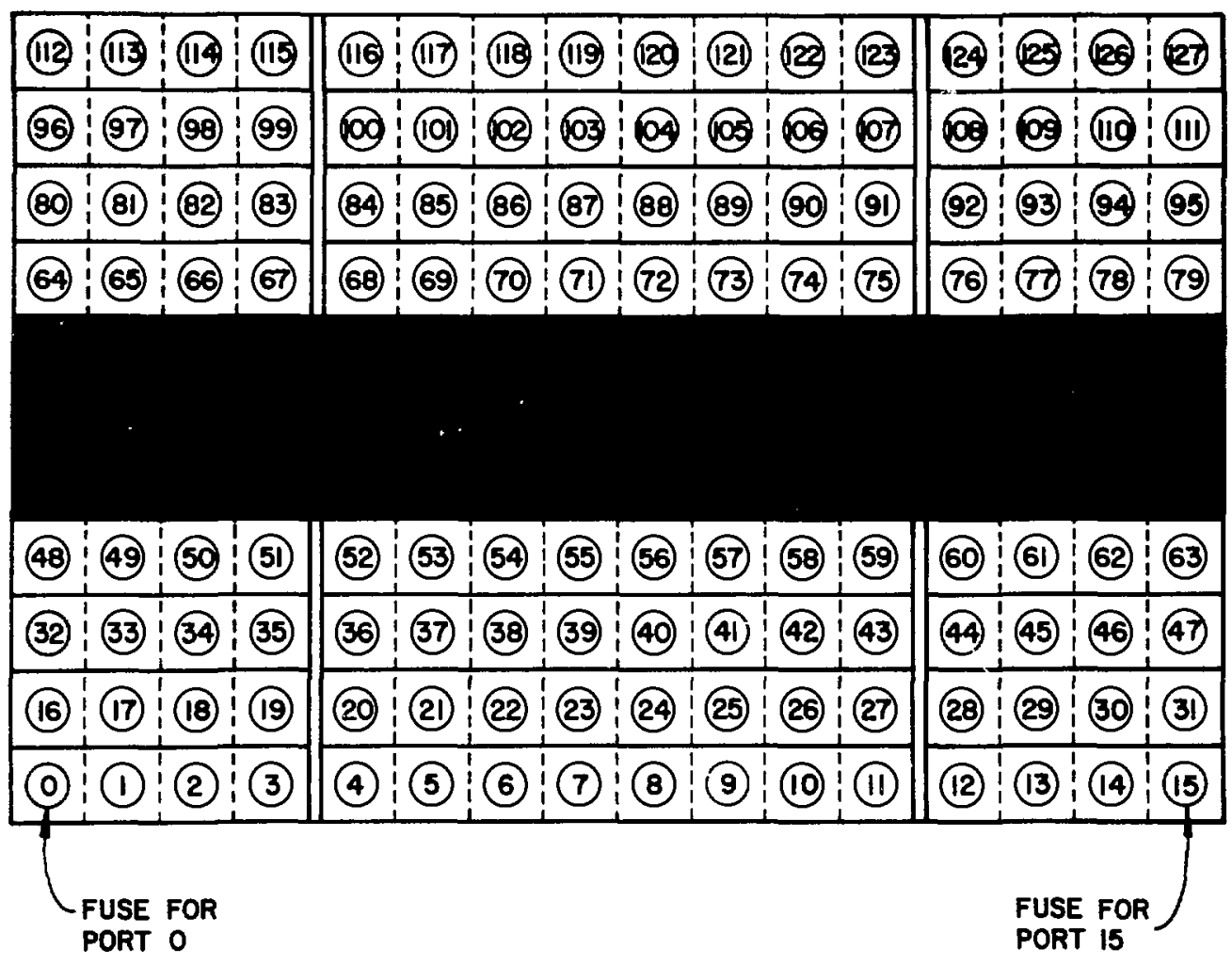

Fig. 9-13.

Auttiplexor port fuse tocation at front of production computer. 


\section{PROCEDURE 13, DATA RECEIVE}

Data can be received from a remote terminal and displayed on either of the system consoles in the DYMAC computer room by typing

$X F E R / A$ QTY:N \$TTOM R .

The symbol $R$ indicates the RETURN key, $N$ is the port number, and $M$ is the console designation, where $M=0$ for the foreground console and $M=1$ for the background console. Data typed on the remote terminal, followed by a RETURN, is echoed on the remote terminal and displayed on the system console. To terminate this procedure, press the CTRL and A keys simultaneously. 


\section{PROCEDURE 14, DATA TRANSMIT}

Data can be transmitted to a remote terminal from the computer by typing

XFER/A \$TTI QTY:N R

on the system console. $\mathrm{N}$ is the number of the port to which the remote terminal is connected. Data typed on the computer console, followed by a RETURN, is now displayed on the remote terminal. To terminate this procedure, press the CTRL and A keys simultaneously. 


\section{ACKNOWLEDGMENTS}

Several people assisted in creating the DYMAC Communications System and in preparing this manual. Breck Glascock designed the basic framework for the system, developed some of the diagnostic procedures, and designed the Test Panel I and the Diagnostic Panel. He also wrote the initial documentation for the communications system. Jim Case created the computerized WIRERUN Listing. Jerry Lopez developed some of the diagnostic procedures and designed the Fox Generator. Dave Woodwell, Greg Wentz, and Joe Rodriguez provided maintenance support. Tina Sibbitt assisted in rewriting text, clarifying procedures, preparing tables, and in an initial reorganization of the manual. Dorothy Amsden gave the manual its final structure, prepared the introductory material and first two sections, simplified illustrations and tables, and reorganized the appendixes. 


\section{APPENDIX A PARTS LIST}

The DYMAC Communications System consists primarily of commercial equipment. The rest of the equipment was designed and fabricated at LASL.

\section{LASL-FABRICATED EQUIPMENT}

LASL-fabricated equipment is explained in the text. Complete cimcuit diagrams are given in Appendix $\mathrm{F}$.

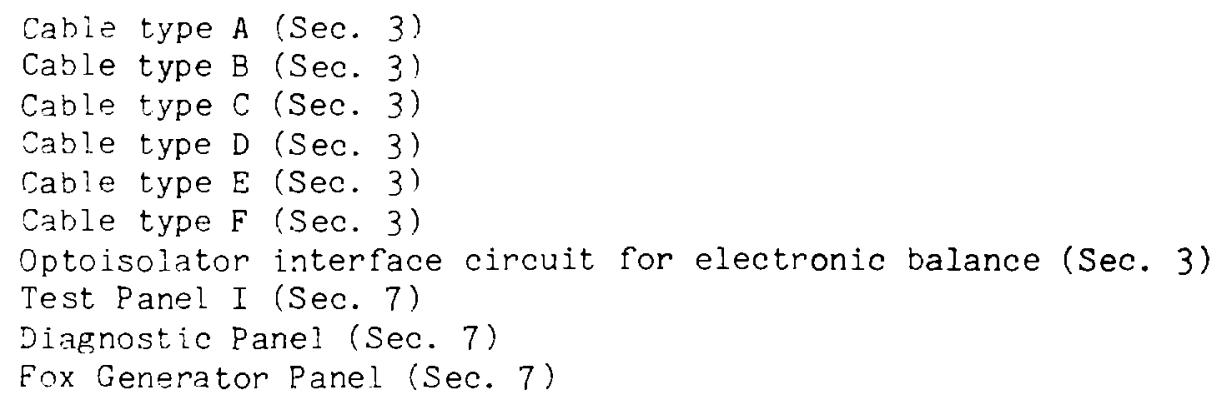

\section{COMMERCIALLY PURCHASED EQUIPMENT}

The equipment purchased for the communications system is described below. Appendix B lists the equipment alphabetically, with the affiliated purchase order number, date ordered, and vendor. Appendix C lists vendor addresses and phone numbers.

\section{Eclipse Multiplexor Connectors and Accessories}

The 6-pin AMP block connectors (and their sockets) used for connections to the multiplexor were ordered under P.0. KJ7-98176-1 
and P.0. KJ7-6604C-1. The socket crimping tool is AMP 90202-2. Spare connectors, sockets, and the crimping tool are available from LASL Group Q-3.

\section{Jackfield Label Strips}

Label strips designate each group o: jacks on one jackstrip. The label above the jacks gives the number of the room associated with those jacks and the number of the outlet in the room. The label below the jacks gives the number of the MUX port that is connected to the outlet. See P.0. KJ7-98220-1. Spare label strips are available from LASL Group Q-3.

\section{Jackfield Marker Plugs and Dummy Plugs}

See P.0. KJ8-8014D-T and P.0. 1-KS9-5520M-1. Spare marker and dummy plugs are available in the DYMAC computer room.

\section{Jackstrips}

Jackstrips were ordered in P.0. KJ9-3314K-1. Spare jackstrips are available from LASL Group Q-3.

\section{Junction Boxes (enclosures)}

The junction boxes used in the basement and in the computer room are standard NEMA (National Electrical Manufacturers Association) type-12 enclosures. See P.0. LJ7-88516-1. No spare enclosures are available.

\section{Outlet Boxes and Mating Plugs}

Outlet boxes and mating plugs are standard equipment used by telephone companies and are available from many electronic supply stores. The boxes are Herald PH33A; the plugs are Herald PL9A. See P.0. KE7-6635C-T. Spare boxes and plugs are available from LASL Group Q-3.

\section{Patchcords}

Single- and twin-plug patchcords are used for connections at the jackfield. See P.O. LE7-88519-T. Standard twin-plug patchcords are modified by LASL so that the sleeve of the transmit plug is not connected to the sleeve of the receive plug. This is done to prevent 
shorting the Eclipse $-12 \mathrm{~V}$ supply to ground. Spare patcheords are available in the DYMAC computer room.

Special twin-plug patcheords are also used at the jackfield. These patchcords have six separate conductors: two for the tip connections, two for the ring connections, and two for the sleeve connections (the transmit and receive sleeves are not connected). See P.0. KJ9-3288K-1.

\section{Preterminated AMP Connector Cables}

Several different cables with 50-pin AMP connectors are used to interconnect the computer room junction boxes, the jackfield, and the computer. Some of the cables have AMP connectors on both ends (plug-to-plug); the others have a connector on only one end (receptacle-to-stub). See P.0. K07-89521-1. Spare cables are available from LASL Group Q-3.

\section{Terminal Tables}

Stands that support data-entry terminals are $0.8128-m$ wide, 0.4572-m deep, and 0.6731-m high. See P.0. KZ9-0630H-1. Spare tables are available from LASL Group Q-3.

\section{Terminal, Teleray 3741 CRT}

Altogether 41 Teleray terminals were ordered for the DYMAC system. See P.0. Z99-0619H-1. LASL made several modifications to the terminals:

a. CAPS LOCK key permanently locked on keyboard.

b. Modification to $20-\mathrm{mA}$ current loop circuits by insertion of a $62 \mathrm{k}-\mathrm{ohm}$ resistor between ground and base of the terminal's receive op to isolator.

c. Modification to 20-mA current loop circuits by insertion of a $22 \mathrm{k}$-ohm resistor between base and emitter of the terminal's transmit optoisolator.

Terminal, TI 733 Hard-Copy

Eight TI 733 Jow-speed hard-copy printers were ordered for the DYMAC System. See P.O. Z88-5320E. 
DYMAC COMMUNICATIONS SYSTEM

Terminal, TI 810 Label Printer

Five high-speed label printers were ordered for the DYMAC System. See P.0. 288-0618H-1.

Termination Blocks, Terminal Strips, and Accessories

The two large termination blocks in each computer room junction box are standard telephone-type blocks (see P.0. LJ7-88520). The terminal strips, their terminals, connectors, and an insertion tool were ordered from AMP; they are no longer available. Similar units are available from many companies, but they are designed for use with solid wire, whereas the AMP units were designed for use with stranded wire (see P.0. LJ7-88521). No spare termination blocks are available at LASL. Spare terminal strips, terminals, and connectors are available from LASL Group Q-3. An insertion tool for inserting the wire into the terminal strips is located in the DYMAC computer room.

\section{Trunk and Communications Outlet Box Cables}

Each trunk cable is composed of 24 pairs of wires that have individual shields. These cables were ordered by LASL Group ENG-4 under P.0. KE7-83759. No spare trunk cable is available at LASL.

A signal cable (communications cable) is composed of two twisted wire pairs; each pair has its own drain wire. See P.O.

KE9-9565L-1. Spare signal cable is available from LASL Group Q-3. 


\section{APPENDIX B EQUIPMENT PURCHASES}

This appendix lists all purchases made for the DYMAC Communications System, along with date of purchase and vendor. Copies of the purchase orders are on file in the LASL Supply and Property Department.

\begin{tabular}{|c|c|c|c|}
\hline I tem & $\begin{array}{l}\text { Purchase } \\
\text { Order } \\
\text { Number }\end{array}$ & Date & Vendor \\
\hline $\begin{array}{l}\text { Block, connecting, } \\
56 \mathrm{~B} 4-25 \mathrm{~A}\end{array}$ & LJ7-88520-1 & $2 / 14 / 77$ & GTE Automatic Electric \\
\hline $\begin{array}{l}\text { Blook, modular, } \\
229956-1\end{array}$ & LJ7-88521-1 & $2 / 14 / 77$ & AMP, Inc. \\
\hline Cable, P25P-25-DE & KO7-89521-1 & $5 / 26 / 77$ & ADC Telecommunications \\
\hline Cable, P25S-25-SE & KO7-8952i-1 & $5 / 26 / 77$ & ADC Telecomunications \\
\hline Cable, P25S-50-SE & K07-8952:-1 & $5 / 26 / 77$ & ADC Telecommunications \\
\hline Cable, R25S-50-SE & K07-89521-1 & $5 / 26 / 77$ & ADC Telecommunications \\
\hline $\begin{array}{l}\text { Cable, signal, } \\
\text { 4-conductar }\end{array}$ & KE9-9565L- 1 & $5 / 25 / 79$ & Cities Service Co. \\
\hline Connectors, 1-86402-4 & $\mathrm{KJ} 7-6604 \mathrm{C}-1$ & $9 / 7 / 77$ & AMP, Inc. \\
\hline Connectors, 552118-1 & LJ7-88521- & $2 / 14 / 77$ & AMP, Inc. \\
\hline Contacts, $87045-2$ & KJ7-98176-9 & $6 / 7 / 77$ & AMP, Inc. \\
\hline
\end{tabular}




\begin{tabular}{|c|c|c|c|}
\hline Item & Number & Date & Vendor \\
\hline Contacts, 87045-2 & $\mathrm{KJ} 7-6604 \mathrm{C}-1$ & $9 / 7 / 77$ & AMP, Inc. \\
\hline $\begin{array}{l}\text { Enclosures, } \\
36 \times 30 \times 8 \text { (inches) }\end{array}$ & LJ7 $-88516-1$ & $2 / 14 / 77$ & $\begin{array}{l}\text { State Electric } \\
\text { Supply Co. }\end{array}$ \\
\hline $\begin{array}{l}\text { Enclosures, } \\
48 \times 24 \times 8 \text { (inches) }\end{array}$ & LJ7-885 16-1 & $2 / 14 / 77$ & $\begin{array}{l}\text { State Electric } \\
\text { Supply Co. }\end{array}$ \\
\hline $\begin{array}{l}\text { Jack and wall plate } \\
\text { (outlet box) }\end{array}$ & KE7 $-6635 \mathrm{C}-\mathrm{T}$ & $10 / 18 / 77$ & Electronic Parts Co. \\
\hline $\begin{array}{l}\text { Jackstrips, } \\
\text { connectorized }\end{array}$ & KJ9-3314K-1 & $3 / 6 / 79$ & Anixter-Pruzan \\
\hline $\begin{array}{l}\text { Latch kits (for } \\
\text { enclosures) }\end{array}$ & LJ7-88516-1 & $2 / 14 / 77$ & $\begin{array}{l}\text { State Electric } \\
\text { Supply Co. }\end{array}$ \\
\hline $\begin{array}{l}\text { Panels (for enclo- } \\
\text { sures, } 36 \times 30 \times 8 \\
\text { inches) }\end{array}$ & LJ7-88516-1 & $2 / 14 / 77$ & $\begin{array}{l}\text { State Electric } \\
\text { Supply Co. }\end{array}$ \\
\hline $\begin{array}{l}\text { Panels (for enclo- } \\
\text { sures, } 48 \times 24 \times 8 \\
\text { inches) }\end{array}$ & LJ7-885 $16-1$ & $2 / 14 / 77$ & $\begin{array}{l}\text { State Electric } \\
\text { Supply Co. }\end{array}$ \\
\hline Patchcords, 5-conductor & LE7-88519-T & $2 / 14 / 77$ & Electronic Parts Co. \\
\hline $\begin{array}{l}\text { Patcheords, EX-7812, } \\
6 \text {-conductor }\end{array}$ & $\mathrm{KJ} 9-3288 \mathrm{~K}-1$ & $2 / 8 / 79$ & Walker Radio \\
\hline $\begin{array}{l}\text { PC Boards, 552167-1, } \\
\text { (terminal strip) }\end{array}$ & LJ7-88521-1 & $2 / 94 / 77$ & AMP, Inc. \\
\hline Plugs, dumny, TT-515-1 & KJ8-8014D-T & $12 / 27 / 77$ & Switcheraft, Inc. \\
\hline Plugs, dummy, TT-515-2 & $1-K S 9-5520 M-1$ & $7 / 3 / 79$ & Switcheraft, Inc. \\
\hline Plugs, dumby, TT-515-3 & KJ8-8014D-T & $12 / 27 / 77$ & Sw1tcheraft, Inc. \\
\hline Plugs, 4-prong & KE7-66 35C-T & $10 / 18 / 77$ & Switcheraft, Inc. \\
\hline Plugs, signal, TT-513-1 & KJ8-8014D-T & $12 / 27 / 77$ & Switcheraft, Inc. \\
\hline Plugs, signal, TT-513-1 & 1-RS9-5520M-1 & $7 / 3 / 79$ & Switcheraft, Inc. \\
\hline
\end{tabular}




\begin{tabular}{|c|c|c|c|}
\hline Item & $\begin{array}{l}\text { Purchase } \\
\text { Order } \\
\text { Number }\end{array}$ & Date & Vendor \\
\hline Plugs, signal, TT-513-3 & $\mathrm{KJ} 8-8014 \mathrm{D}-\mathrm{T}$ & $12 / 27 / 77$ & Switcheraft, Inc. \\
\hline Plugs, signal, TT-513-5 & $\mathrm{KJ} 8-8014 \mathrm{D}-\mathrm{T}$ & $12 / 27 / 77$ & Switcheraft, Ine. \\
\hline Plugs, signal, TT-513-5 & $1-\mathrm{KS} 9-5520 \mathrm{M}-1$ & $7 / 3 / 79$ & Switcheraft, Inc. \\
\hline Plugs, signal, TT-513-8 & $K J 8-8014 D-T$ & $12 / 27 / 77$ & Switcheraft, Inc. \\
\hline Plugs, signal, TT-513-B & $1-K S 9-5520 M-1$ & $7 / 3 / 79$ & Switcheraft, Inc. \\
\hline Printer, TI 810 & $288-0618 \mathrm{H}-1$ & $10 / 3 / 78$ & Texas Instruments \\
\hline Stand, machine & $\mathrm{KZ9}-0630 \mathrm{H}-1$ & $10 / 24 / 78$ & $\begin{array}{l}\text { PBSW Office Products, } \\
\text { Inc. }\end{array}$ \\
\hline Strip kits, designation & $\mathrm{K} J 7-98220-1$ & $8 / 11 / 77$ & ADC Products, Inc. \\
\hline Terminal, Teleray 3741 & $299-0619 \mathrm{H}-1$ & $10 / 6 / 7 B$ & Research, Inc. \\
\hline Terminal, TI 733 & $Z 88-5320 E$ & $12 / 28 / 77$ & $\begin{array}{l}\text { Texas Instruments, } \\
\text { Inc. }\end{array}$ \\
\hline $\begin{array}{l}\text { Terminals (for termi- } \\
\text { nal strips), } 552168-2\end{array}$ & LJ7-88521-1 & $2 / 14 / 77$ & AMP, Inc. \\
\hline Tool, insertion 229373-4 & LJ7-88521-1 & $2 / 14 / 77$ & AMP, Inc. \\
\hline Tool, 90202-2 & KJ7-98176-1 & $6 / 7 / 77$ & AMP, Inc. \\
\hline
\end{tabular}




\section{APPENDIX C VENDOR INDEX}

Vendor

ADC Products, Inc.

ADC Telecommunications

AMP, Ine.

Anixter - Pruzan

C.ities Service co.

Electronic Parts Co.

Data General Corp.

GTE Automatic Electric

PBSW Office Products, Inc.

\begin{tabular}{|c|c|}
\hline Address & Telephone \\
\hline $\begin{array}{l}\text { c/O AQ Electronics } \\
\text { P.O. Box } 6505 \\
\text { Albuquerque, NM } 87107\end{array}$ & $505 / 883-1003$ \\
\hline $\begin{array}{l}4900 \text { West } 78 \text { th St. } \\
\text { Minneapolis, MN } 55435\end{array}$ & $612 / 835-6800$ \\
\hline $\begin{array}{l}\text { P.o. Box } 45168 \\
\text { Dalias, TX } 75245\end{array}$ & $214 / 357-9151$ \\
\hline $\begin{array}{l}9449 \text { Aerospace Dr. } \\
\text { St. Louis, MO } 63134\end{array}$ & $800 / 325-8058$ \\
\hline $\begin{array}{l}\text { Chester Cable Operations } \\
\text { Ostiland Ave. } \\
\text { Chester, NY } 10918\end{array}$ & $914 / 469-2141$ \\
\hline $\begin{array}{l}2620 \text { Rhode Island NE } \\
\text { Albuquerque, NM } 87110\end{array}$ & $505 / 293-6161$ \\
\hline $\begin{array}{l}2601 \text { Wyoming, NE } \\
\text { Albuquerque, NM } 87112\end{array}$ & $505 / 292-2234$ \\
\hline $\begin{array}{l}400 \text { North Wolff } \\
\text { North Lake, IL } 60164\end{array}$ & $312 / 562-7100$ \\
\hline $\begin{array}{l}\text { Division of Boise Cascade } \\
\text { P.O. Box } 25663 \\
\text { Albuquerque, NM } 87125\end{array}$ & $505 / 765-1550$ \\
\hline
\end{tabular}




Vendor
Research, Inc.
State Electric Supply Co.
Switchcraft, Inc.
Teleray Terminals
Research, Inc.
Texas Instruments, Inc.
(data-entry terminals)
Texas Instruments, Inc.
(service manuals)
Walker Radio

\begin{tabular}{|c|c|}
\hline Address & Telephone \\
\hline $\begin{array}{l}\text { c/o J.F. Hurlbut Co. } \\
622 \text { Gardenla Court } \\
\text { Golden, Co } 80401\end{array}$ & $612 / 941-3300$ \\
\hline $\begin{array}{l}3371 \text { Cerrillos Road } \\
\text { Santa Fe, NM } 87509\end{array}$ & $505 / 471-0660$ \\
\hline $\begin{array}{l}5555 \text { N. Elston Ave. } \\
\text { Chicago, IL } 60630\end{array}$ & $312 / 792-2700$ \\
\hline $\begin{array}{l}\text { Box } 24064 \\
\text { Minneapol1s, MN } 55424\end{array}$ & $612 / 941-3300$ \\
\hline $\begin{array}{l}725 \text { East Hampden } \\
\text { Suite } 301 \\
\text { Denver, Co } 80231\end{array}$ & $303 / 751-1780$ \\
\hline $\begin{array}{l}\text { Digital Systems Division } \\
\text { P. 0. Box } 1441 \\
\text { Houston, TX } 17001\end{array}$ & $713 / 491-5115$ \\
\hline $\begin{array}{l}102 \text { Granite Ave. Ni' } \\
\text { Albuquerque, NM } 87162\end{array}$ & $505 / 247-2288$ \\
\hline
\end{tabular}




\section{APPENDIX D OUTLET BOX LOCATIONS}

The plutonium facility wing layouts in Figs. D- 1 through D-4 are useful for finding the outlet boxes. Not all outlet boxes shown are in use, however, each one has been designated for a particular device, as shown in the layouts, with the exception of spare outlet boxes.

On the layouts, outlet box locations for eanh device are indicated by circles, Two or more instrumen's lateled in one circle indicate that the outlet boxes are mounted together and the wires come through the same conduit.

Any device can be plugged into an outlet box. However, the computer software (specifically the LINEDEF table) must reflect the transmission rate of the device. The computer operator can change the transmission rate for a device in the L.INEDEF iable when the production computer is not in operation. 


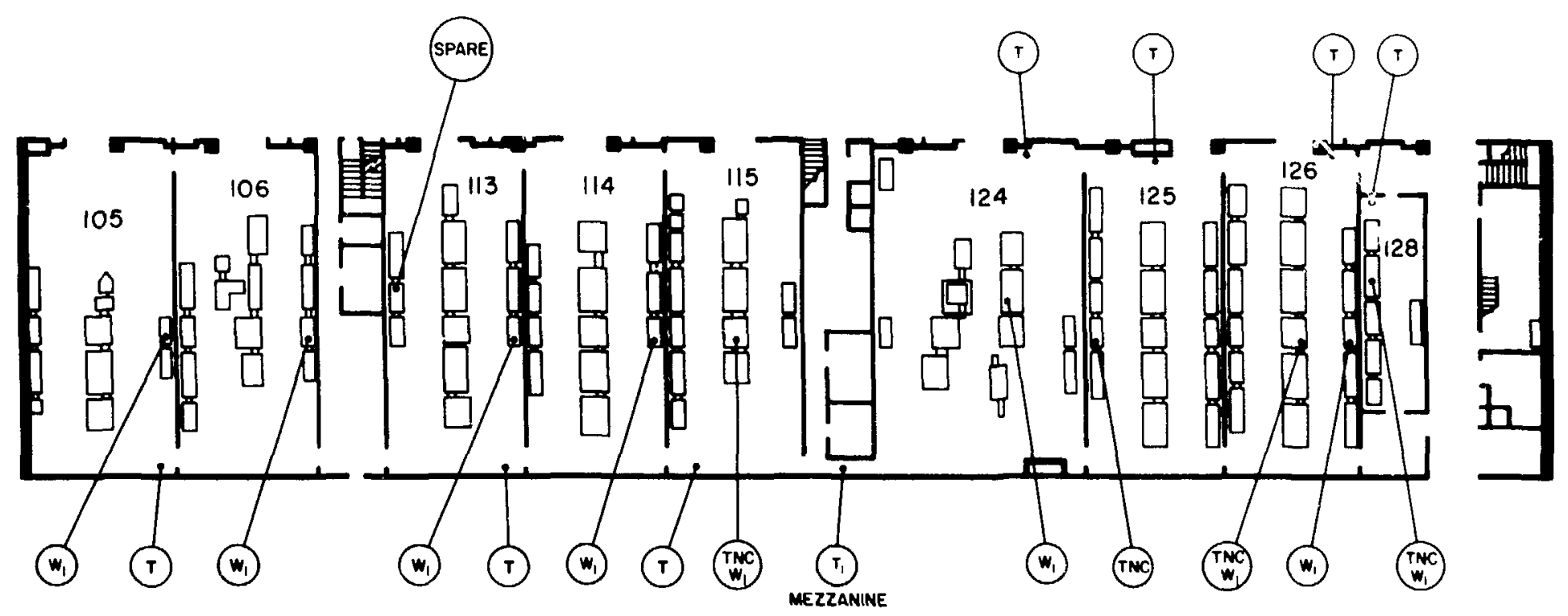



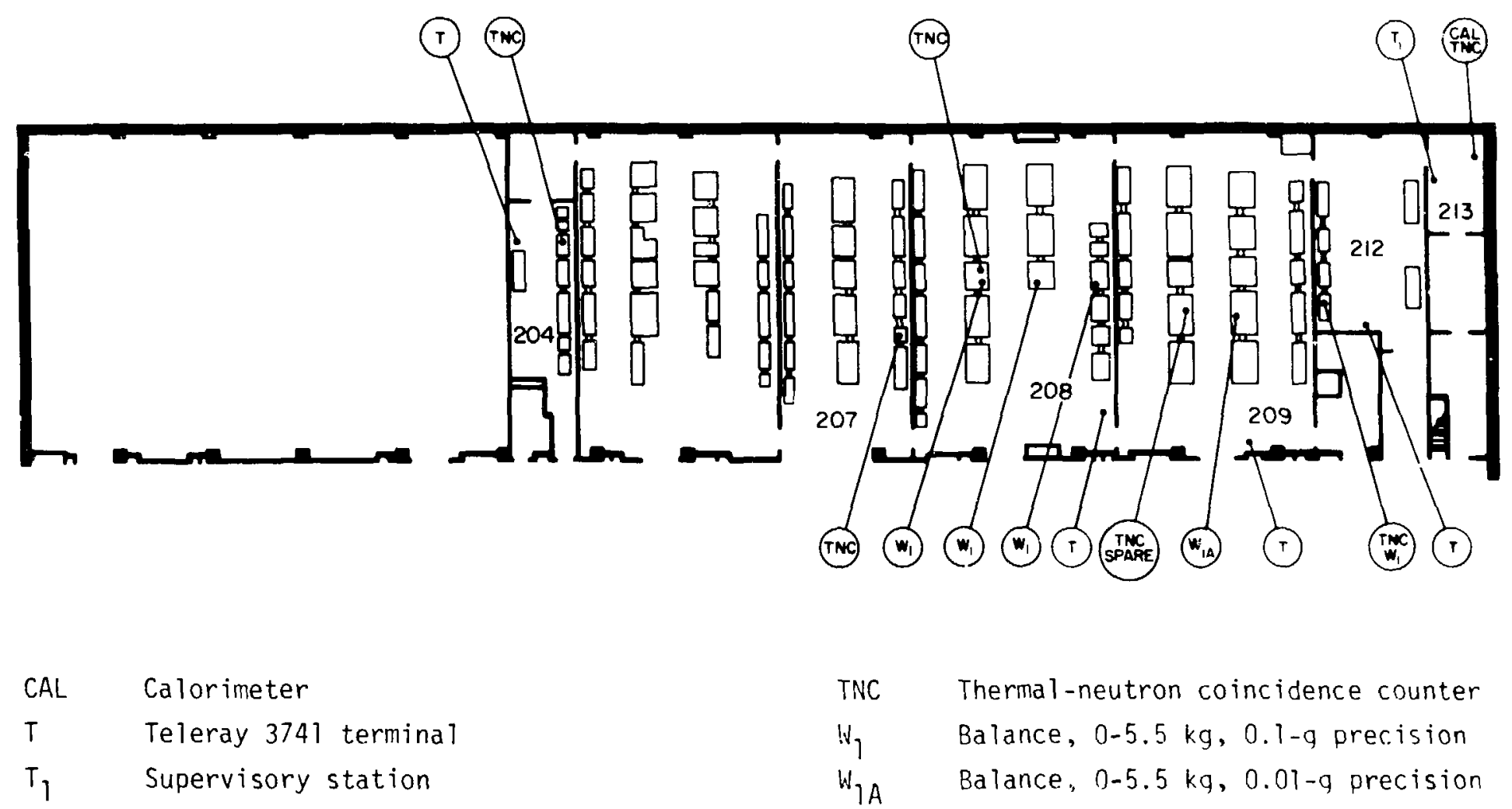


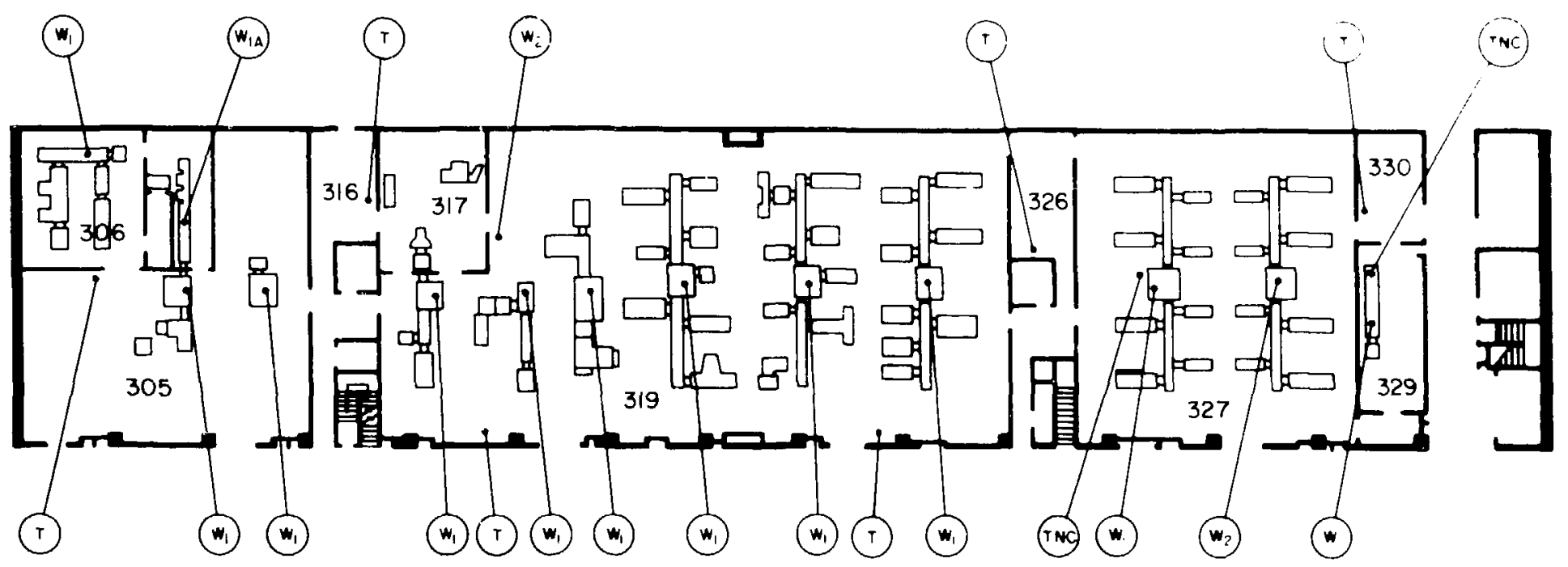

$\begin{array}{ll}T & \text { Teleray } 3741 \text { terminal } \\ T_{1} & \text { Supervisory station } \\ \text { TNC } & \text { Thermal-neutron coinc }\end{array}$

TNC Thermal-neutron coincidence counter

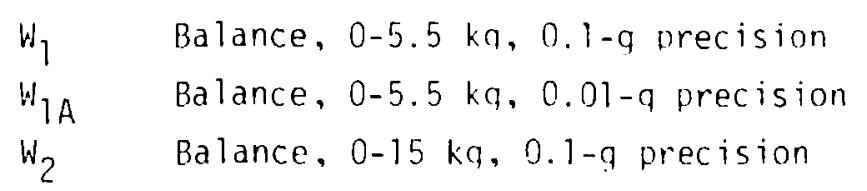

W Balance, $0-5.5 \mathrm{~kg}, 0.1-\mathrm{q}$ precision

$W_{2}$ Balance, $0-15 \mathrm{kq}, 0.1-\mathrm{q}$ precision 


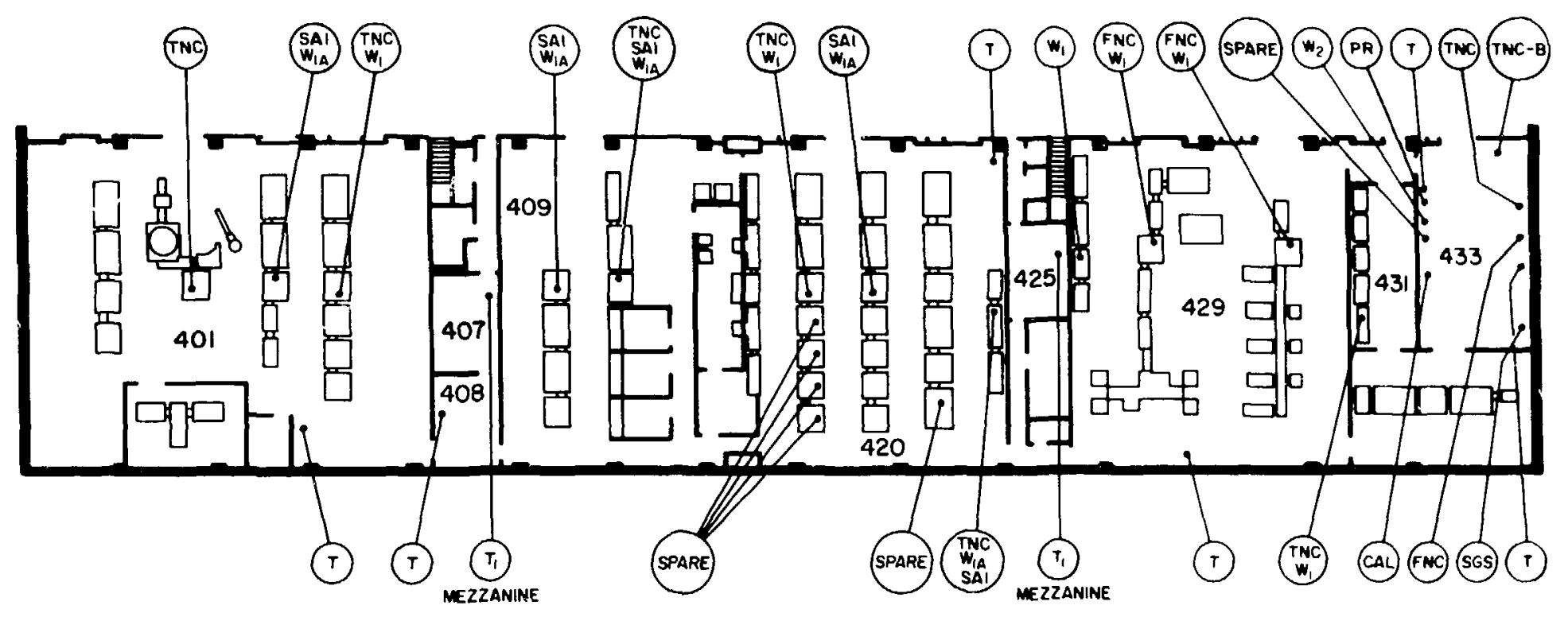

FNC Fast-neutron coincidence counter

TNC Thermal-neutron coincidence counter

PR TI 810 label printer

SAI Solution assay instrument

SGS Segmented gamma scanner

$T \quad$ Teleray 3741 terminal

TNC-B TNC for barrels

W Balance, $0-5.5 \mathrm{~kg}, 0.1-\mathrm{q}$ precision

$W_{1 A}$ Balance, $0-5.5 \mathrm{ka}, 0.01-g$ precision

$W_{2} \quad$ Balance, $0-15 \mathrm{~kg}, 0.7-$ a precision 


\section{APPENDIX E \\ TO OBTAIN DRAWINGS AND WIRERUN LISTING}

Four drawings pertair. to the DYMAC Communications System. They are kept by the LASL Ensineering Department, Group ENG-3, which will provide copies on request. The drawing numbers are appended with a decimal fraction to indicate the latest revision. When changes are made to the communications system, ask Group ENG-2 to record them on the drawings.

Drawing number LA-KY-J-6038 shows the conduit locations and floor penetrations used for each outlet box, as well as the cable routing plan in the basement of the plutonium facility.

Drawing number LA-KY-J-6039 shows the equipment layout for the communications system, such as the outlet box locations, on the first floor of the plutonium faclity, as well as the cable routing plan.

Drawing number LA-KY-J-6040 shows the equipment layout on the mezzanine level of the plutonium facility, as well as the cable routing plan.

Drawing number LA-KY-J-6041 has diagrams of typical outlet box installations.

To obtain a copy of the WIRERUN Listing, an extensive computer printout that specifies all the connections in the DYMAC Communications System, contact the LASL Engineering Department, Group ENG-4. 


\section{APPENDIX F CIRCUIT DIAGRAMS}

All of the circuit diagrams of equipment for the DYMAC Communications System appear in Figs. F-1 through F-19.

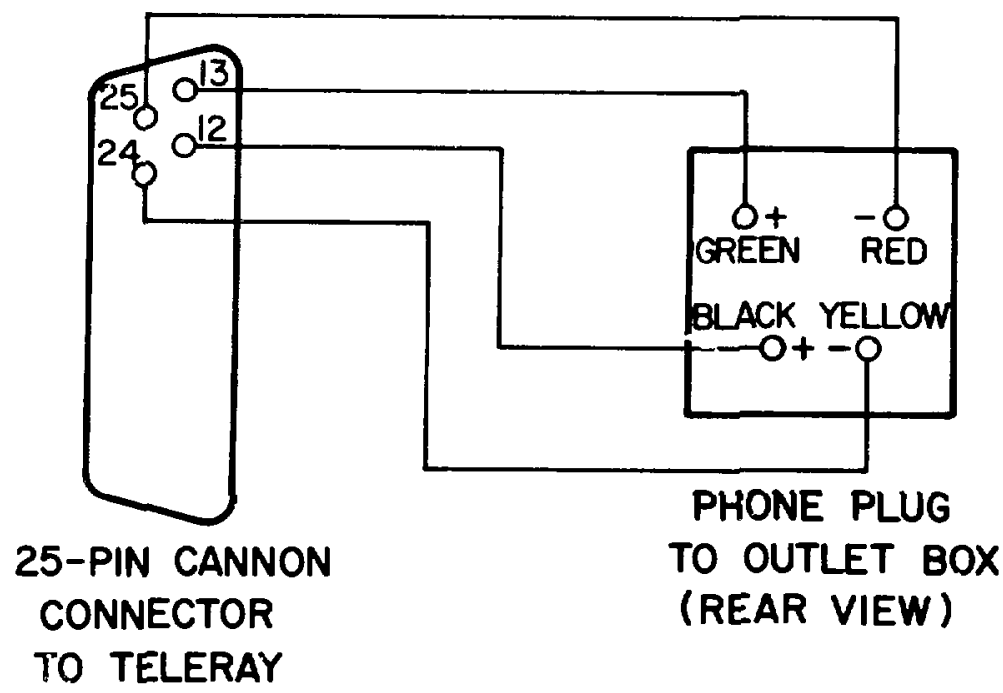

Fig. F-1.

Cable type A connects an outlet box to a Teleray terrinal. It is $2.44 \mathrm{~m}$ long and consists of two pairs of 22-gauge twisted pair wire. 


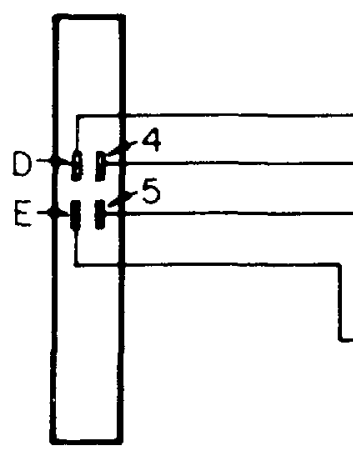

DUAL 10-PIN

PC BOARD

EDGE CONNECTOR

TO

HARD-COPY TERMINAL
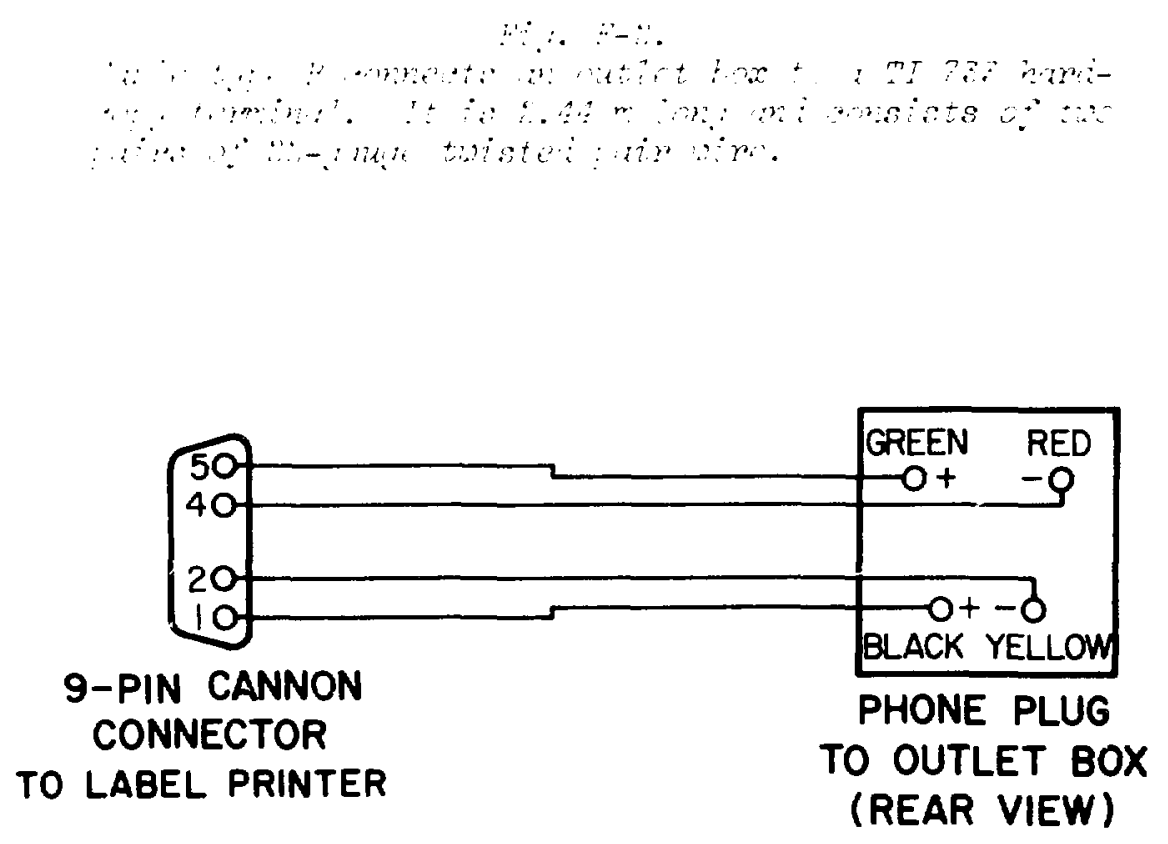

Fi. F-3.

Gize twe C comects in atzet box to a TI 810 label printer. It is $2.44 \mathrm{~m}$ long and consists of two pairs of 22 -gauge twisted rair wire. 


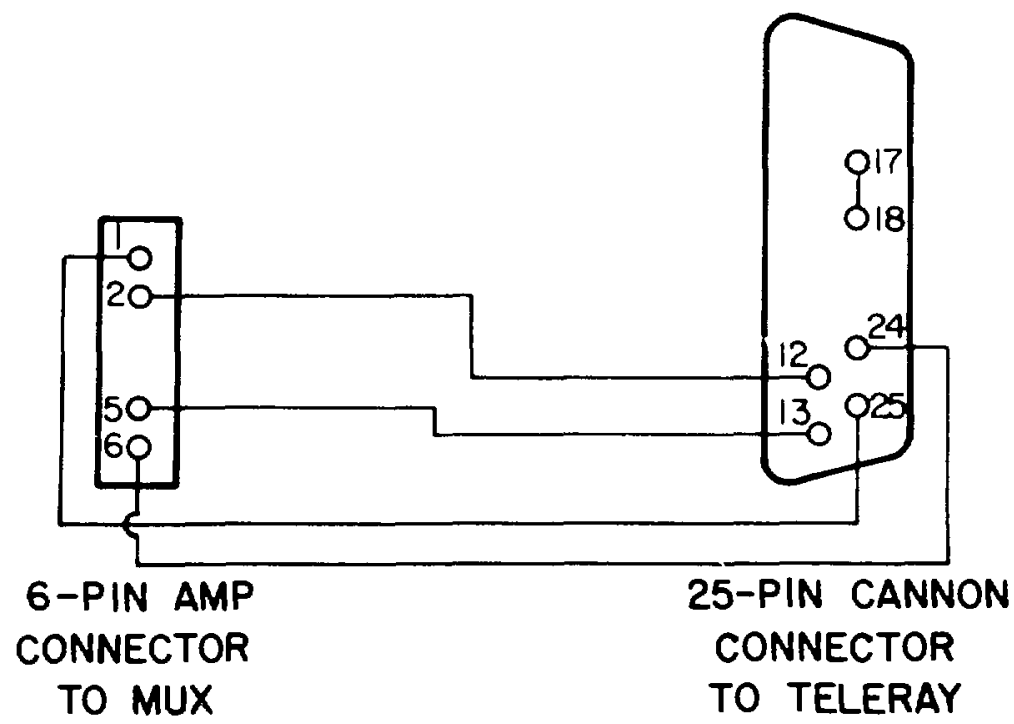

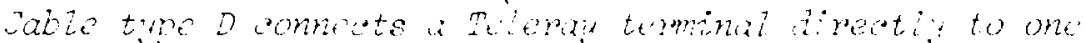
ropt of the inX iniasis.

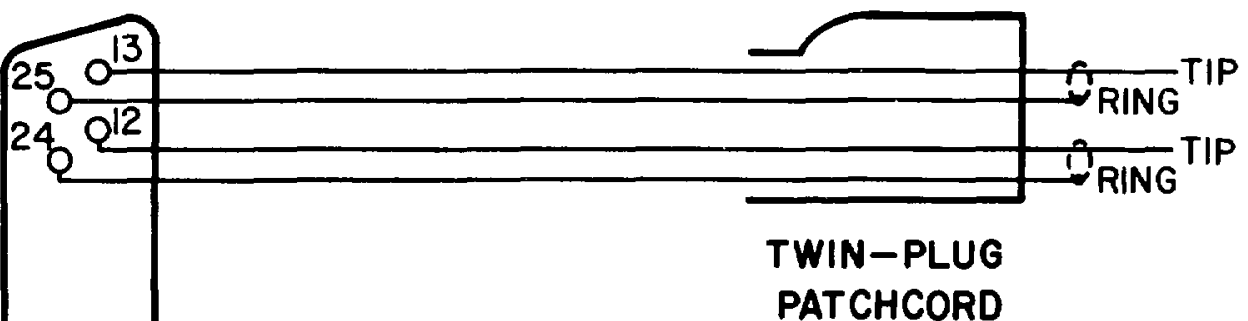

25-PIN CANNON

CONNECTOR

TO TELERAY

Fig. F-5.

Cable type E cornects a Teleray terminal to a jackstrip or to the Diagnostic Panel. 


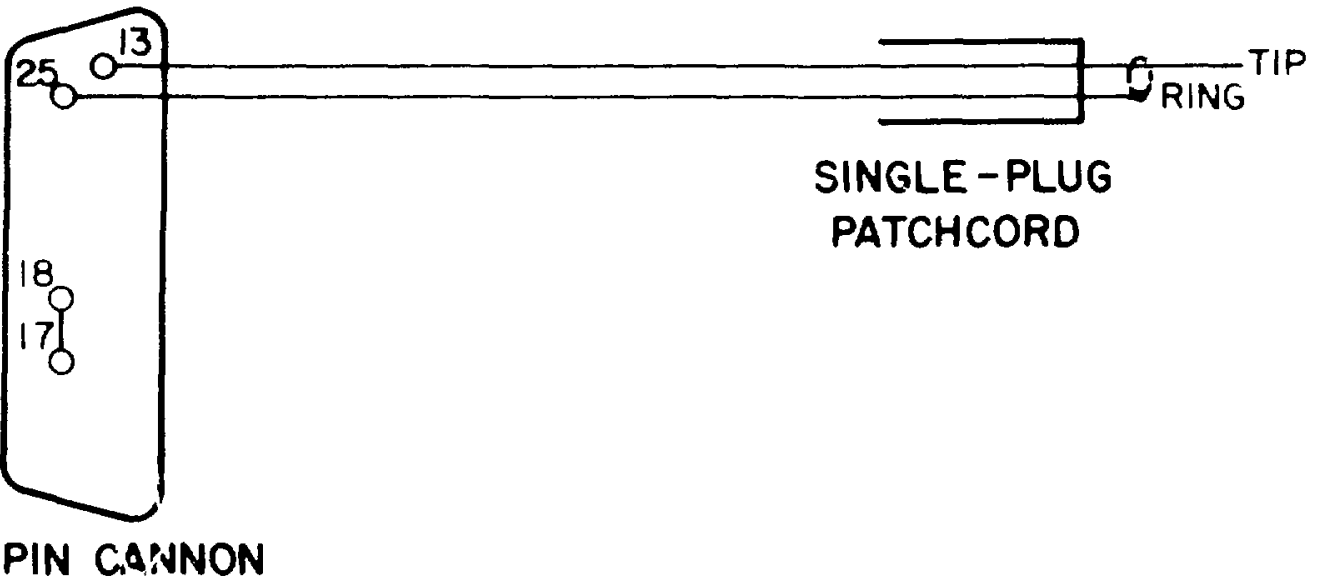

25-PIN CAAINNON

CONNECTOR

TO TELERAY 


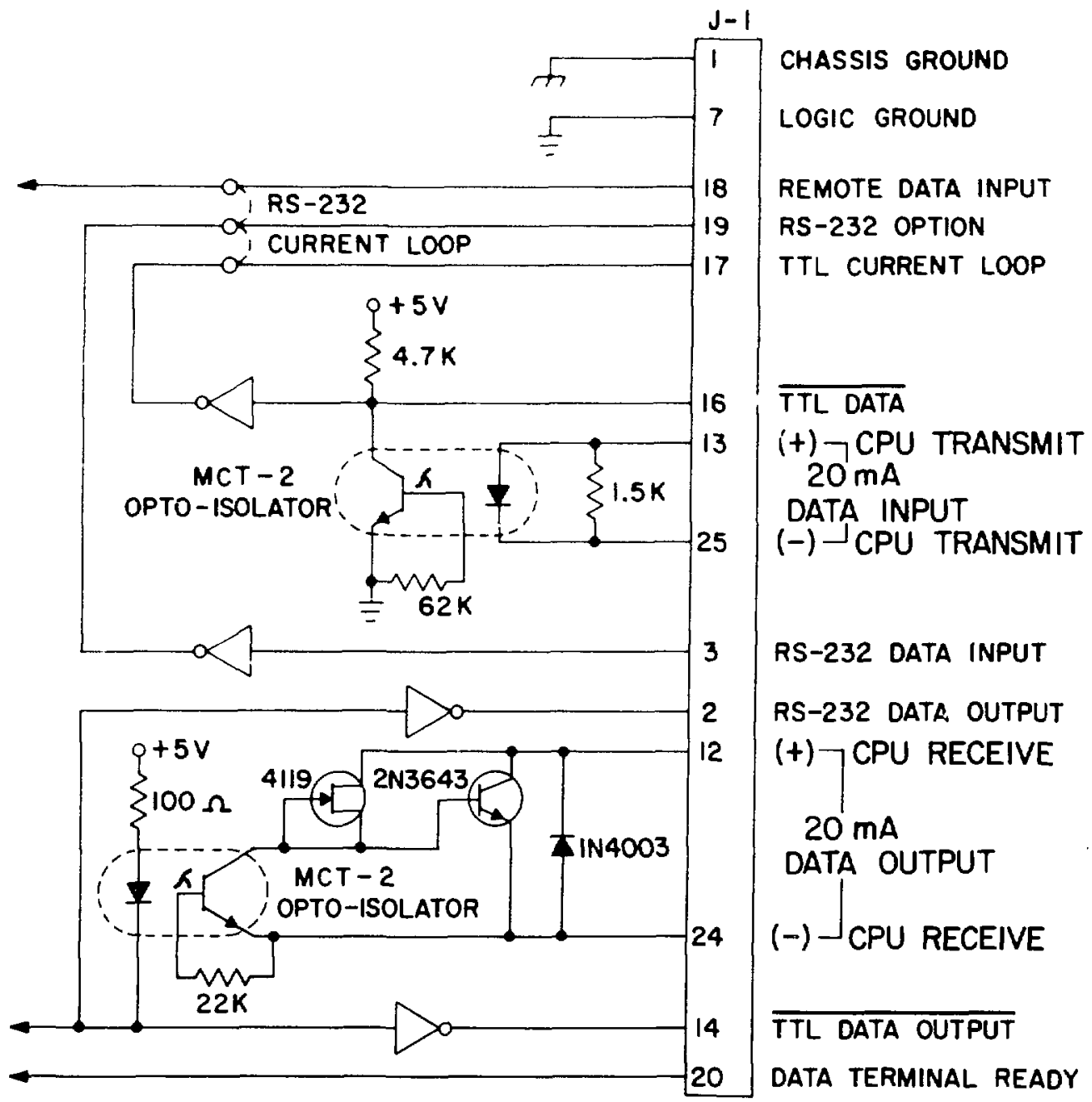

Fig. F-7.

Modified interface circuit for the Teleray 3741 terminal. 


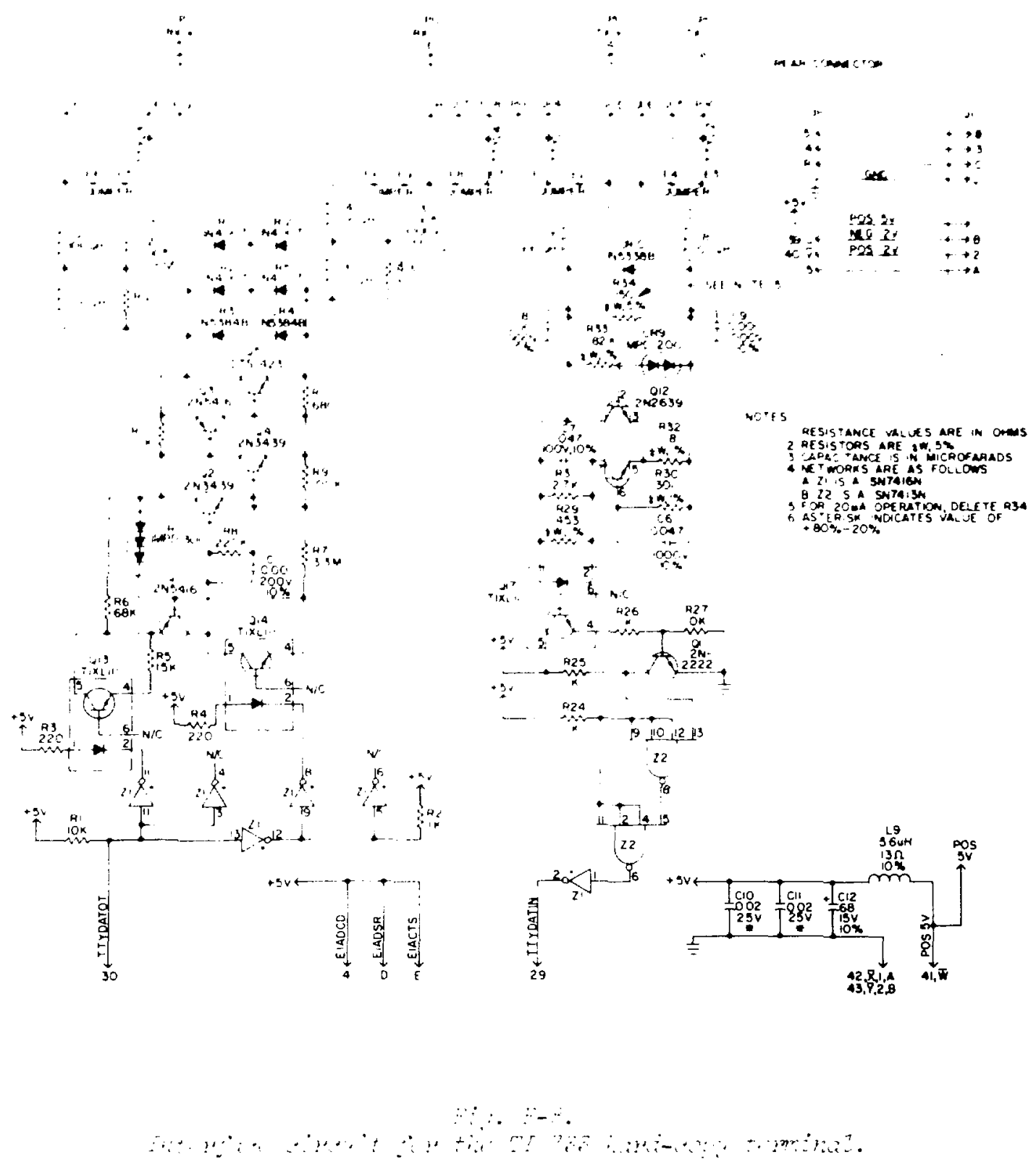




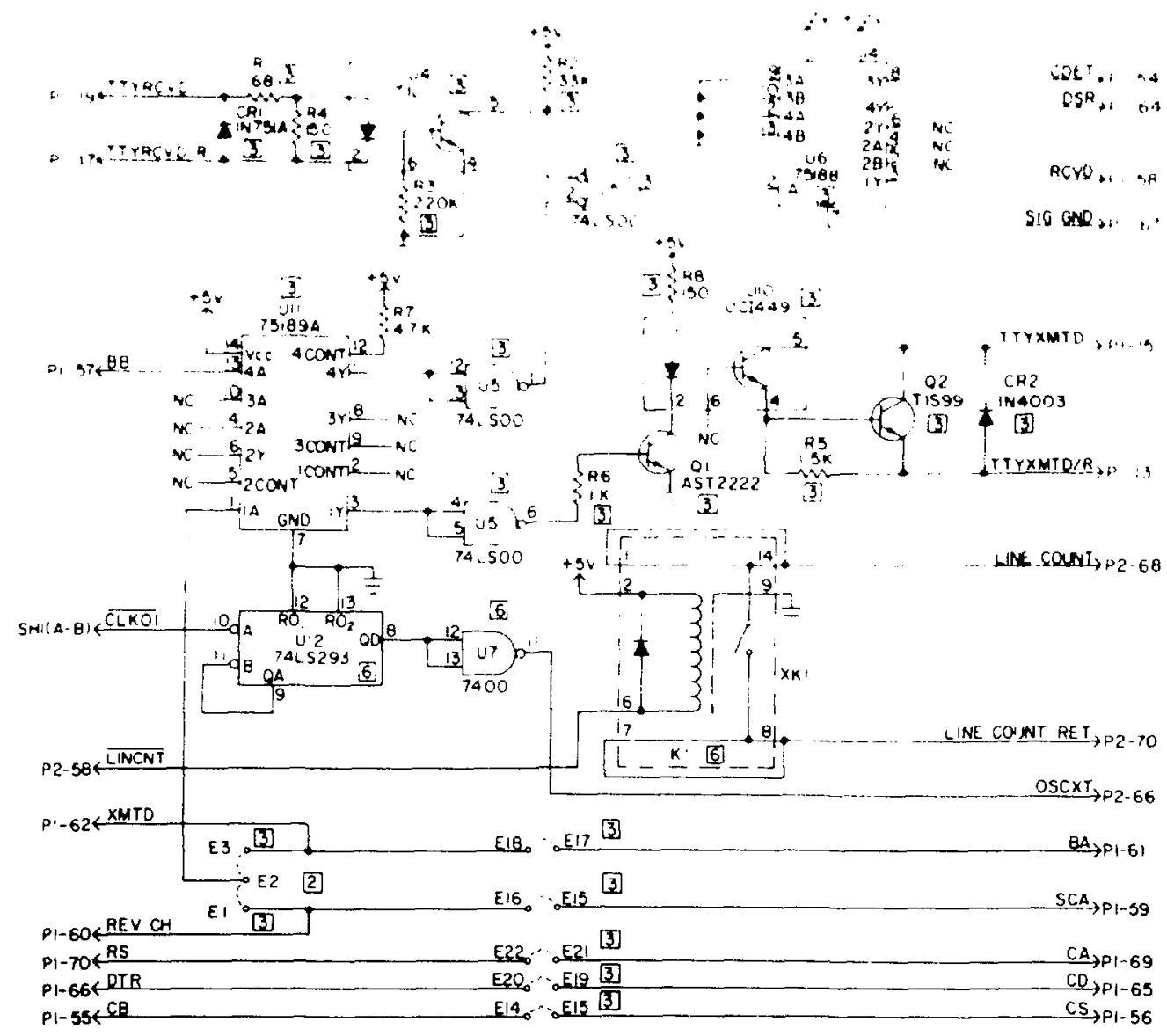

$\because \because E-a^{2}$

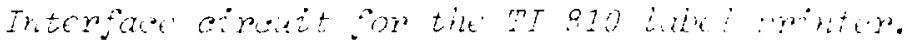




\section{\}$^{+5 v}$ $\sum_{n 10}$}

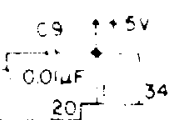
EXTERNAL RESET- 53 - 21 DATA STRCBE 33 23 ND OF CHARACTER 31 ? 24 DATA BIT INPUT, 25 25 DATA BIT INPUT $2 \sqrt{27},-27$ DATA BII INPU: $\sqrt{35},-28$ DATA BIT INPUT 539 UATA BIT INPU 6 [4T]
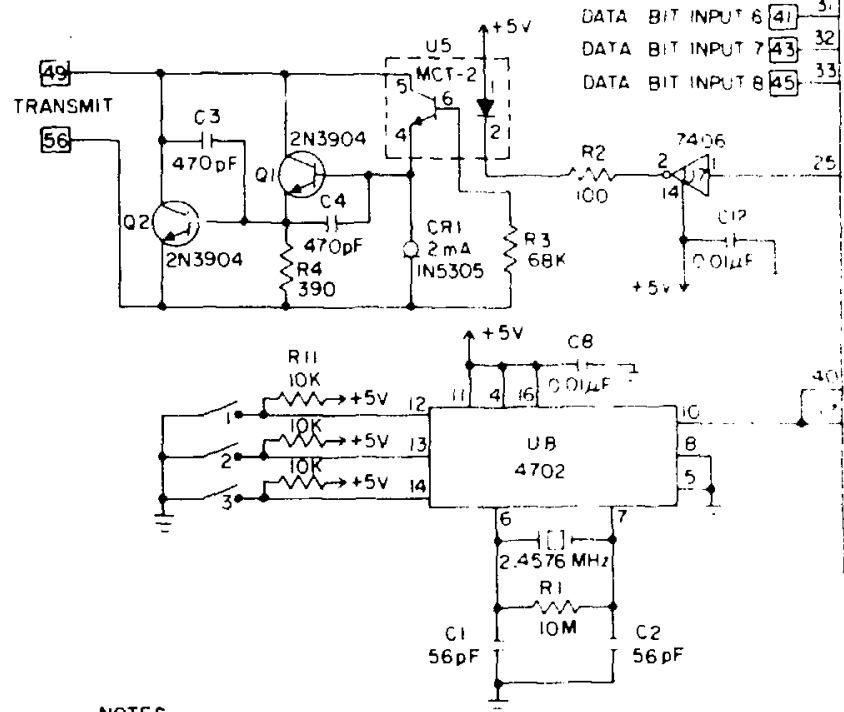

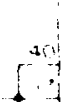

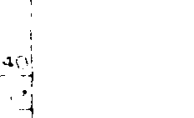

NOTES.

ALL SOUARES $\square$ DENOTE OUIPUT PIN NUMBER ON $\mathrm{F} O$ SWITCHES I, 2 ANO 3 CONTROL THE THANSMISSION RATE

SWITCH 4 CONTROLS THE USE OF PARITY

SWITCH S CONTROLS THE NUMBER OF STCP BITS

SWWTCHES 6 ANO 7 CONTROL THE NUMBER OF
SWITCH 8 CONTROLS EVEN OR ODD PARITY

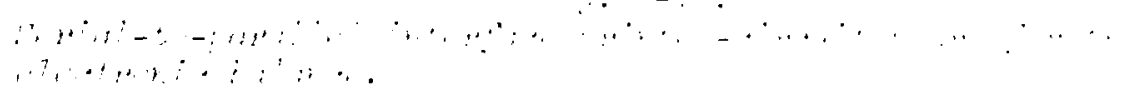



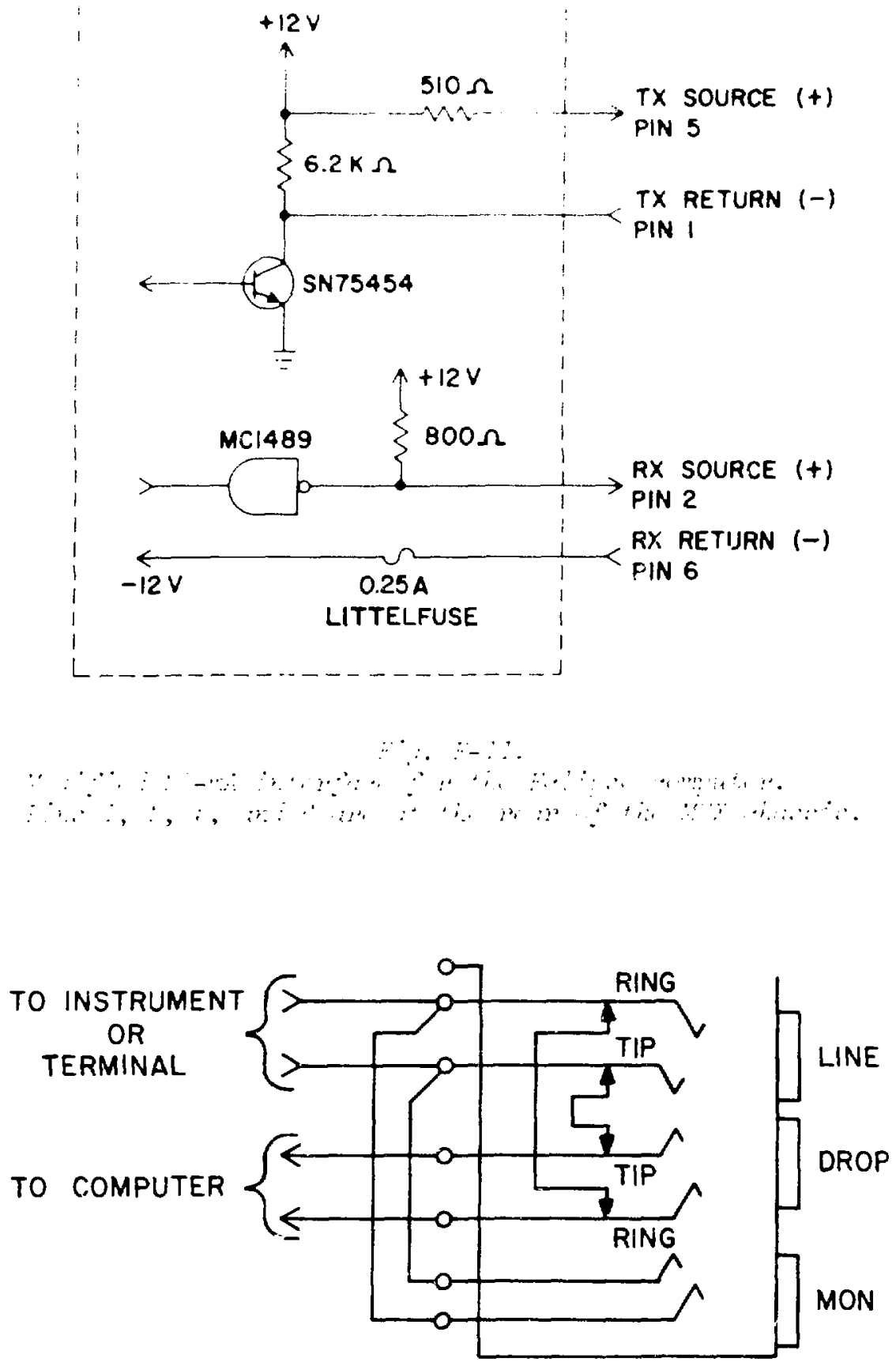

ing. 1-12.

Front-to-rear wining of a jackstrip. 
LA.C182 M

Manua:

UC.32

Issued: January 1980

\section{DYaAC Communicanions System}

Kathleen A. Lindsey
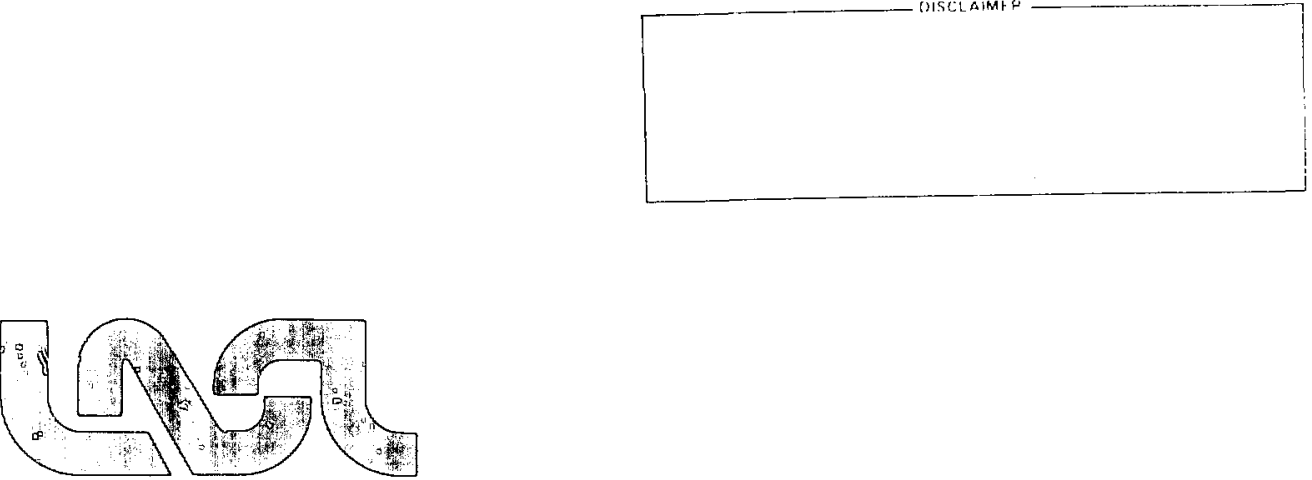


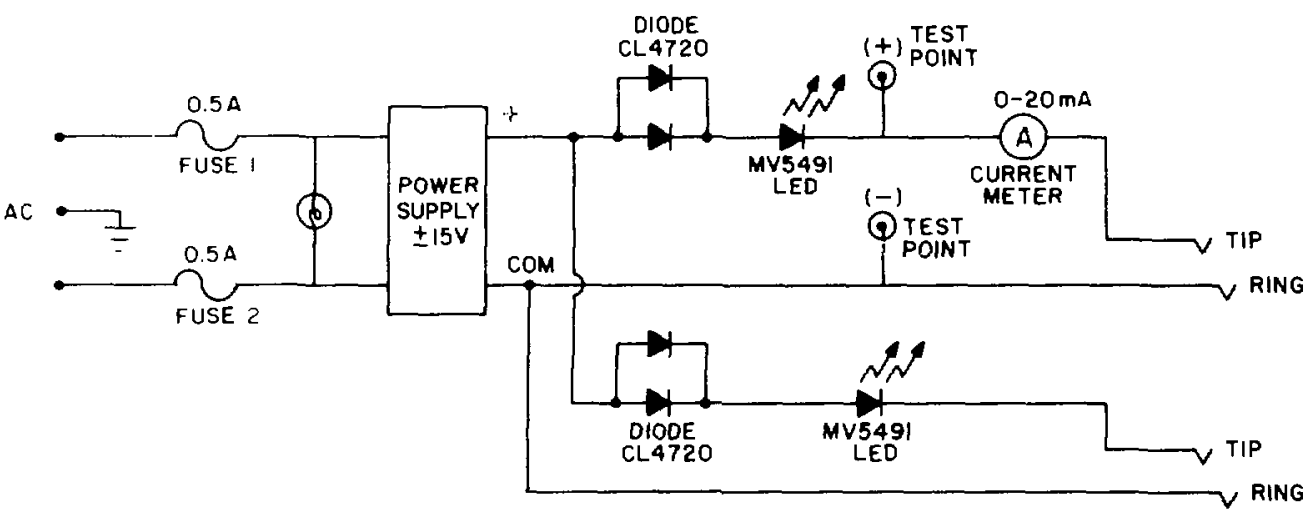

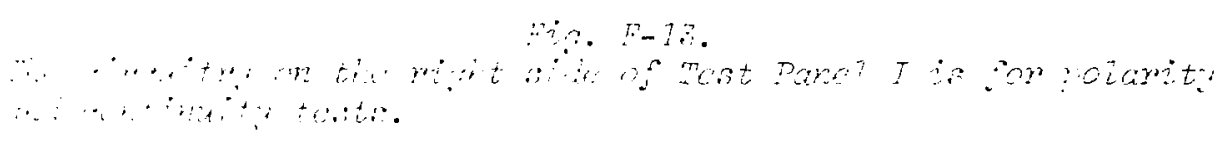
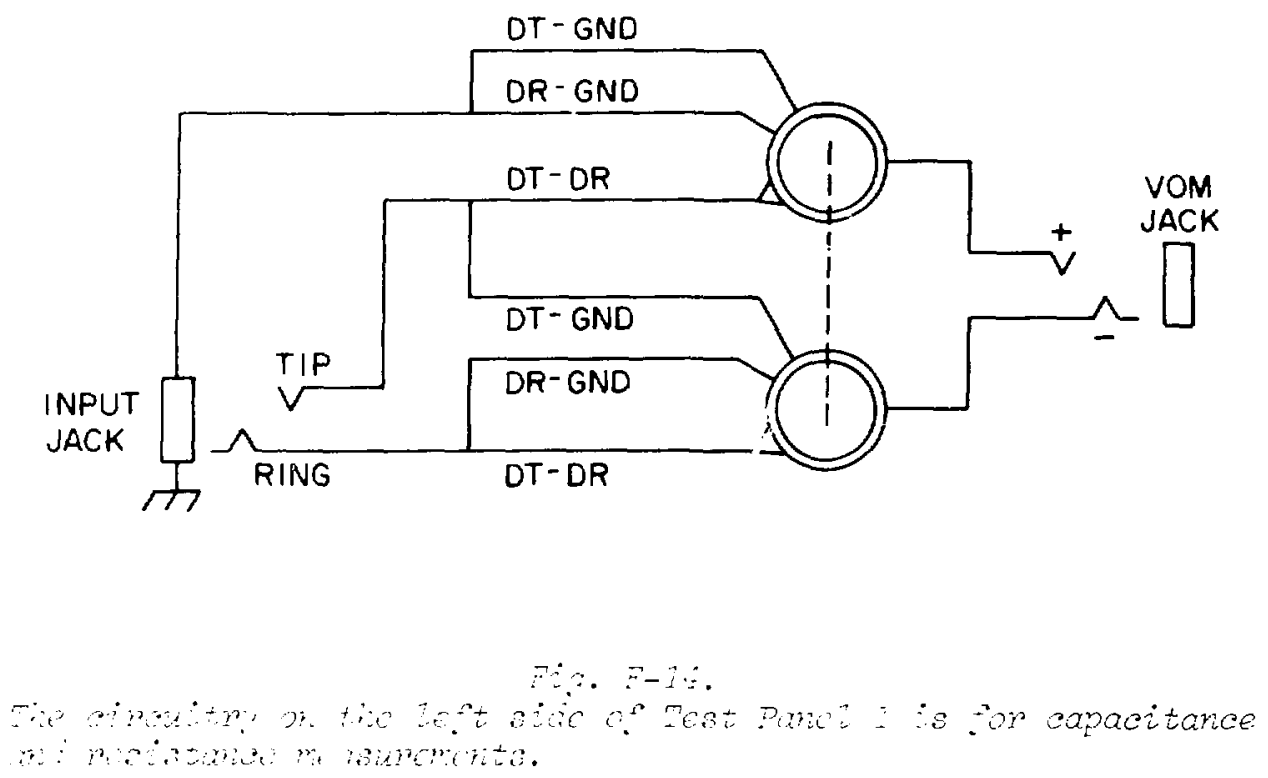


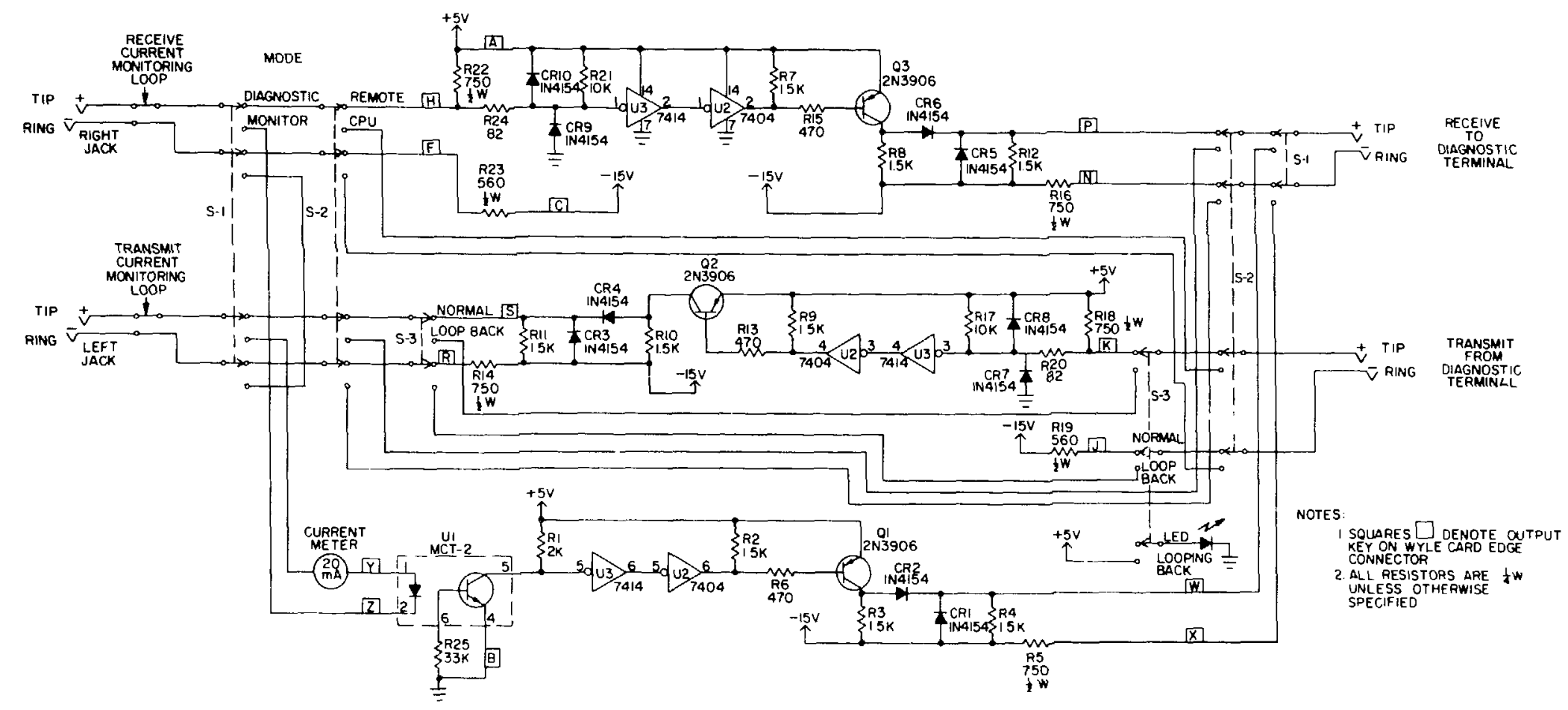




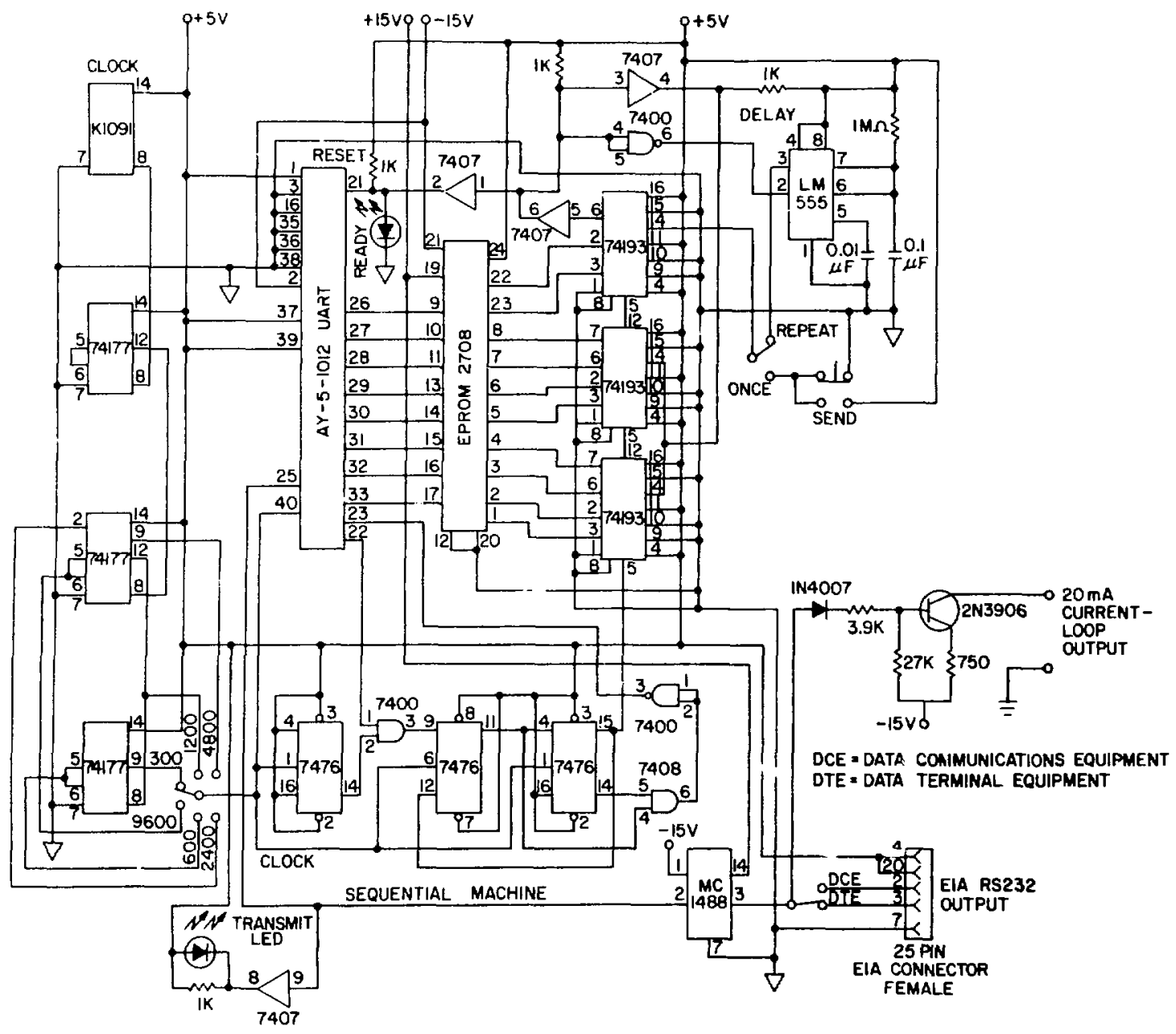

Pris. $\bar{r}-16$.

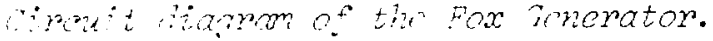




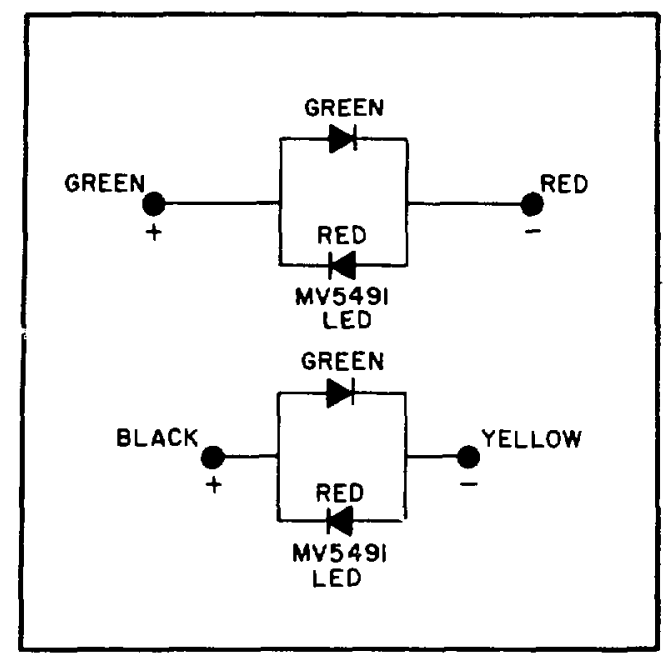

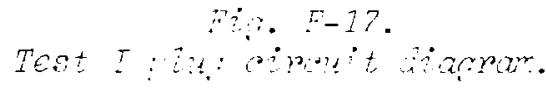

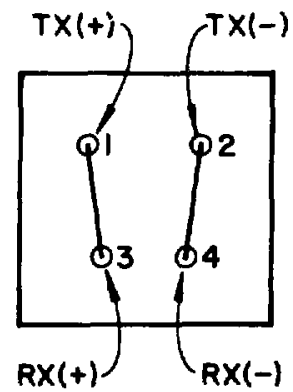

Fire ${ }^{2}-18$.

Loo-Back plif circuit

Jiagram.

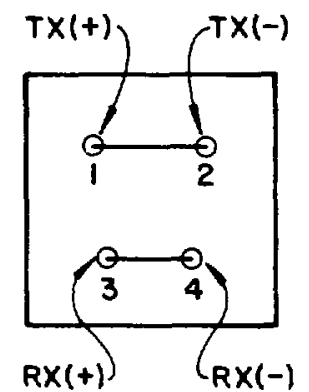

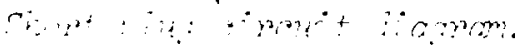




\section{APPENDIX G COMPUTER ROOM CONNECTIONS TO MULTIPLEXOR}

This uppendix identifies the cables used to connect the computer room juncision boxes to the computer multiplexor. The information is grouped by five areas: the four wings in the Plutonium Processing Facility and the Colr Support Building.

The tables give the numbers of the room, outlet box, and type of device serviced by a particular jackfield circuit. The tables also give the cable number that connects each jackfield circuit (LINE SIDE) to a terminal strip in a computer room junction box and the cable number that connects the DROP SIDE of that same jackfield circuit to a MUX port.

For example, jackfield circuit 13 for the 100 Wing services a TNC that is connected to outlet box 01 in room 125. The LINE SIDE of that iackfield circuj.t is connected to terminal strip T02 in junction box J01 by ijne 1 of cable 50?. The DROP SIDE of the same lakfield circuit is connected to MUX port 73 by line 1 of cable 530 .

This apperfix may be used to trace a communications line in the sompiten room from a junction box to a MUX port during troubleshooting prooedures. 
TABLE G-I

100 WING CONNECTIONS TO MULTIPLEXOR

DYMAC Computer Room

\begin{tabular}{|c|c|c|c|c|c|c|}
\hline \multirow[b]{2}{*}{$\begin{array}{l}\text { Jackfield } \\
\text { Circuit }\end{array}$} & \multicolumn{3}{|c|}{$\begin{array}{c}\text { Junction Box Cable } \\
\text { LINE SIDE }\end{array}$} & \multicolumn{3}{|c|}{$\begin{array}{c}\text { Jackfield Cable } \\
\text { DROP SIDE }\end{array}$} \\
\hline & $\begin{array}{l}\text { Junction } \\
\text { Box }\end{array}$ & $\begin{array}{c}\text { Terminal } \\
\text { Strip } \\
\end{array}$ & $\begin{array}{l}\text { Cable } \\
\text { Number }\end{array}$ & $\begin{array}{l}\text { Cable } \\
\text { Number }\end{array}$ & $\begin{array}{l}\text { Line } \\
\text { Number }\end{array}$ & $\begin{array}{l}\text { MUX } \\
\text { Port } \\
\end{array}$ \\
\hline 1 & 501 & T01 & 501 & 529 & 1 & 71 \\
\hline 2 & J01 & T01 & 501 & 529 & 2 & 0 \\
\hline 3 & J01 & TO & 501 & 529 & 3 & 65 \\
\hline 4 & J01 & T01 & 501 & 529 & 4 & 66 \\
\hline 5 & J01 & T01 & 501 & 529 & 5 & 1 \\
\hline 6 & JO 1 & T01 & 501 & 529 & 6 & 67 \\
\hline 7 & J01 & T01 & 501 & 529 & 7 & 68 \\
\hline 8 & J01 & T01 & 501 & 529 & 8 & 2 \\
\hline 9 & Jo 1 & T01 & 501 & 529 & 9 & 69 \\
\hline 10 & $\mathrm{~J} 01$ & T01 & $50 ?$ & 529 & 10 & 70 \\
\hline 11 & JO 1 & T01 & 501 & 529 & 11 & 55 \\
\hline 12 & $\mathrm{~J} 01$ & T01 & 501 & 529 & 12 & 3 \\
\hline 13 & $\mathrm{JO} 1$ & T02 & 502 & 530 & 1 & 73 \\
\hline 14 & J01 & T02 & 502 & 530 & 2 & 4 \\
\hline 15 & Jo 1 & TO2 & 502 & 530 & 3 & 5 \\
\hline 16 & J0 1 & T02 & 502 & 530 & 4 & 6 \\
\hline 17 & J01 & T02 & 502 & 530 & 5 & 74 \\
\hline 18 & J01 & T02 & 502 & 530 & 6 & 58 \\
\hline 19 & J01 & T02 & 502 & 530 & 7 & 7 \\
\hline 20 & I01 & T02 & 502 & 530 & 8 & 39 \\
\hline 21 & 501 & T02 & 502 & 530 & 9 & 75 \\
\hline 22 & J01 & T02 & 502 & 530 & 10 & 60 \\
\hline 23 & JO 1 & T02 & 502 & 530 & 11 & 127 \\
\hline 24 & J01 & T02 & 502 & 530 & 12 & -- \\
\hline $25-36$ & j01 & T03 & 503 & 531 & $1-12$ &.- \\
\hline $37-48$ & J01 & TOL & 504 & 532 & $1-12$ & -- \\
\hline $49-60 b$ & 101 & T05 & 505 & $533^{\circ}$ & $1-12$ & --- \\
\hline $61-67^{b}$ & Jo 1 & T06 & 506 & $534 c$ & $1-12$ & --- \\
\hline
\end{tabular}

aTI 733 hard-copy terminal.

bThe jackstrip is not installed but the cables are in.

CThe DROP SIDE end of cable is not terminated. 
TABLE R-II

200 WING CONNECTIONS TO MULTIPLEXOR

DYMAC Computer Room

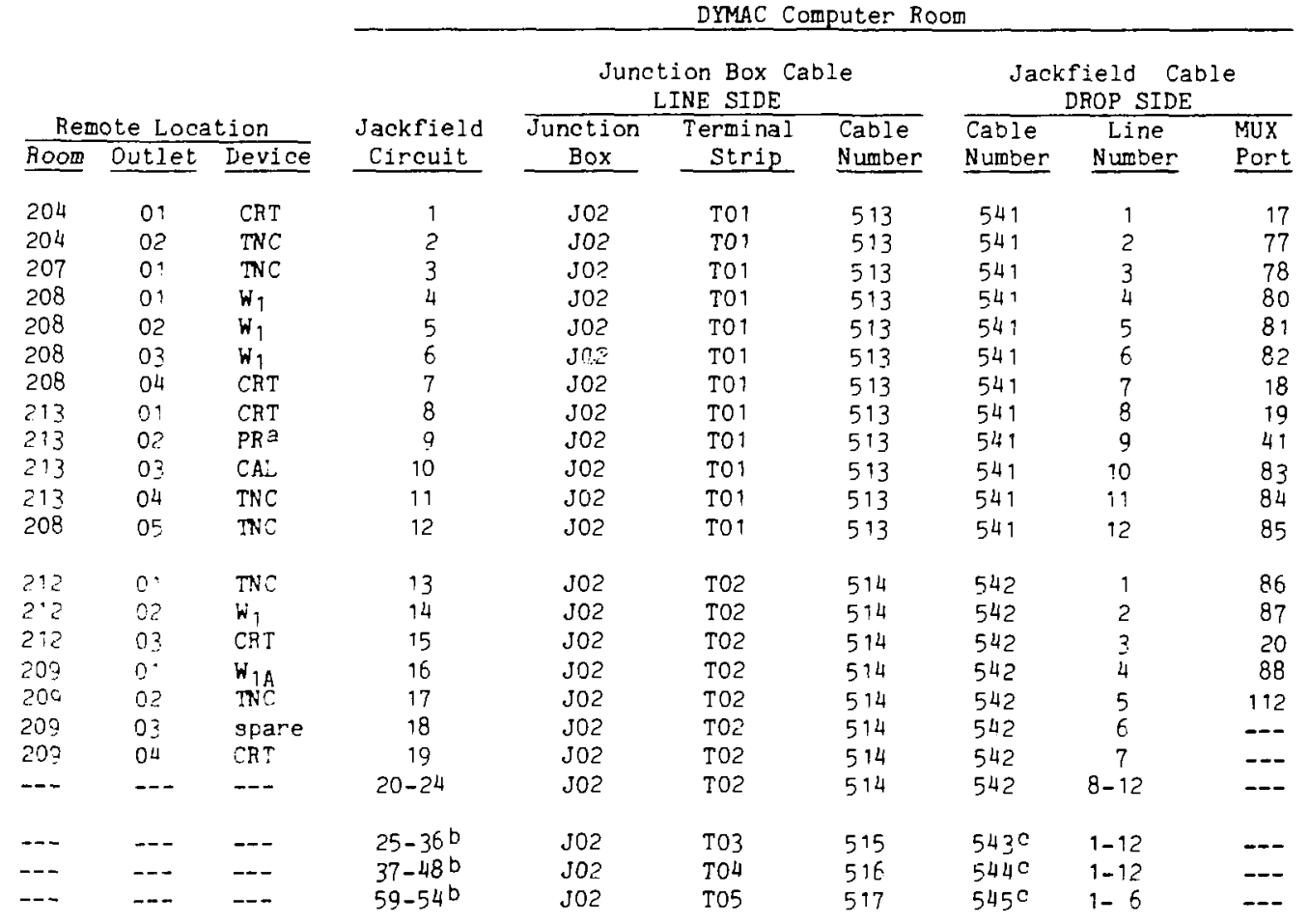

aTI 733 hard-copy terminal.

bThe fackstrip is not installed but the cables are in.

GThe DROP SIDE end of cable is not terminated. 
TABLE G-III

300 WING CONNECTIONS TO MULTIPLEXOR

DYMAC Computer Room

\begin{tabular}{|c|c|c|c|c|c|c|c|c|c|}
\hline & & & & Juno & $\begin{array}{l}\text { ion Box Ca } \\
\text { CNE SIDE }\end{array}$ & & Jack & $\begin{array}{l}\text { ield Ca } \\
\text { ROP SIDE }\end{array}$ & \\
\hline Rez & te Loca & tion & Jackfleld & Junction & Terminal & Cable & Cable & Line & MUX \\
\hline Room & Outlet & Device & Circuit & Box & Strip & Number & Number & Number & Port \\
\hline 305 & 01 & CRT & 1 & J01 & T07 & 507 & 535 & 1 & 8 \\
\hline 305 & 02 & $w_{1}$ & 2 & J01 & T07 & 507 & 535 & 2 & 61 \\
\hline 306 & 01 & $W_{1}$ & 3 & J01 & T07 & 507 & 535 & 3 & 62 \\
\hline 308 & 01 & $W_{1 A}$ & 4 & J0 1 & T07 & 507 & 535 & 4 & 64 \\
\hline 316 & 01 & CRT & 5 & J01 & T07 & 507 & 535 & 5 & 9 \\
\hline 319 & 01 & $w_{1}$ & 6 & J01 & T07 & 507 & 535 & 6 & 49 \\
\hline 319 & 02 & $\mathrm{~W}_{2}$ & 7 & Jo 1 & T07 & 507 & 535 & 7 & 50 \\
\hline 319 & 03 & $W_{1}$ & 8 & J0 1 & T07 & 507 & 535 & 8 & 51 \\
\hline 319 & 04 & CRT & 9 & J01 & T07 & 507 & 535 & 9 & 10 \\
\hline 319 & 05 & $W_{?}$ & 10 & J01 & T07 & 507 & 535 & 10 & 52 \\
\hline 319 & 06 & $W_{9}$ & 11 & Jo 1 & T07 & 507 & 535 & 11 & 53 \\
\hline 319 & 07 & $W_{1}$ & 12 & J01 & T07 & 507 & 535 & 12 & 54 \\
\hline 319 & 08 & $w_{1}$ & 13 & 301 & T08 & 508 & 536 & 1 & 48 \\
\hline 319 & 09 & CAT & 14 & Jo1 & T08 & 508 & 536 & 2 & 11 \\
\hline 325 & 01 & CRT & 15 & 301 & T08 & 508 & 536 & 3 & 12 \\
\hline 326 & 02 & Pra & 16 & J01 & TO8 & 508 & 536 & 4 & 40 \\
\hline 327 & 01 & TNC & 17 & J01 & T08 & 508 & 536 & 5 & 72 \\
\hline 327 & 02 & $w_{1}$ & 18 & J01 & T08 & 508 & 536 & 6 & 56 \\
\hline 327 & 03 & $W_{2}$ & 19 & J01 & T08 & 508 & 536 & 7 & 57 \\
\hline 329 & 01 & $W_{1}$ & 20 & J01 & T08 & 508 & 536 & 8 & 59 \\
\hline 329 & 02 & TNC & 21 & J01 & T08 & 508 & 536 & 9 & 76 \\
\hline 330 & 01 & CRT & 22 & J01 & T08 & 508 & 536 & 10 & 13 \\
\hline $33^{b}$ & 01 & CRT & 23 & J01 & T08 & 508 & 536 & 11 & 16 \\
\hline $33^{b}$ & 02 & $P R C$ & 24 & $J 01$ & T08 & 508 & 536 & 12 & 37 \\
\hline 305 & 03 & $w_{1}$ & 25 & J01 & T09 & 509 & 537 & 1 & 79 \\
\hline-- & $-\cdots$ & -- & $26-36$ & J01 & T09 & 509 & 537 & $2-12$ & --- \\
\hline-- & $\ldots$ & -- & $37-44$ & J01 & T10 & 510 & 538 & $1-8$ & $\cdots$ \\
\hline-- & -- & -- & spare & J01 & $\mathrm{T} 10$ & 510 & 538 & 9 & 47 \\
\hline-- & $\cdots$ & --- & 46 & J01 & T10 & 510 & $53 B$ & 10 & --- \\
\hline$-\cdots$ & $\cdots$ & -- & spare & J01 & $\mathrm{T} 10$ & 510 & 538 & 11 & 15 \\
\hline-- & $\cdots$ & --- & spare & $\mathrm{J} 01$ & T10 & 510 & 538 & 12 & 14 \\
\hline-- & -- & -- & $49-60^{d}$ & JO 1 & T11 & 511 & $539 e$ & $1-12$ & --- \\
\hline$\ldots$ & -- & -- & $6 i-67^{d}$ & J01 & $T 12$ & 512 & $540^{e}$ & $1-7$ & --- \\
\hline
\end{tabular}

aTI 733 hard-copy terminal.

bvault.

$c_{\text {TI }} 810$ label printer.

The fackstrip is not yet installed but the cables are in.

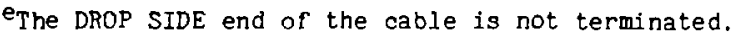


TABLE $G-I V$

400 WING CONNECTIONS TO MULTIPLEXOR

DYMAC Computer Room

\begin{tabular}{|c|c|c|c|c|c|c|}
\hline \multirow[b]{2}{*}{$\begin{array}{c}\text { Jackfield } \\
\text { Circuit } \\
\end{array}$} & \multicolumn{3}{|c|}{$\begin{array}{c}\text { Junction Box Cable } \\
\text { LINE SIDE }\end{array}$} & \multicolumn{3}{|c|}{$\begin{array}{c}\text { Jackfield Cable } \\
\text { DROP SIDE }\end{array}$} \\
\hline & $\begin{array}{l}\text { Junction } \\
\text { Box } \\
\end{array}$ & $\begin{array}{l}\text { Termina] } \\
\text { Strip } \\
\end{array}$ & $\begin{array}{l}\text { Cable } \\
\text { Number }\end{array}$ & $\begin{array}{l}\text { Cable } \\
\text { Number } \\
\end{array}$ & $\begin{array}{l}\text { Line } \\
\text { Number }\end{array}$ & $\begin{array}{l}\text { MUX } \\
\text { Port } \\
\end{array}$ \\
\hline 1 & J02 & T06 & 518 & 546 & 1 & 21 \\
\hline 2 & $\mathrm{~J} 02$ & T06 & 518 & 546 & 2 & 89 \\
\hline 3 & $\mathrm{JO2}$ & T06 & 518 & 546 & 3 & 90 \\
\hline 4 & $\mathrm{~J} 02$ & T06 & 518 & 545 & 4 & 91 \\
\hline 5 & J02 & TOE & 518 & 546 & 5 & 92 \\
\hline 6 & $\mathrm{~J} 02$ & T06 & 518 & 546 & 6 & 22 \\
\hline 7 & $\mathrm{JO2}$ & T06 & 518 & 546 & 7 & 93 \\
\hline 3 & $\mathrm{~J} 02$ & TOG & 518 & 546 & 8 & 94 \\
\hline 9 & $\mathrm{~J} 02$ & TOE & 518 & 546 & 9 & 96 \\
\hline 10 & J02 & mo6 & 518 & 546 & 10 & 97 \\
\hline 11 & $J 02$ & T06 & 518 & 546 & $1 ?$ & 98 \\
\hline 12 & J02 & TOE & 518 & 546 & 12 & 99 \\
\hline 13 & J02 & TO? & 510 & 547 & 1 & 100 \\
\hline 14 & J02 & T07 & 519 & 547 & 2 & 104 \\
\hline 15 & $\mathrm{~J} 02$ & TO7 & 510 & 547 & 3 & 102 \\
\hline 15 & J02 & TO? & 519 & 547 & 4 & 103 \\
\hline$i ?$ & J02 & TO? & 519 & 547 & 5 & 104 \\
\hline 18 & J02 & T07 & 519 & 547 & 6 & 105 \\
\hline 19 & J0: & TO & 519 & 547 & 7 & 106 \\
\hline 20 & J01 & T0? & 519 & 547 & 8 & 107 \\
\hline 21 & Jo ${ }^{4}$ & T0? & 510 & 547 & 9 & 108 \\
\hline 22 & J01 & T0? & 519 & $54 ?$ & 10 & 109 \\
\hline 23 & 301 & T07 & 519 & $54 ?$ & 11 & 110 \\
\hline 24 & $\mathrm{JO}^{\dagger}$ & т0? & 519 & $54 ?$ & 12 & 23 \\
\hline 25 & $\mathrm{~J} 02$ & Т08 & 520 & 548 & 1 & --- \\
\hline 25 & J0? & T08 & 520 & 548 & 2 & 113 \\
\hline 27 & $\mathrm{~J} 02$ & T08 & 520 & 548 & 3 & 114 \\
\hline 28 & J02 & T08 & 520 & 548 & 4 & 115 \\
\hline 29 & $\mathrm{~J} 02$ & T08 & 520 & 548 & 5 & 116 \\
\hline 30 & $\mathrm{~J} 02$ & T08 & 520 & 548 & 6 & 117 \\
\hline 31 & $i \cap 2$ & T08 & 520 & 548 & 7 & 24 \\
\hline 32 & $\mathrm{~J} 02$ & TO8 & 520 & 548 & 8 & 118 \\
\hline 33 & J02 & T08 & 520 & 548 & 9 & 119 \\
\hline 34 & J02 & 208 & 520 & 548 & 10 & 25 \\
\hline 35 & $J 0 \hat{c}$ & T08 & 520 & 548 & $\uparrow 1$ & 120 \\
\hline 30 & $\mathrm{~J} 02$ & Т08 & 520 & 548 & 12 & 121 \\
\hline
\end{tabular}


TABLE G-IV (continued)

400 WING CONNECTIONS TO MULTIPLEXOR

DYMAC Computer Room

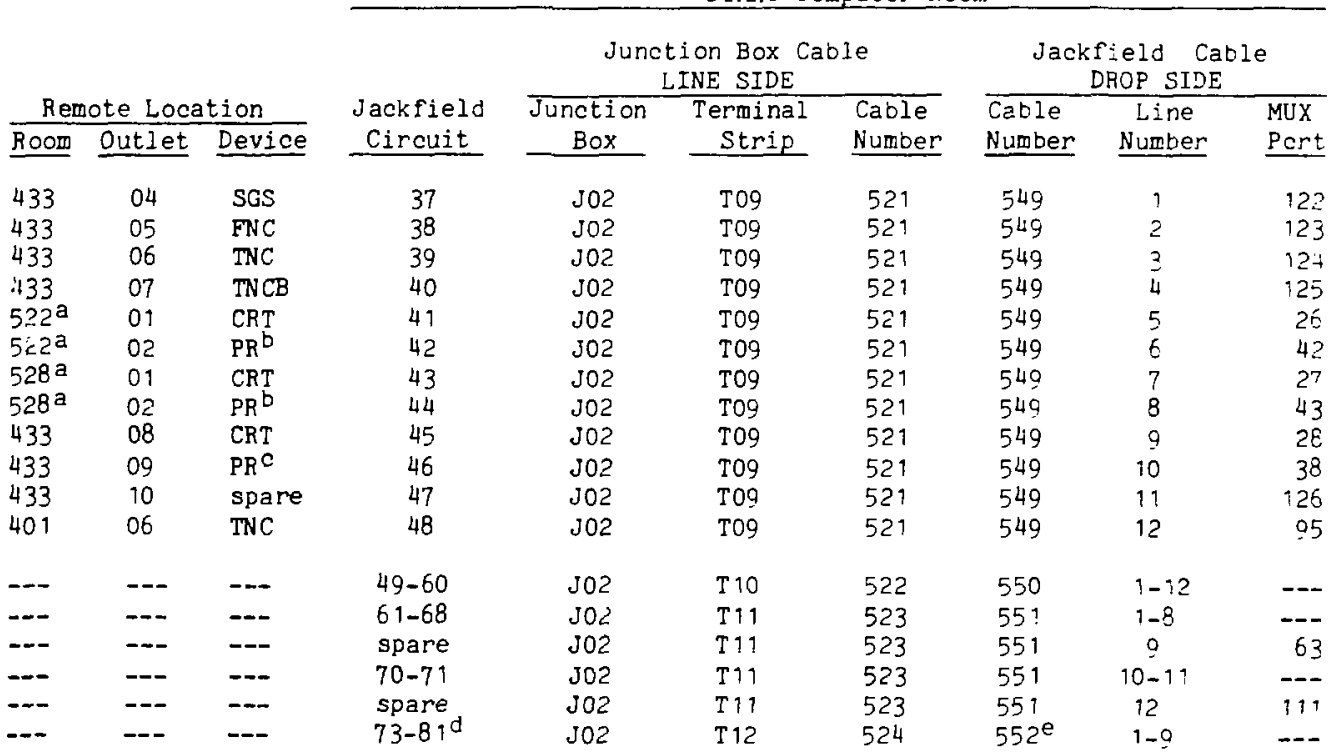

amezzanine.

bTI 733 hard-copy terminal.

CTI 810 label printer.

The jackstrip is not installed but the cables are in.

$e_{T h e}$ DROP SIDE end of cable is not terminated. 
TABLE $G-V$

COLD SUPPORT BUILDING CONNECTIONS TO MULTIPLEXOR

DYMAC Computer Room

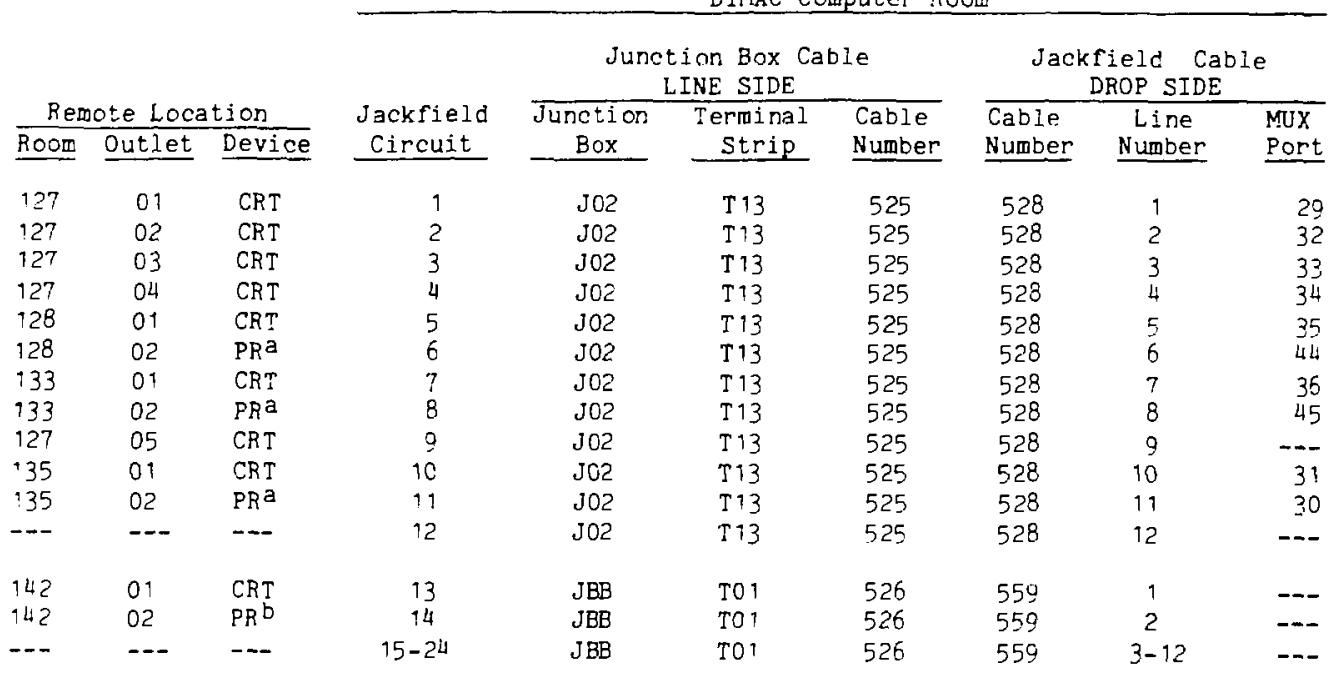

aTI 810 label printer.

bTI 733 hard-copy terminal. 


\section{APPENDIX H \\ CABLE CONNECTIONS}

All cable connections in the DYMAC Communications System are specified in this appendix.

TABLE H-I

CABLING FROM COMPUTER ROOM JUNCTION BOXES TO JACKFIELD

\begin{tabular}{|c|c|c|}
\hline $\begin{array}{c}\text { Junction } \\
\text { Box }\end{array}$ & $\begin{array}{l}\text { Terminal } \\
\text { Strip }\end{array}$ & Jackstrip ${ }^{a}$ \\
\hline Jo? & T01 & $100-1$ to $100-12$ \\
\hline J04 & T02 & $100-13$ to $100-24$ \\
\hline J01 & TO3 & $100-25$ to $100-36$ \\
\hline jol & TO4 & $100-37$ to $100-48$ \\
\hline J01 & T05 & no strip \\
\hline J0 1 & T06 & no strip \\
\hline J0 1 & T07 & $300-1$ to $300-12$ \\
\hline J01 & T08 & $300-13$ to $300-24$ \\
\hline J01 & T09 & $300-25$ to $300-36$ \\
\hline J01 & $\mathrm{T} 10$ & $300-37$ to $300-48$ \\
\hline J01 & T11 & no strip \\
\hline J01 & $\mathrm{T} 12$ & no strip \\
\hline jo2 & T01 & $200-1$ to $200-12$ \\
\hline 302 & T02 & $200-12$ to $200-24$ \\
\hline$j 02$ & T03 & no strip \\
\hline J02 & $\mathrm{TOH}$ & no strip \\
\hline $\begin{array}{l}\mathrm{J} 02 \\
\mathrm{~J} 02\end{array}$ & $\begin{array}{l}\text { T05 } \\
\text { T05 }\end{array}$ & $\begin{array}{l}\text { no strip } \\
400-1 \text { to } 400-12\end{array}$ \\
\hline $\begin{array}{l}\mathrm{J} 02 \\
\mathrm{~J} 02\end{array}$ & TO7 & $400-13$ to $400-24$ \\
\hline J02 & T08 & $400-25$ to $400-36$ \\
\hline $\mathrm{J} 02$ & T09 & $400-37$ to $400-48$ \\
\hline 302 & T 30 & $400-49$ to $400-60$ \\
\hline $\mathrm{J} 02$ & T11 & $400-61$ to $400-72$ \\
\hline jOZ & T12 & no strip \\
\hline $\mathrm{jOZ}$ & $T 13$ & $\operatorname{CSB}^{b}-1$ to $\operatorname{CSB}-12$ \\
\hline JBB & T01 & $\mathrm{CSB}^{\mathrm{b}}-13$ to $\mathrm{CSB}-24$ \\
\hline JBB & T02 & no strip \\
\hline
\end{tabular}

afrom (wing-outlet box) to (wing-outlet box).

${ }^{b}$ Cold Support Building. 
TABLE H-II

IACKFIELD-TO-MULTIPLEXOR CABLE CODE

\begin{tabular}{|c|c|c|c|c|c|}
\hline $\begin{array}{c}\text { Line } \\
\text { Number }\end{array}$ & $\begin{array}{l}\text { Wime } \\
\text { Colont }\end{array}$ & $\begin{array}{l}\text { Mul: :plexor } \\
\text { AMP Connector } \\
\text { Pin Number }\end{array}$ & Signa? & Poienity & $\begin{array}{l}\text { 5o-pir } \\
\text { Conreaton } \\
\text { number } \\
\end{array}$ \\
\hline \multirow[t]{4}{*}{, } & white-biue & 5 & transui: & pius & $2 E$ \\
\hline & blue-wh:te & $?$ & transm: : & minus & $:$ \\
\hline & wh t:e-orange & 2 & receive & piss & $?$ \\
\hline & orange-white & 6 & receive & minus & 2 \\
\hline \multirow[t]{4}{*}{$?$} & white-green & 5 & transmit & plas & 28 \\
\hline & green-white & 1 & transmit & minus & 3 \\
\hline & white-brown & ? & receive & plus & 29 \\
\hline & brown-white & 6 & receive & minus & 4 \\
\hline \multirow[t]{4}{*}{$?$} & white-slate & 5 & transmit & plus & 30 \\
\hline & slate-white & 1 & transmit & minus & 5 \\
\hline & red-blue & 2 & receive & plus & 31 \\
\hline & blue-red & $\epsilon$ & receive & minus & 6 \\
\hline \multirow[t]{4}{*}{4} & red-orange & 5 & transwit & plus & 32 \\
\hline & orange-red & 1 & transmit & minus & 7 \\
\hline & red-green & 2 & receive & plus & 33 \\
\hline & green-red & 6 & receive & minus & 8 \\
\hline \multirow[t]{4}{*}{5} & red-brown & 5 & transmit & plus & 34 \\
\hline & brown-red & 1 & transmit & minus & 0 \\
\hline & red-slate & 2 & receive & plus & 35 \\
\hline & slate-red & 6 & receive & minus & 10 \\
\hline \multirow[t]{4}{*}{6} & black-blue & 5 & transmit & plus & 36 \\
\hline & blue-black & 1 & transmit & minus & $i 1$ \\
\hline & black-orange & 2 & receive & plus & 37 \\
\hline & orange-black & 6 & receive & minus & 12 \\
\hline \multirow[t]{4}{*}{7} & black-green & 5 & transmit & plus & 38 \\
\hline & green-black & 1 & transuit & minus & 13 \\
\hline & black-brown & 2 & receive & plus & 30 \\
\hline & brown-black & 6 & receive & minus & 94 \\
\hline \multirow[t]{4}{*}{8} & black-slate & 5 & transmit & plus & 40 \\
\hline & slate-black & 1 & transmit & minus & 15 \\
\hline & yellow-black & 2 & receive & plus & 49 \\
\hline & black-yellow & 6 & receive & minus & 16 \\
\hline \multirow[t]{4}{*}{9} & yellow-orange & 5 & transmit & plus & 42 \\
\hline & orange-yellow & 1 & transmit & minus & 17 \\
\hline & yellow-green & 2 & receive & plus & 43 \\
\hline & green-yellow & 6 & receive & minus & 18 \\
\hline
\end{tabular}


TABLE H-II (cont inued)

JACKEIELD-TO-MULTIPLEXOR CABLE CODE

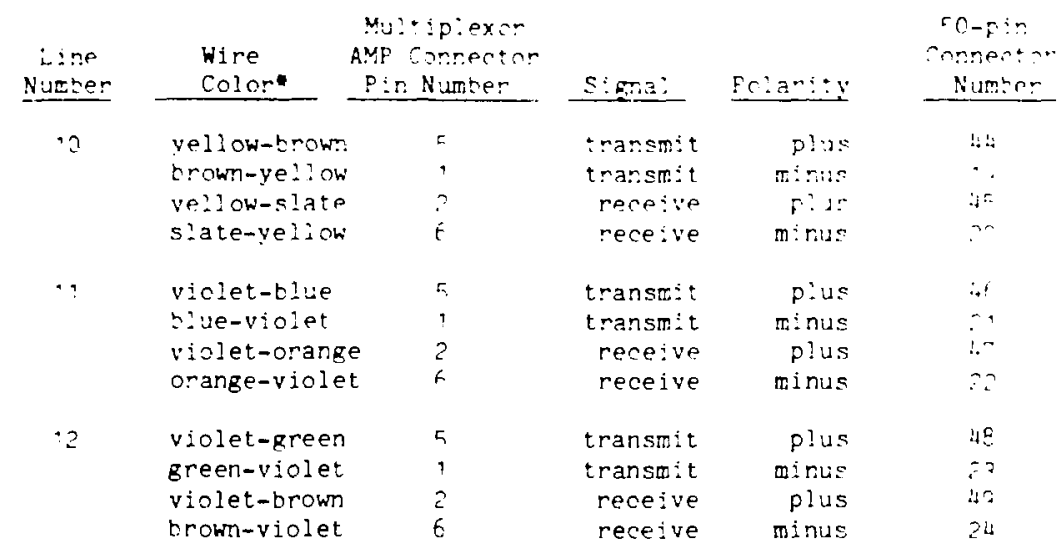

The wire color is given first and the color of the stripe second. For example, white-blue means a white wire with a blue stripe.

TABLE H-JII

WIRING BETWEEN SECONDARY COMPUTER AND JACKFIELD 
DYMA: GMPMINA: 'AT?'JH: :YYTEM

TADAS H-IV

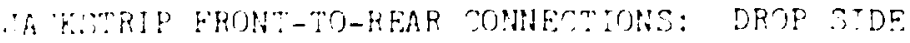

\begin{tabular}{|c|c|c|c|}
\hline $\begin{array}{l}\text { rank } \\
\text { Circu:t }\end{array}$ & $h: r e$ & 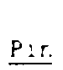 & $\begin{array}{c}\text { Eide } \\
\text { crnestor }\end{array}$ \\
\hline , & $\therefore: F$ & 26 & $p^{\circ}$ \\
\hline . & $r: n g$ & · & $p^{*}$ \\
\hline$?$ & $\because \because$ & $?$ & $F$. \\
\hline$?$ & $r: n_{E}$ & & $p^{\cdot}$ \\
\hline$=$ & tif & $p^{E}$ & $p^{*}$ \\
\hline 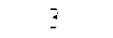 & $r: n g$ & 3 & $\mathrm{P}^{-}$ \\
\hline . & . & & . \\
\hline · & · & . & ' \\
\hline ?? & $\because i p$ & $\Delta \dot{\varepsilon}$ & $p:$ \\
\hline 23 & ring & 27 & $\mathrm{P}_{1}$ \\
\hline 24 & $t: p$ & $4 a$ & $P^{\prime}$ \\
\hline $2 L$ & $r: n \varepsilon$ & 24 & Pi \\
\hline 25 & $t i p$ & 26 & $P_{2}$ \\
\hline 25 & ring & 1 & P2 \\
\hline 26 & tip & $2 ?$ & P? \\
\hline 26 & ring & 2 & P? \\
\hline . & $\cdot$ & . & \\
\hline · & $\cdot$ & · & · \\
\hline 47 & $t i p$ & 48 & $\mathrm{P} 2$ \\
\hline 47 & ring & 23 & P2 \\
\hline 48 & tip & 49 & P2 \\
\hline 48 & ring & 24 & P2 \\
\hline
\end{tabular}

$\mathrm{H}-4$ 
AABLE ONNH?!INS

TAB:E :H-V

TAKKSTRAP FRONT-OO-REAR CONNETTONS: DINE SINE

\begin{tabular}{|c|c|c|c|}
\hline $\begin{array}{l}\therefore \text { ack } \\
\text { arcuit } \\
\end{array}$ & hise & $P$ & $\begin{array}{l}\text { Reref:ac!b } \\
\text { innentur }\end{array}$ \\
\hline 1 & $t: f$ & .74 & $\therefore$ \\
\hline$\cdot$ & $r: n E$ & ' & $\therefore$ \\
\hline$\therefore$ & $\therefore$ & $\therefore$ & . \\
\hline 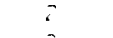 & $r: n F$ & $\therefore$ & $3^{\circ}$ \\
\hline : & $t i f$ & . & II \\
\hline 2 & $r: n g$ & 2 & $\therefore 1$ \\
\hline . & . & . & . \\
\hline$\cdot$ & . &. & : \\
\hline 23 & $\because F$ & 48 & J: \\
\hline$\because 3$ & ring & 22 & ¿1 \\
\hline 24 & $t: p$ & 43 & $\mathrm{~J}^{\prime}$ \\
\hline 24 & ring & 24 & S: \\
\hline 25 & $t: p$ & 26 & ${ }_{32}$ \\
\hline$? 5$ & ring & 1 & d? \\
\hline 27 & $t$ ip & 27 & $\mathrm{~J} 2$ \\
\hline 26 & ring & 2 & $\mathrm{~J} 2$ \\
\hline . & & : & : \\
\hline . & • & $\cdot$ & $\cdot$ \\
\hline 47 & tip & 48 & J2 \\
\hline 47 & ring & 23 & $\mathrm{~J} 2$ \\
\hline 48 & tip & 49 & 52 \\
\hline 48 & ring & 24 & $\mathrm{~J} 2$ \\
\hline
\end{tabular}

$\mathrm{H}-5$ 


\section{APPENDIX J COMMUNICATION LINES}

Tahles in this appendix give the following information for each communications line in a particular wing of the Plutonium Processing Facility or in the Cold Support Building: room number, outlet box number, nearest dropbox or glovebox, device number, nearest telephone number, and MUX port connection. This information is useful ti) the DYMAC computer operator in determining which device is responsible when transmission errors occur on a particular MUX port and in notifying the responsible person.

Also in this appendix are the numbers of the jackfield circuits used for lines in the Plutonium Processing Facility or in the Cold Sipport Bujlifing, with the proper resistance and capacitance measurements for each line from that jackfield aircuit to the corresponding outlet box. This information is useful for troubleshooting a line to determine if the cables from the jackifield to the out let hox are connected properly. 
TABLF. .I-I

DEVICE GOCATIONS IN loO bING:

\begin{tabular}{|c|c|c|c|c|c|c|c|c|c|c|c|}
\hline \multicolumn{6}{|c|}{ Remcte Locat: on } & \multicolumn{6}{|c|}{$\because M_{A} \therefore Z^{+}{ }^{+}, F-r$} \\
\hline Fram & n inet & $\begin{array}{l}\text { G::vo- } \\
\text { Box } \\
\end{array}$ & Device & $\begin{array}{l}\text { Instrumen: } \\
\text { Number } \\
\end{array}$ & $\begin{array}{c}\text { Nearest } \\
\text { Teiegncre } \\
\end{array}$ & $\begin{array}{l}\text { lackese: } \\
\text { rrcu:: } \\
\end{array}$ & 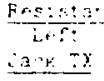 & 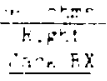 & 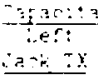 & 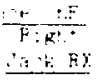 & 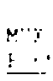 \\
\hline$\because r$ & 8 & $0: 2$ & bi. & Bu? & $7-354:$ & - & 9 & IE & $\cdots .2$ & $\cdots$. & - \\
\hline$y=$ & $\therefore$ & --- & CR: & 5020 & $7-x^{2}+i_{1}=$ & $\therefore$ & $\because$ & $\therefore$ & $\because{ }^{\prime}$ & $\therefore \therefore$ & \\
\hline$\cdots$ & $0^{\circ}$ & 0.25 & $\omega$. & But & $7-35.45$ & . & $\because$ & $i:$ & $\therefore$. & $\cdots$ & . : \\
\hline$\cdots$ & $c^{\circ}$ & $\cdots$ & spare & --- & $7-7546$ & - & $\therefore$ & $\therefore$ & xe.c & $\therefore$ & . \\
\hline$\cdots:$ & $0 z$ & --- & CPT & $T C \geq 8$ & $7-3 r, 4 t$ & $s$ & 80 & 20 & $\because \because$ & $\therefore .$. & - \\
\hline$\cdots$ & $\therefore$ & $D \cdot 08$ & $w$, & $B 4=$ & $7-2545$ & $:$ & $\because$ & $\because$ & $\therefore \ldots$ & $\therefore$ & . \\
\hline$\because$ & $\mathrm{c}^{\circ}$ & {$[10=$} & w. & 844 & $7-25 \angle 5$ & r & " & $\because$ & $\therefore$ & $\because$ & $\therefore$ \\
\hline$\cdots$ & ar & +- & CRT & TC27 & $7-254 \vdots$ & 8 & $\therefore$ & 16 & 20.6 & $\therefore:$ & \\
\hline$\cdots$ & 0 & 0.02 & hi. & 843 & $3-25,43$ & $i$ & $\bullet$ & ii & $\therefore \cdot 4$ & is . & $\therefore$ \\
\hline$\cdots=$ & $0 \vdots$ & $0: 03$ & TNC & $\mathrm{N} 2 \mathrm{~B}$ & $7-3 \times 4 ?$ & $c$ & $\because$ & $\therefore$ & $2+\cdots$ & $\therefore 2$ & $\cdots$ \\
\hline$\because$ & 0. & 6.83 & $w$, & $B 4 ?$ & $7-25 R E$ & $\therefore$ & $\cdot \leftarrow$ & $x^{k}$ & $\therefore \therefore$ & $\because 3$ & F: \\
\hline$\therefore$ & $0:-$ & -- & CRT & TC2E & $7-258=$ & $\because$ & * & 1. & $28:=$ & $\because \because$ & . \\
\hline$?$ & $0:$ & $D 111$ & $\mathrm{TNC}$ & Na? & $7-258 t$ & $1=$ & $\because$ & $\therefore$ & $\div .2$ & $\therefore \therefore$ & $\because$ \\
\hline$u^{2}$ & 0. & -- & CRT & $\mathrm{TC25}$ & $7-2586$ & 14 & $\because$ & $\therefore$ & 28.5 & $-5 .=$ &. \\
\hline$\because$ & $\therefore$ & --- & CAT & $T=24$ & $7-258^{-1}$ & 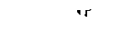 & $\because$ & * & $\because 7.1$ & $27 . r$ & r \\
\hline$\because$ & $0^{\circ}$ & -- & CRT & TC23 & $7-2560$ & $\cdot t$ & , & $\cdots$ & 30.5 & $x^{6}=$ & $\therefore$ \\
\hline$\because \hat{x}$ & 02 & C.50 & $\mathrm{TNC}$ & $\mathrm{N} 25$ & $7-2560$ & 1. & $\because$ & $\because:$ & 20.7 & $\because G . E$ & 7. \\
\hline$\because \varepsilon$ & 03 & 0150 & $w_{1}$ & B4O & $7-2569$ & :E & $\because$ & 11 & 20.0 & $30 . \hat{2}$ & $\therefore \varepsilon$ \\
\hline $500 \mathrm{a}$ & $0^{\circ}$ & -- & CRT & TCáa & $7-25.87$ & ${ }^{\circ} \mathrm{C}$ & 18 & 18 & $34 . \%$ & 34.9 & - \\
\hline $50 \approx a$ & $0 ?$ & -. & $\mathrm{PR}^{\mathrm{G}}$ & THOT & $7-258^{7}$ & 20 & 18 & $: \varepsilon$ & 33.5 & 32.2 & $\therefore$ \\
\hline $2 E$ & 02 & D 115 & TNC & $N 26$ & $7-2587$ & $2^{\circ}$ & $\because$ & 1.7 & $28 . ;$ & 27.6 & $7=$ \\
\hline $2^{4}$ & 0 ? & D 115 & $W_{1}$ & B41 & $7-2587$ & $a$ & $\because$ & ij & 29.1 & 27.8 & $5 c$ \\
\hline$\cdot 26$ & OL & D114 & $w_{1}$ & B 38 & $7-2587$ & $2 i$ & 0 & $a$ & 27. & 27.2 & 2 \\
\hline--- & -- & $\ldots$ & -- & $-\cdots$ & $\ldots$ & $24-48^{\circ}$ & --- & --- & -. & --- & -- \\
\hline-- & --- & -- & $\cdots$ & --- & --- & $40-t>d$ & $\cdots$ & --- & --- & -.. & --- \\
\hline
\end{tabular}

àzzanine.

bTI 733 hard-copy terminal.

$c_{\text {Not assigned. }}$

dJackstrip not installed. 
InBl, $1-11$

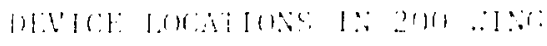

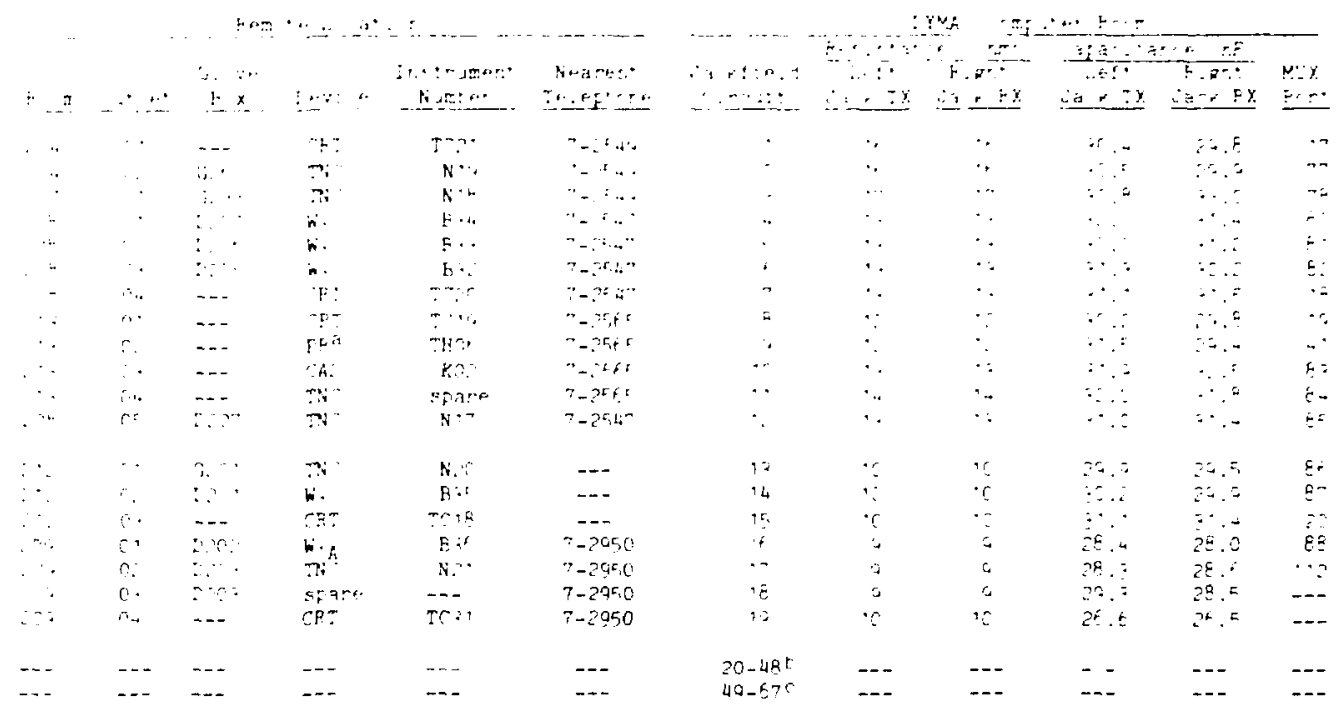

a! -it hamd-ary teroina?.

thi: assifred.

izckseraf not installed. 
DYMAC COMMUNICATIONS SYSTEM

TABLI: .I-I]

DEVICE IOCOTIONS IN 3OO WINO

\begin{tabular}{|c|c|c|c|c|c|c|c|c|c|c|c|}
\hline \multicolumn{6}{|c|}{ Remrie Locatior. } & \multicolumn{6}{|c|}{ DYMAC Sorpitem RCor } \\
\hline & & & & & & & Resistan & ce tohms & $\therefore a p a r a^{2}$ & nna nf & \\
\hline Booc. & Cutie: & $\begin{array}{l}\text { G:ove- } \\
\text { Box }\end{array}$ & Device & $\begin{array}{l}\text { Instrument } \\
\text { Number } \\
\end{array}$ & $\begin{array}{l}\text { Nearest } \\
\text { Telephone }\end{array}$ & $\begin{array}{l}\text { Jackifieid } \\
\text { Eircuit }\end{array}$ & $\begin{array}{r}\text { iert } \\
\text { ach IX }\end{array}$ & $\begin{array}{l}\text { High: } \\
\text { Jack RX }\end{array}$ & $\begin{array}{r}\text { Lert } \\
\text { Lach TX } \\
\end{array}$ & $\begin{array}{c}\text { R:er: } \\
\text { Jack: PX }\end{array}$ & $\begin{array}{l}\text { MUX } \\
\text { PCrt } \\
\end{array}$ \\
\hline$: 05$ & $\mathrm{C}^{\circ}$ & -- & $\mathrm{CR}$ ? & $T C 17$ & $7-23 ?:$ & $:$ & if. & 16 & $\therefore I_{1}$ & 29.7 & 8 \\
\hline 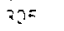 & $0:$ & $\mathrm{EZ}+9$ & $\mathbf{H}^{\prime}$ & $\mathrm{B} 25$ & $7-2373$ & 2 & 15 & 15 & $2 \div .1$ & 21.5 & $\because$ \\
\hline $2 C^{r}$ & $c^{\circ}$ & $6 ?+4$ & hi. & $\mathrm{B} 27$ & -- & 3 & $\because$ & 13 & 21.4 & 21.6 & $t:$ \\
\hline$\therefore 9$ & c & $G=-0$ & $H_{1 A}$ & B26 & --- & 4 & 15 & 15 & 23.1 & $2 z, 5$ & $\therefore \therefore$ \\
\hline$\because \because$ & $\mathrm{c}^{-1}$ & -- & $C F^{2}$ & $T C 16$ & $7-2372$ & 5 & 10 & 10 & 23.4 & .24 .2 & 0 \\
\hline 70 & $0^{\circ}$ & 0300 & $\boldsymbol{H}_{1}$ & $82^{4}$ & $7-2372$ & 6 & 16 & 16 & 23.1 & $\therefore \therefore 7$ & $\therefore$ \\
\hline$\therefore c$ & $0=$ & -- & $h_{2}$ & $\mathrm{~B} 2^{2}$ & $7-237 \hat{\imath}$ & $?$ & 17 & 17 & $=3.8$ & 27.9 & 50 \\
\hline 70 & $0 ?$ & 0308 & $w_{1}^{c}$ & $\mathrm{~B} 23$ & $7-2372$ & 8 & 17 & $1 ?$ & 23.2 & 22.4 & $5:$ \\
\hline $7 \cdot 9$ & 34 & $\cdots$ & CA: & TC 15 & $7-2372$ & 9 & 16 & 16 & 23.0 & 22.0 & ic \\
\hline 20 & 05 & 0307 & $w_{1}$ & $\mathrm{~B} 22$ & $7-2372$ & 10 & 13 & 13 & 23.9 & 23.3 & $5: 2$ \\
\hline$\therefore 0$ & 06 & 5306 & $H_{1}$ & $82^{\prime}$ & $7-2372$ & 11 & $1 \hat{2}$ & 12 & 23.8 & 23.4 & $5 \%$ \\
\hline$\overline{-0}$ & $0^{7}$ & D 305 & $\mathrm{H}_{1}$ & B20 & $7-2372$ & 12 & 13 & 13 & 24.2 & 24.3 & 54 \\
\hline 319 & 08 & D 304 & $H_{1}$ & B 9 & $7-2372$ & $1 ;$ & 12 & 12 & 23.4 & 22.8 & $\therefore 8$ \\
\hline \pm 0 & 09 & $-\infty$ & CRT & TCin & $7-2372$ & 94 & 10 & 10 & 20.1 & 20.1 & 19 \\
\hline 326 & 01 & $-\cdots$ & CRT & TC13 & $7-2374$ & 15 & 11 & 11 & 22.7 & 22.8 & 12 \\
\hline 326 & 02 & -- & $\mathrm{PR}^{\mathrm{a}}$ & THOS & $7-2374$ & 16 & 11 & $i 1$ & 24.7 & 23.3 & 40 \\
\hline $32^{7}$ & 0 & D 303 & $\mathrm{NNC}$ & $N i 4$ & $-\infty$ & 17 & 8 & 8 & 224 & 22.7 & 72 \\
\hline 327 & 02 & D303 & $w_{i}$ & B 18 & -- & 18 & 7 & $?$ & 23.3 & 23.0 & 56 \\
\hline 327 & 03 & D 302 & $w_{2}$ & $B: 1$ & $m$ & 19 & 8 & e & 22.4 & 22.3 & 57 \\
\hline $32 ?$ & 01 & D 301 & $w_{1}^{2}$ & \pm .6 & $7-2373$ & 20 & 8 & 8 & 21.8 & 20.4 & 59 \\
\hline 320 & 02 & D 301 & TNC & $N: 3$ & $7-2373$ & 21 & 8 & 8 & 21.6 & 21.4 & 75 \\
\hline 270 & $0^{\circ}$ & - & CRT & TC 12 & $7-2373$ & 22 & 8 & 8 & 22.2 & 21.5 & 13 \\
\hline $33^{b}$ & 0 & -- & $\mathrm{CRT}$ & TC1 & $7-2379$ & 23 & 7 & 7 & 10.0 & 20.0 & $T E$ \\
\hline 30 & 02 & -- & $P R^{C}$ & PROI & $7-2379$ & 24 & $?$ & 7 & 19.7 & $20 . \therefore$ & $3 ?$ \\
\hline 305 & 03 & D 310 & W, & $B 28$ & $7-2373$ & 25 & 11 & 11 & 20.1 & 19.7 & 79 \\
\hline$\cdots$ & $-\cdots$ & $-\infty$ & -- & -- & -- & $26-44^{d}$ & -- & $-\infty$ & - & $\ldots$ & $\cdots$ \\
\hline$-\infty$ & $-\infty$ & $-\infty$ & spare & -- & --- & 45 & -- & --- & $\ldots$ & --- & 47 \\
\hline-- & -- & -- & $\ldots$ & -- & --- & $46^{d}$ & -- & -- & -- & $-\infty$ & - \\
\hline.- & -- & -- & spare & $-\infty$ & -- & 47 & -- & $\cdots$ & -- & --- & 15 \\
\hline-- & -- & $-=$ & spare & --- & -- & 48 & -- & -- & $\ldots$ & $\ldots$ & 7 a \\
\hline-- & $\rightarrow$ & -- & $=-$ & -- & $\ldots$ & $49-67^{e}$ & -- & $\ldots$ & --- & -- & $\ldots$ \\
\hline
\end{tabular}

aTI 733 hard-copy terminal.

Basement.

CTI 810 label printer.

dNot assigned.

eJackstrip not ingtalled. 
TABLE J-IV

DEVICE LOCATIONS IN 400 WING

\begin{tabular}{|c|c|c|c|c|c|c|c|c|c|c|c|}
\hline & & thegr & * E Lonat & $\ln \mathrm{r}_{\mathrm{i}}$ & & & & MAC COMP & ter Roor. & & \\
\hline ..... & & & & & & & Pesistan & e chas & Capacita & $\operatorname{leg} \ln F$ & \\
\hline $5-2 \pi$ & $\because \vdots=1$ & $\begin{array}{r}i, \cdots \infty- \\
0 \quad x \\
\end{array}$ & Devine & $\begin{array}{l}\text { Instriment } \\
\text { Number } \\
\end{array}$ & $\begin{array}{l}\text { Neareat } \\
\text { Telephsne }\end{array}$ & $\begin{array}{l}\text { Bacreatd } \\
\text { Oarcuit }\end{array}$ & $\begin{array}{c}\text { Left } \\
\text { Lagrit } T y\end{array}$ & $\begin{array}{c}\text { Right } \\
\text { Iact RY }\end{array}$ & $\begin{array}{c}\text { Left } \\
\text { jack IX }\end{array}$ & $\begin{array}{c}\text { Right } \\
\text { Jack RX }\end{array}$ & $\begin{array}{l}\text { MUX } \\
\text { Port }\end{array}$ \\
\hline. & $\cdots$ & -.. & Cㅁ: & $\operatorname{TrC}^{2}$ & $\pi-3172$ & $:$ & 18 & $i 8$ & 29.2 & 29.3 & $2 ?$ \\
\hline..$\cdot$ & $\therefore$ & $r \ldots \cdots$ & SA: & אינ5 & $7-35 \cdot 7$ & 2 & , 8 & 18 & $2^{x} \therefore$ & 26.7 & 89 \\
\hline$\therefore$ & $\therefore$ & $\therefore \ldots$ & hi. A & $\mathrm{B}^{* ?}$ & 7.792 & 3 & 15 & 18 & 25. & 27. & 90 \\
\hline..$\cdot$ & $\because$ & $i{ }^{\prime}$ & $n^{2}$ & No8 & $7-25: 7:$ & L & 8 & 18 & $2^{2} .4$ & 26.9 & c. \\
\hline$\ldots \cdots$ & .75 & $n^{\prime \prime}$ & $w$ & BIC: & $5-e^{2}+?$ & c & $T R$ & $: 8$ & 25.8 & $2 t .2$ & $5 \bar{z}$ \\
\hline שיר . . & $\cdots$ & $\cdots$ & $C R T$ & TCO & 7.357 .74 & f & +1 & 19 & $2^{-} .4$ & $27 \cdot 7$ & 22 \\
\hline$\therefore$ & 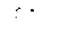 & 50 & $S A:$ & G)4 & $7-20,76$ & ᄀ & 2 & $\cdot 2$ & 23.0 & 22.7 & $\leqq$ \\
\hline$\because \because$ & $n$ & {$[\ldots$.} & $W_{A} A$ & Bor & $7-2574$ & 8 & 12 & $\because$ & $2 \hat{z} . \hat{z}$ & 24.6 & 94 \\
\hline .2 & $0:$ & $\therefore: 41$. & $\pi^{2}$ & No? & $7-2574$ & 9 & $\because$ & 12 & $22 .^{\circ}$ & 22.0 & ge \\
\hline$n^{n}$ & 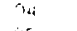 & n..... & SA: & $r_{1}=$ & $7-2574$ & 10 & 7 & 12 & 22.5 & 22.2 & $c_{7}$ \\
\hline$\cdots \cdots$ & in & $\mathrm{D} \mathrm{H}^{*} \mathrm{H}$ & $W_{\mathcal{A}}$ & Bné & $7-2574$ & $\therefore$ & $1 ?$ & 13 & 22.2 & 21.8 & 9.9 \\
\hline$\therefore$ & $\therefore$ & 5.4 & $\mathrm{TN}$ & NOr & $7-2575$ & 12 & $?$ & 13 & 23.8 & 23.6 & 99 \\
\hline 420 & $\because$ & $D_{4} \%$ & $w_{1}$ & $\mathrm{BO}^{n}$ & $7-2575$ & 13 & 12 & $1 ?$ & 23.9 & 23.9 & 100 \\
\hline $4 \because$ & $\because=$ & 5438 & spare & --- & $7-2575$ & 14 & 2 & 13 & 24.6 & 24.7 & 101 \\
\hline$\because$ & $\alpha$ & G4 20 & spare & --- & $7-25^{\prime 25}$ & 15 & 12 & 13 & 24.4 & 24.9 & 102 \\
\hline$\therefore$ & $o^{r}$ & $0+40$ & spare & --- & $7-2575$ & 16 & 12 & 13 & 25.4 & 25.4 & 103 \\
\hline $.2 r$ & f & G... & spare & $-\cdots$ & $7-2575$ & 17 & 3 & 13 & 25.7 & 25.4 & 104 \\
\hline$\therefore$ & $m$ & $n \leq 10$ & SAI & $G ! 2$ & $7-25,75$ & $: 8$ & 13 & 13 & 25.3 & 23.6 & .05 \\
\hline 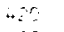 & 39 & $\therefore 1 !$ & $w \cdot A$ & Bof & $7-25 ? 5$ & 19 & 13 & $1 \bar{z}$ & 24.0 & 23.9 & $10 E$ \\
\hline $4^{n-7}$ & 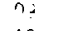 & GL? & spare & --- & $7-25 ? 5$ & 20 & 13 & 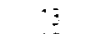 & 23.7 & 22.9 & 107 \\
\hline$\ldots ?$ & $\because$ & 020 & $T N^{-}$ & NOS & $?-2575$ & $2^{\prime}$ & 12 & 12 & $2 ! .6$ & $2: 9$ & 108 \\
\hline 4 & " & 0410 & bif & Bor & $7-2575$ & 22 & 12 & 12 & 22.3 & 21.8 & 109 \\
\hline$\ldots$ & $\because$ & $D \div \%$ & $S A Z^{2}$ & Q11 & $7-2575$ & 23 & 12 & $1 \bar{c}$ & 21.5 & 22.3 & $1: 0$ \\
\hline 4,7 & $\because$ & --- & $C R ?$ & Tro\& & $7-2575$ & 24 & 13 & 13 & 23.6 & 23.2 & 23 \\
\hline.- & --- & --- & sfare & --- & --- & 25 & -- & --- & -- & --- & -- \\
\hline$\therefore \%$ & 0 & 2409 & $w$, & $\mathrm{BO} 4$ & $7-2577 ?$ & $2 \epsilon$ & 9.5 & 9.5 & 23.7 & 23.6 & $1: 3$ \\
\hline-20 & 0 & 21.07 & $\mathrm{~N}=$ & N04 & $7-25+7$ & $2 ?$ & 7.5 & 7.5 & 20.7 & 21.4 & 114 \\
\hline 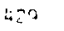 & 02 & nutof & $w_{1}$ & $\mathrm{BO} 3$ & $7-257 ?$ & 28 & 7.5 & 7.5 & 21.8 & 23.4 & 115 \\
\hline$\therefore-a$ & $2-4$ & Duch & $F \mathrm{~N}=$ & N 35 & $7-257 ?$ & 20 & 7.5 & 7.5 & 22.0 & 22.0 & 115 \\
\hline 1.32 & 05 & D40: & $h_{i}$ & BO2 & $7-2577$ & 30 & 7.5 & 7.5 & 22.0 & 21.4 & 117 \\
\hline 427 & $D S$ & -- & CAT & $\mathrm{TCO}$ & $7-257 ?$ & $3^{4}$ & 9 & 9 & 25.7 & 23.4 & 24 \\
\hline 431 & $0:$ & GLO" & TNC & N03 & $7-2579$ & 32 & 7.5 & 7.5 & 19.9 & 19.5 & 118 \\
\hline+2 & 02 & $640^{\circ}$ & $w_{1}$ & 301 & $7-2579$ & 32 & 7.5 & 7.5 & 20.5 & 20.3 & 119 \\
\hline 433 & 01 & --- & CRT & $T C O E$ & $7-2580$ & 34 & 9 & $\stackrel{9}{9}$ & 24.5 & 24.0 & 25 \\
\hline $4 ? 3$ & 02 & -- & $w_{2}$ & B55 & $7-2580$ & 35 & 9 & $\stackrel{9}{9}$ & 23.7 & 23.8 & 120 \\
\hline 43 & $n=$ & --- & CAL & Ko1 & $7-2580$ & 36 & 9 & 9 & 23.1 & 23.1 & 121 \\
\hline
\end{tabular}


TABLE J-IV (continued)

DEVICE LOCATIONS IN 400 WING,

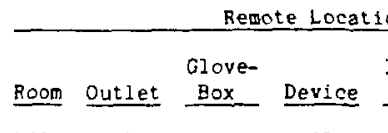

Instrument Nearest Number Telephone

$\begin{array}{lll}433 & 04 & -- \\ 433 & 05 & -- \\ 433 & 06 & -- \\ 433 & 07 & -- \\ 522 a & 01 & -- \\ 522 a & 02 & -- \\ 528^{a} & 01 & -- \\ 528 a & 02 & -- \\ 433 & 08 & -- \\ 433 & 09 & -- \\ 433 & 10 & -- \\ 401 & 06 & 0418\end{array}$

\section{SGS}

$$
\text { FNC }
$$

TNC
TNCB

CRT
$P R^{\mathrm{B}}$

CRT
PRD

CRT

$P R^{C}$

spare

TWC

\section{G01}

N35

No2

NO 1

TCO5

THO4

$\mathrm{TCO} 4$

$\mathrm{THO}_{3}$

$\mathrm{TCO} 3$

PRO2

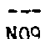

$\because \because=$

$\because \equiv$

\begin{abstract}
spare
spare
\end{abstract}

spare

-..

:-

$-$

$\because$

$$
\begin{aligned}
& 7-2580 \\
& 7-2580 \\
& 7-2580 \\
& 7-2580 \\
& 7-256 \\
& 7-2568 \\
& 7-2566 \\
& 7-2571 \\
& 7-2580 \\
& 7-2580 \\
& 7-2580 \\
& 7-2572
\end{aligned}
$$

--
--
---
DYMAC Computer Room

Jackfield Resistance ohms! Capacitance $\frac{\text { ChF }}{\text { Left Right }}$

Circuit Jack TX Jack RX Jack TX Jack RX Fort

\begin{tabular}{|c|c|c|c|c|}
\hline $49-68 \mathrm{C}$ & -- & $\ldots$ & -- & -- \\
\hline $\begin{array}{c}69 \\
70-7\end{array}$ & $\begin{array}{l}--- \\
--\end{array}$ & $=$ & - & $\cdots$ \\
\hline & & & & --. \\
\hline
\end{tabular}

$\begin{array}{rr}37 & 9 \\ 38 & 0 \\ 39 & 9 \\ 40 & 7 \\ 41 & 18 \\ 42 & 18 \\ 43 & 9 \\ 44 & 9 \\ 45 & 9 \\ 46 & 9 \\ 47 & 9 \\ 48 & 11\end{array}$

24.3

$23.7 \quad 24.3 \quad 127$

$23.8 \quad 24.3 \quad 124$

$22.0 \quad 22.6 \quad 125$

$25.125 .4 \quad 26$

$25 . ? \quad 25.0 \quad 42$

$23.3 \quad 23.2 \quad 27$

$22.8 \quad 22.2$ 45

$23.5 \quad 24.2 \quad 28$

$23.7 \quad 23.5 \quad 36$

$23.4 \quad 23.5 \quad 126$

amezaline.

DTI 733 hard-copy terminal.

CTI 810 label printer.

dNot assigned.

ejackstrip not installed. 
TABLE J-V

DEVICE LOCATIONS IN COLD SUPPORT BUILDING

\begin{tabular}{|c|c|c|c|c|c|}
\hline Roon & Out let & $\begin{array}{c}\text { Glove- } \\
\text { Box }\end{array}$ & Devlce & $\begin{array}{c}\text { Instrument } \\
\text { Number } \\
\end{array}$ & $\begin{array}{c}\text { Nearest } \\
\text { Telephone }\end{array}$ \\
\hline 127 & 01 & $-\cdots$ & CRT & - & $7-3470$ \\
\hline 127 & 02 & $\ldots$ & CRT & --- & $7-3470$ \\
\hline 127 & 03 & -- & CAT & $-\cdots$ & $7-3470$ \\
\hline 127 & O4 & -- & CRT & -- & $7-3470$ \\
\hline 128 & 01 & --- & $\mathrm{CHT}$ & $\mathrm{TCO} 2$ & $7-2378$ \\
\hline 128 & 02 & -- & $\mathrm{PR}^{\mathrm{a}}$ & $\mathrm{THOZ}$ & $7-2378$ \\
\hline 133 & 01 & -- & CAT & $\mathrm{TCO} 1$ & $7-2372$ \\
\hline 137 & 02 & --- & $\mathrm{PH}^{\mathrm{a}}$ & THO 1 & $7-2373$ \\
\hline 127 & 05 & -- & $C R T$ & -- & $7-3470$ \\
\hline 135 & 01 & --- & $\mathrm{CRT}$ & TC30 & $7-2369$ \\
\hline 135 & 02 & --- & $\mathrm{PR}^{\mathrm{a}}$ & THOB & $7-2369$ \\
\hline-- & --- & --- & --- & --- & --- \\
\hline 142 & 01 & --- & CRT & TC 32 & $7-2366$ \\
\hline 142 & 02 & --- & $P R C$ & THOG & $7-2366$ \\
\hline-- & -- & $\cdots$ & --- & --- & --- \\
\hline
\end{tabular}

\begin{tabular}{|c|c|c|c|c|c|}
\hline & \multicolumn{4}{|c|}{ DYMAC Computer Room } & \multirow[b]{3}{*}{$\begin{array}{l}\text { RUX } \\
\text { Port }\end{array}$} \\
\hline \multirow[b]{2}{*}{$\begin{array}{l}\text { Jackfield } \\
\text { Circult }\end{array}$} & \multicolumn{2}{|c|}{ Resistance (ohms) } & \multicolumn{2}{|c|}{ Capacitance (nF) } & \\
\hline & $\begin{array}{c}\text { Left } \\
\text { Jack TX }\end{array}$ & $\begin{array}{l}\text { Right } \\
\text { Jack HX }\end{array}$ & $\begin{array}{c}\text { Left } \\
\text { Jack TX }\end{array}$ & $\begin{array}{c}\text { A1ght } \\
\text { Jack RX }\end{array}$ & \\
\hline 1 & 4.7 & 4.7 & 5.25 & 5.08 & 20 \\
\hline 2 & 4.7 & 4.7 & 5.39 & 5.30 & 32 \\
\hline 3 & 4.7 & 4.7 & 5.42 & 5.44 & 33 \\
\hline 4 & 4.7 & 4.7 & 5.48 & 5.30 & 34 \\
\hline 5 & 4.2 & 4.1 & 4.20 & 4.20 & 35 \\
\hline 6 & 4.2 & 4.2 & 4.12 & 4.18 & 44 \\
\hline 7 & 4.6 & 4.6 & 5.17 & 5.25 & 36 \\
\hline 8 & 4.6 & 4.6 & 5.55 & 5.50 & 45 \\
\hline 9 & 4.7 & 4.7 & 5.37 & 5.29 & --- \\
\hline 10 & 5 & 5 & 6.5 & 6.4 & 31 \\
\hline 11 & 5 & 5 & 6.5 & 6.5 & 30 \\
\hline $12^{b}$ & $\ldots$ & -- & -- & -- & $-\infty$ \\
\hline 13 & 4 & 4 & 4.01 & 4.08 & $-\infty$ \\
\hline 14 & 4 & 4 & 3.78 & 3.78 & --- \\
\hline $15-24 \mathrm{~b}$ & --- & -- & -- & $-\ldots$ & -- \\
\hline
\end{tabular}

3TI 610 iabel printer.

$b_{\text {Not }}$ assigned.

CTI 733 hard-copy terminal. 


\section{APPENDIX K EQUIPMENT MAINTENANCE}

\begin{tabular}{|c|c|c|}
\hline Equipment & $\begin{array}{l}\text { Responsible for } \\
\text { Maintenance }\end{array}$ & Telephone \\
\hline Balance, electronic & LASL Group Q-3 & $677-5735$ \\
\hline Communications & LASL Group Q-3 & $667-5735$ \\
\hline Computer (Eclipse) & Data General Corp. & $\begin{array}{l}672-3600^{a} \\
265-8011^{b} \\
983-6311^{c}\end{array}$ \\
\hline $\begin{array}{l}\text { Fast-neutron coincidence } \\
\text { counter }\end{array}$ & LASL Group Q-3 & $667-5735$ \\
\hline Label printer, TI 810 & LASL Group E-1 & $667-5940$ \\
\hline $\begin{array}{l}\text { Segmented gamma } \\
\text { scanner }\end{array}$ & Jomar Systems & $662-9811$ \\
\hline $\begin{array}{l}\text { Solution assay } \\
\text { instrument }\end{array}$ & LASL Group Q-3 & $667-5735$ \\
\hline $\begin{array}{l}\text { Terminals, Teleray } 3741 \text { CRT } \\
\text { and TI } 733 \text { hard-copy }\end{array}$ & LASL Group E-1 & $667-5940$ \\
\hline $\begin{array}{l}\text { Thermal-neutron } \\
\text { coincidence counter }\end{array}$ & LASL Group Q-3 & $667-5735$ \\
\hline $\begin{array}{l}\text { aWhite Rock. } \\
b_{\text {Albuquerque. }} \\
{ }^{\text {c }} \text { Answering service. }\end{array}$ & & \\
\hline
\end{tabular}

